\title{
4 Die Geschichte der offiziellen Geschichtsschreibung der Kampagne gegen Rechtsabweichler
}

Dieses Kapitel untersucht, wie die KPCh nach dem Tode Maos um einen Konsens um die Bewertung der „historischen Fehler“ der Partei nach 1949 im Allgemeinen und der Kampagne gegen Rechtsabweichler im Besonderen gerungen hat. Dabei soll aufgezeigt werden, dass dieses Ringen für die politischen Erben Maos um Deng Xiaoping eine komplizierte Gratwanderung darstellte, welche insbesondere in der Phase des politischen Umbruchs mit einem Kampf um die Aufrechterhaltung der Herrschaftslegitimation einherging. Dieser Kampf um die Herrschaftslegitimation der Partei ist seitdem untrennbar mit dem Kampf um die Kontrolle über ihre eigene Geschichte verbunden. Anders ausgedrückt, lassen sich Politik und Geschichtsschreibung in der VR China nicht voneinander trennen. Dieses Kapitel soll deshalb analytisch darlegen, wie sich die offizielle Geschichtsschreibung der Kampagne gegen Rechtsabweichler im Laufe der Jahrzehnte - von Deng Xiaoping zu Xi Jinping - weiterentwickelt hat und wie diese von aktuellen gesellschaftlichen, ideologischen und vor allem politischen Entwicklungen geprägt worden ist.

Ein ausgeprägtes Bewusstsein über die Bedeutung der Kontrolle der eigenen Geschichte lässt sich bereits vor der Machtübernahme der KPCh und der Ausrufung der VR China erkennen. Dies zeigen insbesondere die unter höheren Funktionären der KPCh in den Jahren 1942 bis 1944 geführten Diskussionen um die Geschichte der Partei seit ihrer Gründung im Jahre 1921. Die Ergebnisse der Diskussionen wurden schließlich in der Resolution über einige Fragen in der Geschichte unserer Partei zusammengefasst, welche am 20. April 1945 während der 6. Plenarsitzung des 7. Zentralkomitees angenommen wurde. Die Resolution von 1945, wie auch die im Folgenden diskutierte Resolution von 1981, kann als eine Art Regelwerk der KPCh für den Umgang mit den eigenen Fehlern, aber auch für die Kanonisierung der eigenen Verdienste betrachtet werden. Dies wird auch in Maos am 12. April 1944 in Yan'an gehaltener berühmter Rede Unsere Schulung und die gegenwärtige Lage deutlich, in der er unter anderem auf den Umgang mit historischen Erfahrungen und den darin begangenen Fehlern Einzelner einging:

Das Zentralkomitee hält es für notwendig, sich darum zu kümmern, daß die Kader alle Fragen hinsichtlich der Geschichte unserer Partei ideologisch gründlich durchdenken und daß man gleichzeitig bei der Beurteilung von Genossen, die in der Vergangenheit Fehler gemacht haben, eine milde Politik betreibt, damit einerseits volle Klarheit über die historischen Erfahrungen unserer Partei gewonnen und eine Wiederholung der Fehler vermieden

Ә OpenAccess. ( 2021 Anja Blanke, publiziert von De Gruyter. (cc) BY-NC-ND Dieses Werk ist lizenziert unter der Creative Commons Attribution-NonCommercial-NoDerivatives 4.0 International Lizenz.

https://doi.org/10.1515/9783110719253-006 
und andererseits alle Genossen für die gemeinsame Arbeit zusammengeschlossen werden können. ${ }^{154}$

Damit setzte er noch vor der Machtübernahme der KPCh eine Richtlinie fest, die auch für den Umgang mit seinem politischen Wirken und somit auch mit seinen eigenen Fehlern und Verdiensten nach seinem Ableben angewendet werden könnte.

Eine erste Bewertung der Ereignisse der Jahre 1957 und 1958 fand bereits vor dem eigentlichen Ende der Kampagne durch hohe Parteimitglieder statt. Ausgerechnet Liu Shaoqi 刘少奇, zwischen 1954 und 1959 Vorsitzender des Nationalen Volkskongresses (Zhonghua renmin gongheguo quanguo renmin daibiao dahui 中华人民共和国全国人民代表大会) und zwischen 1959 und 1968 Präsident der VR China, ${ }^{155}$ betonte am 05. Mai 1958 in seiner Rede auf der 2. Sitzung des VIII. Parteitags der KPCh, dass die Kampagne gegen Rechtsabweichler ein notwendiger und korrekter Schritt für den Sieg über die Bourgeoisie sei:

The Anti-Rightist struggle has been of profound significance within our party. We expelled a number of rightists from the party. There were alien class elements who had sneaked into the party and renegades to the cause of socialism. They developed individualism, sectarianism, localism, and nationalism to an extreme degree within the party and carried-out revisionist and other antisocialist and anti-Communist activities. In league with the rightists outside the party, they attacked the party and the socialist system. To rid the party of these alien class elements and renegades is a great victory for its cause. ${ }^{156}$

In jener Rede beließ er es jedoch nicht nur bei einer bloßen Rechtfertigung der Notwendigkeit der Kampagne, er ging sogar noch weiter, indem er betonte, dass der Weg, der ab dem 08. Juni 1957 eingeschlagen worden ist, weitergegangen werden müsse, um die Widersprüche zwischen Proletariat und Bourgeoisie auch weiterhin zu bekämpfen. Der durch die Kampagne ausgetragene Kampf hätte, so Liu, an einigen Stellen sogar noch intensiver geführt werden müssen. ${ }^{157}$ Eine klare innerparteiliche Einigkeit zum Umgang mit der Kampagne und ihren Opfern lässt

154 Mao 1969, S. 187.

155 Liu Shaoqi, zuerst einer der wichtigsten Förderer Maos, galt lange Zeit als sein legitimer Nachfolger. Später wurde er zu einem Kritiker seiner Politik und schließlich zum Staatsfeind erklärt. Zu Beginn der Kulturrevolution wurde er 1967 zunächst unter Hausarrest gestellt und 1968 aus der Partei ausgeschlossen. Er starb 1969 in Haft. Im Februar 1980 wurde er schließlich von Deng Xiaoping während des 5. Plenums des 11. Zentralkomitees posthum rehabilitiert. Zum Leben und Wirken Liu Shaoqis siehe Dittmer 2015.

156 Zit. in Jacobs und Baerwald 1963, S. 89

157 Ebd., S. 90. 
sich allerdings nicht feststellen, da einige ranghohe Parteikader vereinzelt auch eine kritische Haltung bezüglich der Durchführung des Kampfes gegen die Rechten einnahmen, wie etwa Hu Yaobang, der damalige Vorsitzende der Kommunistischen Jugendliga. ${ }^{158}$ Diskussionen über die Fehler, die seit der Gründung der VR China begangen worden sind, und darüber, wie man diese korrigieren und bewerten könnte, sind dann im größeren Stile während der Lushan-Konferenz (Lushan huiyi 庐山会议) aufgekommen. Gemäß den Aufzeichnungen des damaligen Sekretärs Mao Zedongs Li Rui 李锐 bezog sich das Gros der Debatten jedoch auf den Großen Sprung nach vorn. Ein Teil der anwesenden Parteikader forderte dabei eine Abkehr von dem Ende der 1950er Jahre eingeschlagenen politischen Pfad. Die Kampagne gegen Rechtsabweichler wurde während des rund einmonatigen Parteitreffens im Juli und August des Jahres 1959 ebenfalls am Rande erwähnt, wobei auch kritische Stimmen laut geworden sind. ${ }^{159}$ Schlussendlich konnten sich die Kritiker der Kampagne allerdings nicht durchsetzen und wurden vor allem während der Kulturrevolution ausgeschaltet, sodass bis zum Ende der Kulturrevolution keine umfassende Neubewertung des Umgangs mit den Rechtsabweichlern erfolgen konnte. ${ }^{160}$

Der eigentliche Prozess der Neubewertung und somit auch der Prozess der offiziellen Geschichtsschreibung der Kampagne gegen Rechtsabweichler begann erst nach dem Tode Mao Zedongs und fand vorwiegend unter der Leitung Deng Xiaopings statt. Dieser hatte ein natürliches Interesse daran, die Kontrolle über diese Vorgänge zu behalten, da er in die Kampagne gegen Rechtsabweichler als Generalsekretär unmittelbar involviert gewesen war und somit Gefahr lief, als Täter aufgedeckt zu werden, was wiederum seine politischen Ambitionen zu gefährden drohte.

Für totalitäre bzw. autoritäre Regime ist es für die Wahrung ihrer Stabilität also von höchster Wichtigkeit, die Kontrolle über ihre Vergangenheit und insbesondere ihrer darin begangenen „historischen Fehler“ zu behalten. In China galt dies umso mehr in Phasen, in denen die Herrschaftslegitimation der KPCh volatil gewesen ist. Das war sie nicht nur während der gesamten 1950er Jahre, als das gesamte Regime noch sehr jung war und sich noch in der Konsolidierungsphase befand, dies galt mindestens gleichermaßen für die Phase nach dem Tode Maos und dem Ende der Kulturrevolution. Auch in dieser Phase war die Stabilität der Legitimation der KPCh durch das „zehnjährige Chaos“, die daraus erfolgten Rückschläge im sozialistischen Aufbau, aber auch durch die Vielzahl der Opfer

158 Goldman 1991, S. 220 ff.

159 Siehe Li 1999a.

$160 \mathrm{Hu}$ Yaobang wurde während der Kulturrevolution zweimal Gegenstand politischer Verfolgung und wurde jedoch auch zweimal wieder rehabilitiert. Siehe Yang et al. 2016, S. $115 \mathrm{ff}$. 
jener Jahre erneut sehr angegriffen. Was die Kampagne gegen Rechtsabweichler betrifft, verhielt es sich immerhin so, dass ein nicht unerheblicher Teil der chinesischen Intellektuellen betroffen war. Ein Großteil von ihnen wurde nach 1976 nun auch für den Aufbau des Landes gebraucht. Außerdem hat es nach dem Ende der Kulturrevolution keinen Regimewechsel gegeben, was ein öffentliches Aufrollen der Verbrechen der vergangenen rund 25 Jahre faktisch unmöglich machte und auch dazu führte, dass Täter und Opfer nun Seite an Seite weiterleben mussten.

Hannah Arendt unterscheidet in ihrem Essay Wahrheit und Politik von 1964 in Bezug auf die politische Konstruktion von „Wahrheit“ und damit auch auf die Konstruktion der Geschichte zwischen einer sogenannten Vernunftwahrheit und einer Tatsachenwahrheit. Als besonders problematisch für Regime wie das der VR China erweisen sich demnach eben jene Tatsachenwahrheiten wie die um die Ereignisse der Kampagne gegen Rechtsabweichler, denn:

[...] unwillkommene Tatbestände sind von einer unbeweglichen Hartnäckigkeit, die durch nichts außer der glatten Lüge erschüttert werden kann. Die Schwierigkeit liegt darin, dass Tatsachenwahrheit wie alle Wahrheit einen Gültigkeitsanspruch stellt, der jede Debatte ausschließt, und die Diskussion, der Austausch und Streit der Meinungen, macht das eigentliche Wesen allen politischen Lebens aus. ${ }^{161}$

Angewendet auf die politischen Realitäten Chinas nach 1976, zeigt dies auch, weshalb die Kontrolle der Vergangenheit eine solche Herausforderung für die politischen Erben Mao Zedongs gewesen ist. Da viele Zeitzeugen respektive Opfer der Kampagne noch lebten, war es für die Partei notwendig, dass an die Stelle der Tatsachenwahrheit eine politisch erwünschte Konstruktion der Vergangenheit treten und sich als Teil des kollektiven Gedächtnisses etablieren würde.

\subsection{Die 1980er Jahre - Konsens, Konsolidierung und intellektuelle Freiheiten}

Die politischen Erben Maos um Deng Xiaoping setzten erneut dazu an, China zu verändern und seine Entwicklung voranzutreiben. Dafür wollten sie nach seinem Tod am 09. September 1976, der nicht nur das Ende der Kulturrevolution, sondern auch das Ende des „Roten Zeitalters“ bedeuten würde, einen Schlussstrich unter die Fehler, die durch ihn selbst, aber auch durch die Partei im Allgemeinen begangenen worden sind, ziehen. Dies geschah im Wesentlichen auf dreierlei Ebe-

161 Arendt 1994, S. 342. 
nen: auf einer juristischen, auf einer emotionalen und auf der Ebene der historischen Bewertung bzw. der offiziellen politischen Geschichtsschreibung.

Die in Kapitel 3 beschriebene juristische Aufarbeitung der Kampagne gegen Rechtsabweichler umfasste jedoch nicht die Anklage möglicher Täter, wie zum Beispiel lokaler Kader, die in jenen Jahren wissentlich oder nachweislich zu falschen Verurteilungen von Konterrevolutionären oder Rechtsabweichlern beigetragen hatten. ${ }^{162}$ Stellvertretend für die Verfehlungen der Kulturrevolution wurde jedoch die sogenannte Viererbande (sirenbang 四人帮) um Maos Ehefrau Jiang Qing 江青, Zhang Chunqiao 张春桥, Yao Wenyuan 姚文元 und Wang Hongwen 王 洪文 öffentlich angeklagt. Durch den zwischen dem 20. November und 29. Dezember 1980 als mediales Großereignis ausgetragenen Schauprozess unternahm die Regierung den Versuch, der Bevölkerung zu vermitteln, dass die eigentlichen Ziele der Kulturrevolution von der Viererbande verzerrt worden seien und dass alles, was dabei schief gelaufen ist, durch eben jene Gruppe verursacht worden sei. ${ }^{163}$ In den Mitgliedern der Viererbande die Schuldigen für die negativen Auswüchse der Kulturrevolution gefunden zu haben und diese der Öffentlichkeit zu präsentieren, hat dabei eine Möglichkeit geschaffen, das Trauma des Einzelnen auf diese vier Personen zu projizieren. ${ }^{164}$ Damit unternahm die KPCh den Versuch, die emotionale Ebene in der Aufarbeitung der „historischen Fehler“ des „roten Zeitalters“ anzusteuern.

Die größte Herausforderung stellte schließlich die abschließende historische Bewertung der Rolle der KPCh und Mao Zedongs sowie die offizielle Bewertung seiner Verantwortung für die „historischen Fehler“ der beiden vergangenen Jahrzehnte dar. Dies war jedoch dringend geboten, da man einen endgültigen Schlussstrich unter die Fehler der Vergangenheit ziehen und mit der Entwicklung Chinas entscheidend voranschreiten wollte. Fast parallel zum Schauprozess gegen die Viererbande - vor der Öffentlichkeit weitgehend verborgen - fanden die Arbeiten am Entwurf zur Resolution über einige Fragen zur Geschichte der KP Chinas seit 1949 statt. In dieser sollte eine offizielle Bewertung des Erbes Mao Zedongs sowie der historischen Ereignisse der VR China seit ihrer Gründung vorgenommen werden.

Auch wenn der öffentliche Fokus in dieser Phase des politischen Umbruchs vor allem auf dem Trauma lag, das China durch die Kulturrevolution erlitten hatte, und nicht so sehr auf den vorangegangenen Ereignissen wie der Kampagne gegen Konterrevolutionäre (1950/51) oder eben der Kampagne gegen Rechtsabweichler,

162 Vgl. Leese 2015.

163 Weigelin-Schwiedrzik 2012, S. 34.

164 Wang 2014, S. 130 ff. Zum Prozess gegen die Viererbande siehe auch Cook 2016. 
war die Art und Weise ihrer Bewertung für die Wahrung der Stabilität und die Sicherung der Legitimität Deng Xiaopings als zentraler Akteur der Kampagne von höchster Wichtigkeit. Außerdem ergaben sich mit den Einzelfallkorrekturen der Rechtsabweichler und ihrer damit verbundenen Rückkehr in die Gesellschaft Unsicherheiten, wie sie mit dem Erlebten umgehen und inwiefern sie ihre Erinnerungen weitergeben würden. Einerseits hatte er also kein Interesse daran, dass diese Fehler öffentlich thematisiert würden, da sie seinen politischen Ambitionen im Weg stehen könnten, andererseits dürfte ihm bewusst gewesen sein, dass er die Kampagne gegen Rechtsabweichler nicht komplett negieren konnte.

\section{Vom Ringen um einen Konsens}

Bereits im Jahr 1979 wurde die Ausarbeitung der Resolution von der Partei in Auftrag gegeben. Die Arbeiten daran wurden vom Politbüro und dem Sekretariat des Zentralkomitees geleitet. Deng Xiaoping hatte gemeinsam mit Hu Yaobang die redaktionelle Leitung inne, Hu Qiaomu 胡乔木, ${ }^{165}$ später einer der schärfsten Kritiker der Reform- und Öffnungspolitik, zeichnete für die Entwurfsgruppe verantwortlich. ${ }^{166}$ Die Entwurfsgruppe stand bezüglich der Bewertung der Leistungen und Verantwortlichkeiten Mao Zedongs vor einer großen Herausforderung: der differenzierten Bewertung Mao Zedongs. Einerseits sollten seine Verdienste betont werden, andererseits durften seine Fehler jedoch auch nicht komplett negiert werden.

Hua Guofeng 华国锋, der eigentliche Nachfolger Maos und zwischen 1976 und 1981 der Vorsitzende der KPCh, ${ }^{167}$ hatte kurz nach dessen Tod noch ganz andere Töne angeschlagen. In seiner Rede während der öffentlichen Trauerfeier für Mao Zedong am 18. September 1976 hatte er ausdrücklich die Verdienste Maos während der Kulturrevolution betont. Auch nach der Trauerfeier bekräftigte er immer wieder, dass an dem von Mao eingeschlagenen Weg unbedingt festzuhalten sei

165 Zur Rolle Hu Qiaomus während der Kampagne gegen geistige Verschmutzung 1983 sowie seiner Haltung zu den Studentenprotesten auf dem Platz des Himmlischen Friedens siehe Baum 1997.

166 Deng 1985, S. 316.

167 Die ersten fünf Jahre nach Maos Tod waren geprägt vom Machtkampf zweier politischer Lager innerhalb der KPCh - die Anhänger Hua Guofengs unterstützten seine „Zwei Alles“-Doktrin 两个凡是, wonach an allen Entscheidungen Maos festzuhalten sei und alle seine Weisungen ausgeführt werden müssten. Nach ihren Vorstellungen sollte auch der Klassenkampf fortgesetzt werden. Die Anhänger Deng Xiaopings hingegen unterstützten seine Praxis „Die Wahrheit in den Tatsachen suchen“实事求是 und damit seine vorwiegend auf den wirtschaftlichen Aufbau und die Öffnung Chinas gerichtete Politik. Zu den innerparteilichen Entwicklungen der KPCh nach Maos Tod siehe Mühlhahn 2017, S. 87-94. 
und somit auch der Klassenkampf weitergeführt werden müsse. Im Jahr 1977, rund zwanzig Jahre nach dem Beginn der Kampagne gegen Rechtsabweichler, betonte er, dass die Durchführung des Kampfes gegen die Rechten richtig und notwendig gewesen sei - auf die Fehler, die während der Durchführung der Kampagne durch die Partei begangen worden sind, ging er hingegen nicht ein:

Vorsitzender Mao sagte außerdem: „Wir haben bei uns das sozialistische System im wesentlichen errichtet. Was die Umgestaltung des Systems des Eigentums an den Produktionsmitteln betrifft, haben wir schon den fundamentalen Sieg davongetragen; aber an der politischen und ideologischen Front ist der volle Sieg noch nicht errungen." Im Frühjahr 1957 nahmen die bürgerlichen Rechten die Gelegenheit wahr, daß unsere Partei eine Bewegung zur Ausrichtung des Arbeitsstils entfaltete, um einen blindwütigen Angriff gegen zu Sozialismus zu starten, in der Hoffnung, das Proletariat politisch und ideologisch niederzuwerfen. Unter Führung des Vorsitzenden Mao schlugen die ganze Partei und das ganze Volk die Angriffe der bürgerlichen Rechten zurück und errangen an der politischen und ideologischen Front einen großen Sieg in der sozialistischen Revolution. Dieser Kampf war ein überzeugender Beweis für die Richtigkeit der These des Vorsitzenden Mao. ${ }^{168}$

Und so warb er am 14. März 1977 des gleichen Jahres in seiner Rede während der Arbeitskonferenz der KPCh in aller Deutlichkeit dafür, den korrekten politischen Weg Maos weiterzugehen:

To sum up the above in a single sentence, we must comprehensively and correctly implement Chairman Mao's proletarian revolutionary line in our country's socialist political, economic and cultural realms, in industry, agriculture, commerce, culture and education, and in the military, the government and the Party. Only then would we be able to achieve great order. $^{169}$

Insgesamt konnte sich dieser durchweg positive und unkritische Bewertungsansatz des Wirkens Maos innerhalb der Partei und vor allem in der Öffentlichkeit jedoch nicht durchsetzen und so schwand nicht nur Hua Guofengs Machtbasis innerhalb kurzer Zeit, sondern die Unterstützer Deng Xiaopings konnten auch einen anderen, differenzierteren Ansatz der Bewertung der politischen Leistungen Maos anstoßen. Die Kritik an ihm durfte dabei allerdings auch nicht zu radikal ausfallen, um die Legitimität der gesamten Partei sowie die seiner politischen Nachfolger nicht zu gefährden. Die für die Ausarbeitung der Resolution verantwortlichen Genossen hatten in diesem Zusammenhang wohl vor allem die möglichen negativen Auswirkungen, die ein Umgang Maos ähnlich dem der Entstalinisierung in der Sowjetunion hätte nach sich ziehen können, im Hinterkopf, die

168 Hua 1977a, S. 15 f.

169 Hua 1977b, https://digitalarchive.wilsoncenter.org/document/121681. 
den Personenkult um den im Jahr 1953 verstorbenen Josef Stalin radikal beendete. Denn im Gegensatz zu den politischen Nachfolgern Stalins hatten sie keine Legitimationsfigur wie Lenin in der Hinterhand, auf den sie die Herrschaftslegitimation der KPCh auch ohne Mao hätten stützen können.

Deng Xiaoping wohnte als Leiter der chinesischen Delegation Nikita Chruschtschows sogenannter Geheimrede bei, die dieser am 25. Februar 1956 zum Abschluss des XX. Parteitags der KPdSU hielt und welche die Entstalinisierung einläutete. Kurz nach der Rückkehr der Delegation nach Peking wurden die Eindrücke der Ereignisse in Moskau innerhalb des Politbüros diskutiert. Deng gab einen ausführlichen Bericht über seine Beobachtungen und Einschätzungen vom Parteitag in Moskau ab. ${ }^{170}$ Im Führungszirkel der KPCh war man sich weitgehend einig, dass man die Einschätzung Chruschtschows nicht teile, da Stalin weltweit schließlich der erste Führer gewesen sei, der ein sozialistisches Land aufgebaut habe. Insgesamt kamen sie zu dem Schluss, dass Stalin in seinen späten Jahren zwar durchaus Fehler gemacht habe, auf die sie allerdings nicht spezifisch eingingen, seine Verdienste jedoch deutlich überwögen. ${ }^{171}$ Von dieser Haltung würde Deng Xiaoping auch rund ein Viertel Jahrhundert später nicht nur nicht mehr abweichen, sondern seine Eindrücke vom XX. Parteitag der KPdSU und von dessen Folgen für die Sowjetunion hatten auch einen entscheidenden Einfluss auf den Umgang der neuen politischen Führung Chinas mit der Ikone Mao.

In einem Interview mit der Journalistin Oriana Fallaci, welches am 01. September 1980 in der Washington Post veröffentlicht worden ist, macht er deutlich, dass er den Umgang Chruschtschows mit Stalin für einen schwerwiegenden Fehler halte, auch deshalb, weil Stalin sich trotz gewisser Fehler insgesamt nicht nur um China, sondern auch um die gesamte kommunistische Bewegung verdient gemacht habe:

We think that Stalin's merits and contributions to the revolution exceed his mistakes. Using our Chinese habit, the grades for Stalin are 30 percent for his mistakes and 70 percent for his merits. Also Chairman Mao used to say so and, after the 20th Congress of the Soviet Communist Party, the Chinese Communist Party expressed a very clear evaluation of Stalin. In fact, we said that we would always regard Stalin's works as classical works in the international communist movement. You know, we are also aware of the mistakes committed by Stalin toward the Chinese revolution. When, after the Second World War, there was a rup-

170 Siehe auch Yang 1999.

171 Shen und Xia 2015, S. $151 \mathrm{ff}$. 
ture between the Chinese Communist Party and the Kuomintang and we engaged in the liberation of war, Stalin was against us. Yet, not even this ever changed our views of him. ${ }^{172}$

Im Verlauf dieses Gesprächs betont er auch, dass die chinesische Führung mit Mao keinesfalls im gleichen Maße kritisch umgehen würde.

Wie schwierig es tatsächlich jedoch gewesen ist, $\mathrm{zu}$ einer differenzierten Bewertung des verstorbenen Führers zu kommen, sollte sich während des Entstehungsprozesses der Resolution zeigen, deren Entwürfe mehrfach umgearbeitet worden sind. Insgesamt gibt es Zeugnis über mindestens neun Gespräche und Reden über die verschiedenen Entwürfe der Resolution, welche zwischen dem 19. März 1980 und 22. Juni 1981 stattgefunden haben. Diese geben jedoch nur einen Einblick zur Haltung Deng Xiaopings; die anderen Positionen lassen sich aufgrund des eingeschränkten Zugangs zu entsprechendem Archivmaterial zum gegenwärtigen Zeitpunkt nicht rekonstruieren. Man kann allerdings davon ausgehen, dass darüber hinaus noch weitere Gesprächsprotokolle existieren, welche möglicherweise von der KPCh unter Verschluss gehalten werden. In diesen Gesprächen brachte Deng Xiaoping immer wieder seine Unzufriedenheit zum Ausdruck, denn die ausarbeitenden Genossen hatten in den ihm vorliegenden ersten Entwürfen noch nicht den Ton getroffen, der ihm für die Resolution vorschwebte:

Der Ton des Dokuments ist insgesamt zu bedrückend, es liest sich nicht wie eine Resolution. Eine Überarbeitung scheint notwendig, verlangt jedoch viel Arbeit. Der Schwerpunkt sollte darauf liegen, was die Mao-Zedong-Ideen sind und welche Gedanken des Genossen Mao Zedong korrekt sind. Das Falsche muß kritisiert werden, allerdings in angemessener Weise. Die Probleme können nicht gelöst werden, wenn man allein die Fehler des Genossen Mao Zedong kritisiert. Entscheidend ist die Frage der Systeme und Institutionen. Genosse Mao Zedong hat viele korrekte Bemerkungen gemacht, aber die fehlerhaften Systeme und Institutionen der Vergangenheit drängten ihn in die falsche Richtung. Die Fehler des Genossen Mao Zedong in seinen späteren Jahren in theoretischer wie praktischer Hinsicht müssen erwähnt werden, aber auf angemessene Weise und in zusammenfassender Form. ${ }^{173}$

Insgesamt, so machen es die Gesprächsprotokolle deutlich, sollten Maos Verdienste - entsprechend der chinesischen Bewertung der Verdienste Stalins - in eine gute frühe Phase und eine schlechte späte Phase unterteilt werden: „Allgemein gesagt, war die Führung des Genossen Mao Zedong vor dem Jahre 1957 korrekt. Nach dem Kampf gegen die Rechten in jenem Jahr beging er jedoch mehr

172 Fallaci 1980, https://www.washingtonpost.com/archive/politics/1980/09/01/deng-a-thirdworld-war-is-inevitable/a7222afa-3dfd-4169-b288-bdf34f942bfe/?noredirect=on\&utm_term=. 5 dcd437c04a0.

173 Deng 1985, S. 323 f. 
und mehr Fehler." ${ }^{174}$ In der Endfassung der Resolution, welche einen eigenen Abschnitt mit dem Titel „Die historische Stellung des Genossen Mao Zedong und die Mao-Zedong-Ideen“ enthält, heißt es hierzu:

Genosse Mao Zedong war ein großer Marxist und ein großer proletarischer Revolutionär, Stratege und Theoretiker. Obwohl er in der „Kulturrevolution“ schwere Fehler beging, überwiegen alles in allem seine Verdienste für die chinesische Revolution. Seine Verdienste sind zweifellos primär, seine Fehler sekundär. ${ }^{175}$

Die Mao-Zedong-Ideen hingegen werden in der Resolution in ihrer Gesamtheit deutlich kanonisiert. Dieser festgelegte Kanon hat bis ins gegenwärtige China Bestand:

Die Mao-Zedong-Ideen sind ein wertvoller geistiger Reichtum unserer Partei, sie werden auch langfristig der Leitfaden für unsere Tätigkeit bleiben. Die mit dem Marxismus-Leninismus und den Mao-Zedong-Ideen herangebildeten Parteiführer und zahlreichen Kader bildeten das Rückgrat unserer großen Erfolge in der Vergangenheit. Sie sind und bleiben unsere wertvolle Stütze bei der sozialistischen Modernisierung. Obwohl viele wichtige Schriften des Genossen Mao Zedong in der Periode der neudemokratischen Revolution und der sozialistischen Umgestaltung verfaßt wurden, müssen wir sie weiter ständig studieren. Dies nicht nur, weil Vergangenheit und Gegenwart sich nicht trennen lassen und ein mangelhaftes Verständnis der Vergangenheit uns daran hindern wird, die gegenwärtigen Probleme zu begreifen, sondern gerade auch, weil diese Schriften viele Grundsätze, Prinzipien und wissenschaftliche Methoden von allgemeiner Bedeutung erhalten, die heute und in Zukunft eine tragende und ableitende Rolle spielen. ${ }^{176}$

Deng Xiaoping und seine Gefolgsleute erreichten somit in gewisser Weise eine Trennung der Person Mao Zedongs mit all seinen Fehlern von der Ideologie der Mao-Zedong-Ideen. Dies wird auch in der Einschätzung der Kulturrevolution deutlich, in der ebenfalls eine Trennung der Mao-Zedong-Ideen und der Fehler der Kulturrevolution vorgenommen wurde:

Diese falschen „linken“ Thesen des Genossen Mao Zedong, die dann zur Initiierung der „Kulturrevolution“ führten, wichen merklich von den Mao-Zedong-Ideen als Verbindung der allgemeinen Prinzipien des Marxismus-Leninismus mit der konkreten Praxis der chinesischen Revolution ab und müssen von den Mao-Zedong-Ideen unterschieden werden. ${ }^{177}$

174 Ebd., S. 320.

175 Resolution über einige Fragen zur Geschichte der KP Chinas seit 1949 1981, S. 63.

176 Ebd., S. 81.

177 Ebd., S. 37. 
Somit konnten die Mao-Zedong-Ideen auch zukünftig als legitimierender Faktor für die KPCh genutzt werden, da sie auch nach seinem Tod noch so dringend benötigt wurden. In der Einschätzung der Fehler Maos folgten Deng Xiaoping und seine Anhänger damit gewissermaßen dem von Mao selbst im Jahr 1944 formulierten Kredo des ausgewogenen Umgangs mit den Fehlern von Parteimitgliedern, welches bereits Einzug in die Resolution von 1945 gefunden hatte: „An die Behandlung der einzelnen Genossen muß man sorgfältig und behutsam herangehen: weder ein Auge zudrücken, noch die Genossen verletzten - ein solches Herangehen ist eins der Kennzeichen für das Aufblühen und Gedeihen unserer Partei." ${ }^{178}$

Am 19. März 1981 wurde auch die historische Einordnung der Kampagne gegen Rechtsabweichler thematisiert. Von dieser gab es ebenfalls mehrere Versionen, die Dengs Ansicht nach einer Überarbeitung bedurften. Er rechtfertigte den Umgang mit den Intellektuellen in den Jahren dadurch, dass die damaligen politischen Entscheidungen zum Wohle des ganzen Landes notwendig gewesen seien, und deshalb insistierte er im Gespräch mit den verantwortlichen Genossen, dass dies in der Endfassung der Resolution auch deutlich werden müsse:

Den Kampf gegen die Rechten im Jahre 1957 muß man bejahen. Nach der Vollendung der drei großen Umgestaltungen gab es tatsächlich eine Kraft - eine ideologische Strömung - im Land, die antisozialistisch und von bürgerlichem Charakter war. Es war notwendig, sie zurückzuschlagen. Ich habe mehrmals gesagt, daß es damals wirklich Leute gab, die mit dem Säbel rasselten und versuchten, die Führung der Kommunistischen Partei zu leugnen und die sozialistische Richtung unseres Landes zu ändern. Wir hätten nicht vorwärtsschreiten können, ohne sie zurückzuschlagen. Der Fehler lag in der übermäßigen Ausweitung des Kampfes. Die Abteilung für die Einheitsfrontarbeit beim ZK der Partei schrieb einen Bericht an das Zentralkomitee und schlug vor, daß alle diejenigen, die ungerechtfertigt zu Rechten erklärt worden waren, rehabilitiert werden sollten und daß jene, deren Einstufung als Rechte nicht falsch war, nicht rehabilitiert werden dürften. Was einige ehemalige bekannte Persönlichkeiten aus demokratischen Parteien anbelangt, die richtigerweise als Rechte bezeichnet wurden, sollte man bei ihrer Bewertung hinzufügen, daß sie vor dem Kampf gegen die Rechten, insbesondere während der Zeit der demokratischen Revolution, Gutes geleistet haben. Man sollte ihre Familienangehörigen nicht diskriminieren, sondern sorgfältig für deren Leben und Arbeit sorgen und sich politisch angemessen um sie kümmern. ${ }^{179}$

Der letzte Punkt fand schließlich keinen Einzug in die Endfassung des offiziellen Narrativs. Jedoch, so würde sich später herausstellen, sollte genau dies ein zentraler Aspekt sein, der später für eine wiederkehrende und in die Öffentlichkeit getragene Debatte durch Opfer oder ihre Angehörigen führen würde. Eine nicht

178 Mao 1969, S. 188.

179 Deng 1985, S. $319 f$. 
geringe Anzahl derer, die mittel- oder unmittelbar von der Kampagne gegen Rechtsabweichler betroffen waren, fühlten sich durch den Staat eben nicht ,angemessen“ behandelt, wie Kapitel 6 und 7 genauer darlegen werden.

Deng Xiaopings Rolle in der Kampagne gegen Rechtsabweichler wird in der Resolution, welche schließlich am 27. Juni 1981 von der 6. Plenartagung des 11. Zentralkomitees angenommen wurde, komplett negiert. Das offizielle Narrativ der Kampagne gegen Rechtsabweichler in der Endfassung der Resolution fällt insgesamt sehr kurz und prägnant aus. In dieser kam man, entsprechend den Einwänden Dengs vom 19. März, letztlich zu der Einschätzung, dass das Ausmaß der Kampagne gegen Rechtsabweichler zwar übertrieben worden sei, diese zum Schutz der Partei aber dennoch notwendig und richtig gewesen sei:

\begin{abstract}
Im gleichen Jahr wurde dann in der ganzen Partei eine Ausrichtungsbewegung eingeleitet, wobei das Volk aufgerufen wurde, der Partei Kritik und Vorschläge zu unterbreiten. Dies war ein durchaus normaler Schritt zur Entfaltung der sozialistischen Demokratie. Einige wenige bürgerliche Rechte versuchten dies allerdings zu nutzen, um sogenannte „freie Debatten und Meinungsäußerungen“ zu fordern und die Partei und das neue sozialistische System hinterrücks anzugreifen. Sie versuchten die Führung der Kommunistischen Partei zu beseitigen. Von daher war es korrekt und notwendig, den Rechten eine entscheidende Abfuhr zu erteilen. Aber der Rahmen dieses Kampfes wurde beträchtlich überzogen, wobei eine Anzahl von Intellektuellen, patriotischen Persönlichkeiten und Parteikadern zu Unrecht zu „rechten Elementen“ abgestempelt wurden - mit nachhaltigen Konsequenzen. ${ }^{180}$
\end{abstract}

Diese Einschätzung gibt bis heute den offiziellen Erinnerungsrahmen der Kampagne gegen Rechtsabweichler sowie der historischen Ereignisse seit Gründung der Volksrepublik China 1949 im Allgemeinen vor. Von diesem wird in offiziellen Darstellungen, wie staatlichen Museen, offiziellen Geschichtsbüchern und Biografien oder z. B. in Schulbüchern, nur äußerst selten abgewichen. Doch obwohl die Grenzen des offiziellen Umgangs mit der Kampagne damit gesteckt worden sind, war dieser Abschnitt der Resolution so vage formuliert, dass er dennoch, möglicherweise zunächst ungewollt, genügend Raum gelassen hat, um das Narrativ der Kampagne während der nächsten Jahrzehnte immer wieder an die politischen Bedürfnisse der Gegenwart anzupassen.

Die Tatsache, dass einer der zentralen politischen Akteure der Kampagne gegen Rechtsabweichler wiederum einer der entscheidenden Akteure für den Aufbau des Landes und damit für den sich mehrenden Wohlstand des Landes gewesen ist, hatte somit einen direkten Einfluss auf die Schaffung des offiziellen Narrativs. Gleichzeitig erklärt dies, warum die Kampagne gegen Rechtsabweichler - im Gegensatz zur Kulturrevolution - offiziell nie als „historischer Fehler“

180 Resolution über einige Fragen zur Geschichte der KP Chinas seit 1949 1981, S. 30 f. 
eingestuft respektive anerkannt worden ist. Auch die Entscheidung des Herbstes 1978, den Opfern der Kampagne gegen Rechtsabweichler keine Kompensationszahlungen zukommen zu lassen, übte einen wichtigen Einfluss darauf aus. Dadurch, dass sie nicht als „historischer Fehler“ eingestuft worden ist, konnte man diese Entscheidung somit auch im Nachhinein besser rechtfertigen. Über die Kulturrevolution hingegen sagte Deng Xiaoping nicht nur am 18. März 1981 zu den für den Entwurf der Resolution verantwortlichen Parteikadern: „Die ,Kulturrevolution“ war tatsächlich ein großer Fehler." ${ }^{181}$ Auch in der Endfassung der Resolution selbst wird diese in einem eigenen Abschnitt in aller Deutlichkeit als Fehler bewertet. ${ }^{182}$ Eine Einordnung der Kampagne gegen Rechtsabweichler als „historischer Fehler“ stand für Deng Xiaoping, das machen die uns verfügbaren Quellen deutlich, hingegen wohl nie zur Debatte. Das macht die Aufarbeitung der Kampagne bis heute so schwierig. Wenngleich auch der öffentliche kritische Diskurs um die Kulturrevolution und die durch sie ausgelösten Traumata von staatlicher Seite aus nicht unbedingt erwünscht sind, hat ihre Einordnung als „historischer Fehler“ einen breiteren öffentlichen Diskurs zugelassen als die offizielle Bewertung der Kampagne gegen Rechtsabweichler. Deng konnte davon ausgehen, dass ein öffentlicher Diskurs um die Kulturrevolution für seine eigene Legitimität nicht ganz so problematisch sein würde, da er ihr einst ja auch selbst zum Opfer gefallen ist. Ein gewisses Maß an Kontrolle war seit jeher dennoch immer nötig, da niemand abzuschätzen vermochte, welche Konsequenzen ein unkontrollierter öffentlicher Diskurs um die Verfehlungen während jener Jahre mit sich bringen würde. Deng Xiaoping, wie auch seinen politischen Nachfolgern Jiang Zemin, Hu Jintao und Xi Jinping, dürfte bewusst gewesen sein: Gerät die Partei durch einen Verlust der Herrschaftslegitimation ins Wanken, fallen sie selbst möglicherweise zuerst.

Hinsichtlich der Kampagne gegen Rechtsabweichler gilt es zudem zu berücksichtigen, dass man keine Viererbande in der Hinterhand hatte, die man öffentlich für die Verfehlungen jener Jahre an den Pranger hätte stellen können. Der politische Einfluss der einzelnen Mitglieder der Viererbande war in den späten 1950er Jahren noch zu klein gewesen, als dass man eine Verantwortlichkeit durch sie hätte konstruieren können. ${ }^{183}$

Deng Xiaoping selbst hat Zeit seines Lebens nie öffentlich eingeräumt, dass er während der Kampagne gegen Rechtsabweichler eigene Fehler begangen hat. Leidglich in dem bereits erwähnten Interview mit Oriana Fallaci deutet er an, dass

181 Deng 1985, S. 327.

182 Resolution über einige Fragen zur Geschichte der KP Chinas seit 1949 1981, S. 36 - 62.

183 Zum Aufstieg und Fall der Viererbande siehe Meyer 1981. 
er im Laufe seiner politischen Karriere durchaus auch Fehler gemacht habe, wobei er allerdings sehr unspezifisch bleibt:

Well, I too have made mistakes, as I told you. At times, serious mistakes. But I never made them with evil purposes, I always made them with good intentions. So, looking back at my whole life, I don't find a reason to feel a guilty conscience. Look, I guess that I could give to myself 50 percent. Yes, 50 percent would be okay. ${ }^{184}$

Das Interview fand während des Entstehungsprozesses der Resolution statt. Interessant ist hierbei, dass den guten und schlechten Taten Maos für das Land in der von Deng Xiaoping entscheidend mitgestalteten Resolution eine 70-zu-30Bewertung zugesprochen wird, ${ }^{185}$ er seinen eigenen guten und schlechten Taten jedoch eine 50-zu-50-Bewertung beimisst.

Insgesamt sollte im damaligen offiziellen Diskurs das Sprechen über Fehler einzelner politischer Akteure dem im Juni 1981 von ihm selbst formulierten Kredo folgen, dass, obwohl Mao der Hauptverantwortliche für die schwerwiegenden Fehler der Kulturrevolution gewesen sei, die Fehler der Partei insgesamt aber kollektiv getragen werden müssten, wobei auch die Fehleranfälligkeit der noch jungen Institutionen berücksichtigt werden müsse. Übertreibungen in der Kritik Einzelner sollten somit vermieden werden:

Warum müssen wir die Angemessenheit der Bewertung betonen? Weil man in jüngster Zeit in manchen Reden gewisse Fehler des Genossen Mao Zedong übertrieb. Solche Übertreibung muß korrigiert werden, was der aktuellen Situation entspricht und insgesamt dem Ansehen des Staates und der Partei dient. Die Verantwortung für mache Fehler in der Vergangenheit sollte eher kollektiv getragen werden, obwohl Genosse Mao Zedong selbstverständlich hauptverantwortlich war. Wir sagen, daß Systeme und Institutionen der entscheidende Faktor sind, und wir alle wissen, daß dies auch für damals gilt. Zu jener Zeit wurde alles einer einzigen Person zugeschrieben. Es gab auch Dinge, denen wir uns nicht widersetzten und für die wir teilweise selbst die Verantwortung zu tragen haben. Natürlich stimmt, daß es unter den damaligen Umständen ziemlich schwer war, gegenteilige Meinungen zu äußern. Dennoch dürfen wir dem „wir“ nicht ausweichen. ${ }^{186}$

Damit deutete er auch an, dass es in dieser Phase innerhalb der Partei durchaus einen Dissens hinsichtlich der Bewertung der Fehler der Vergangenheit und des

\section{Fallaci 1980.}

185 Auch wenn die Bewertung, dass Maos Taten zu 70 Prozent gut und zu 30 Prozent schlecht gewesen seien, nicht wortwörtlich in der Resolution erwähnt wird, ist diese doch bis heute anerkannt. Mao selbst hat diese Formel im Jahr 1956 für die Bewertung Stalins formuliert. Leese 2010, S. 238.

186 Deng 1985, S. 327. 
politischen Erbes Maos gegeben haben dürfte. Zusammenfassend kann man die Resolution als kleinsten gemeinsamen Nenner unterschiedlicher Positionen innerhalb der höchsten Parteikreise verstehen. Susanne Weigelin-Schwiedrzik etwa schreibt sowohl der Resolution von 1945 als auch der von 1981 eine Funktion als Konsenspapier $\mathrm{zu}^{187}$

Obwohl die Resolution von einem kleinen Kreis unter der Leitung Deng Xiaopings und $\mathrm{Hu}$ Yaobangs verfasst worden ist, sollte dennoch der Eindruck innerparteilicher Transparenz vermittelt werden. Deshalb ist einer der frühen Entwürfe im Oktober 1980 von 4.000 Parteimitgliedern unterschiedlichsten Ranges diskutiert worden. Allerdings sollte sich der Kreis der Diskutanten im Laufe der nächsten Monate bis zur Verabschiedung noch erheblich verkleinern. Im Mai 1981 erklärte Deng, dass eine schnelle Fertigstellung der Resolution für die Stabilität und den Fortschritt des Landes von höchster Wichtigkeit sei und man diese deshalb nicht noch einmal mit einer solchen Vielzahl von Parteimitgliedern diskutieren könne. Und so sind die späten Entwürfe nur noch innerhalb der höchsten Parteikreise diskutiert worden. ${ }^{188}$ Letztlich sollte mit der Veröffentlichung der Resolution wohl ein Schlussstrich unter die „historischen Fehler“ der Partei gezogen werden, mit dem Zweck, die Partei reinzuwaschen und ihre Herrschaftslegitimation aufrechtzuerhalten. Fortan sollte sich das ganze Land auf den wirtschaftlichen Aufbau konzentrieren und nur noch nach vorne blicken. Der erwünschte Effekt der Resolution war also, einen offiziellen Konsens über die Vergangenheit zu finden und den darum entstandenen Dissens im Keim zu ersticken - sowohl innerhalb der Partei als auch im Volk, wie in Deng Xiaopings Rede vom 19. März 1980 deutlich wurde:

\footnotetext{
Diese Resolution sollte unsere Arbeit in der Vergangenheit grundlegend zusammenfassen. Wie ich früher sagte, ist es besser, eine derartige Zusammenfassung in den großen Zügen zu schreiben, als zu sehr in Einzelheiten zu gehen. Der Zweck der Zusammenfassung unserer früheren Arbeiten besteht darin, die Menschen zu veranlassen, sich zusammenzuschließen und den Blick nach vorn zu richten. Wir sollten danach streben, daß man nach Annahme der Resolution die ideologischen Fragen innerhalb der Partei und im Volk klären, einheitliche Erkenntnisse erreichen und die Diskussion über wichtige historische Fragen im großen und ganzen abschließen kann. Natürlich wird die Diskussion über Vergangenes auch in Zukunft schwer zu vermeiden sein, aber solche Diskussionen sollten nur in Verbindung mit Diskussionen über die laufende Arbeit geführt werden. Jetzt gilt es, mit Leib und Seele an den vier Modernisierungen zu arbeiten und vereint nach vorn zu schauen. Dies zu erreichen ist nicht leicht. Wir müssen unser Bestes tun, um eine gute Resolution auszuarbeiten, damit wir
}

187 Weigelin-Schwiedrzik 1984, S. 86.

188 Siehe Rede auf der erweiterten Sitzung des Politbüros des Zentralkomitees am 19. Mai 1981. Deng 1985, S. 333 f. 
Einheit in den Ansichten erzielen und größere Meinungsverschiedenheiten vermeiden können. Dann gibt es in Zukunft, wenn man von vergangenen Ereignissen spricht, keine unterschiedlichen Meinungen mehr. Man wird dann die Diskussion auf den Inhalt der Resolution beschränken sowie auf die Lehren, die aus den Erfahrungen der Vergangenheit zu ziehen sind. ${ }^{189}$

Diese „Einheit in den Ansichten“ sollte nur von recht kurzer Dauer sein, wenn sie denn überhaupt jemals existiert haben sollte, wie diese Arbeit in den folgenden Abschnitten und Kapiteln darlegen wird - ganz im Gegenteil ist die Debatte über die offizielle Bewertung der „historischen Fehler“ der KPCh auch im gegenwärtigen China noch in vollem Gange. Deshalb strebt die Partei mit der Einheit der Ansichten auch ein (kollektives) selektives Vergessen und selektives Erinnern an mit dem Ziel der gesamtgesellschaftlichen und innerparteilichen Einheit. Nicht vergessen werden sollten dabei nicht nur die Verdienste Maos, sondern insbesondere die Verdienste der Partei, die als alternativlos für den Fortbestand der chinesischen Nation kanonisiert worden sind.

\section{Der Widerspruch zwischen der Festigung des Konsenses und neuen intellektuellen Freiheiten}

Gleichwohl wurden in dieser Zeit des politischen Umbruchs die institutionellen Grundlagen für eine Festigung des staatlichen Kanons gelegt. Eine der ersten Maßnahmen war die Gründung der Chinesischen Akademie der Sozialwissenschaften (zhongguo shehui kexueyuan 中国社会科学院) ${ }^{190}$ im Jahr 1977. Diese wurde von der im Jahr 1949 gegründeten Chinesischen Akademie der Wissenschaften (zhongguo kexueyuan 中国科学院), ${ }^{191}$ welche während der Kulturrevolution als Hauptquartier bourgeoisen Gedankenguts gegolten hatte, abgespalten. Die CASS sollte einen wesentlichen Beitrag zur Weiterentwicklung der Sozialwissenschaften in der VR China leisten. Mehr noch, sie sollte die Grundlage für die Festigung der durch Deng Xiaoping transformierten staatlichen Ideologie legen. Dementsprechend sollte die Wissenschaft nicht nur in der Theorie im Einklang mit dem Marxismus agieren und so steht die CASS seit jenen Jahren auch in enger

189 Ebd., S. $317 \mathrm{f}$.

190 Englisch: Chinese Academy of Social Science. Fortan: CASS.

191 Die Chinesische Akademie der Wissenschaften ist seitdem auf Naturwissenschaften, Mathematik und Ingenieurwesen spezialisiert. Gegenwärtig ist sie die größte Forschungseinrichtung der Welt. Siehe Chinesische Akademie der Wissenschaften (Zhongguo Kexueyuan 中国科学院) 2019, http://www.cas.cn/zz/. 
Verbindung zum Propagandaministerium. ${ }^{192}$ Der bereits erwähnte Hu Qiaomu, der später eine führende Rolle in der Ausarbeitung der Resolution innehaben sollte, wurde 1977 der erste Präsident der CASS. Dieses Amt bekleidete er bis zum Jahr 1982. Auf seinen Vorschlag hin wurde innerhalb der CASS im Jahr 1979 auch das Institut zum Studium des Marxismus und der Mao-Zedong-Ideen (Makesi liening zhuyi Mao Zedong sixiang yan jiu yuan 马克思列宁主义毛泽东思想研究院) gegründet. ${ }^{193}$ Am 14. Juni 1978 wurde, ebenfalls auf Initiative Hu Qiaomus, der Chinesische Verlag für Sozialwissenschaften (Zhongguo shehui kexue chuban she 中国社会科学出版社) gegründet und an die CASS angegliedert, was die Verbreitung ihrer Forschungsergebnisse und Schriften erleichtern würde. ${ }^{194}$

Im März des Jahres 1977 wurde schließlich auch die Zentrale Parteihochschule (Zhonggong zhongyang dangxiao 中共中央党校) in Peking wiedereröffnet. Diese war bereits im Jahr 1933 gegründet worden, jedoch musste sie, wie die meisten Bildungsinstitutionen, während der Kulturrevolution schließen. In erster Linie diente die Parteihochschule der Ausbildung von Parteikadern. Im Laufe der kommenden Jahre wurden jedoch auch zunehmend Intellektuelle und Unternehmer ausgebildet. In den Jahren nach der Wiedereröffnung entstand ein immer größer werdendes Netzwerk von lokalen Parteihochschulen, welches im Jahr 1985 bereits auf 11.000 Schulen angewachsen war. ${ }^{195}$ Sie gelten bis heute als „Gehirn“ der Partei. Eine der wichtigsten Grundlagen der Ausbildung war seit jeher die Parteigeschichte, die auch nach dem Tode Maos noch auf dem Stundenplan der Studenten stand. Dennoch wurde die Ausbildung der zukünftigen Entscheidungsträger des Landes mit der Wiedereröffnung, analog zu den politischen Reformen, den Bedürfnissen der Modernisierung des Landes angepasst. Hierfür zeichnete der damalige Generalsekretär der KPCh Hu Yaobang verantwortlich. Dabei war die Neugestaltung des Stundenplans ein politischer Kompromiss: Neben den vor der Kulturrevolution bereits vorhandenen traditionellen Kursen zu den Themen marxistische Philosophie, politische Ökonomie, wissenschaftlicher Sozialismus, Parteigeschichte und Parteiaufbau standen fortan auch Kurse zu den Themen Wirtschaftsmanagement, Rechtswissenschaft, internationale Politik, Dialektik der Natur, der modernen Wissenschaften und der Technologie sowie mindestens eine Fremdsprache als essentieller Teil der Ausbildung auf dem Stundenplan. Das Studium der Parteigeschichte war damit zwar noch immer ein wichtiger Bestandteil der Ausbildung, jedoch war ihre Gewichtung

192 Miller 1996, S. $102 \mathrm{ff}$.

193 Ebd., S. 100.

194 Siehe Renmin Ribao 人民日报 2008, http://book.people.com.cn/GB/69360/8348295.html. 195 Zur historischen Entwicklung der Parteihochschulen siehe Shambaugh 2008a, S. 829ff. 
durch die neuen Inhalte und Schwerpunkte zwischenzeitlich nicht mehr so hoch wie zuvor. Nach der Absetzung Hu Yaobangs im Jahre 1987 wurden die neuen Fächer vom Stundenplan gestrichen und das Studium der Parteigeschichte nahm wieder einen höheren Stellenwert ein. ${ }^{196}$

Eines der wichtigsten Ereignisse für die Festigung des Kanons der offiziellen Geschichtsschreibung der VR China stellte jedoch die Einrichtung des Zentralen Forschungsbüros für Parteigeschichte (Zhongguo zhongyang dang shi yanjiu shi 中 国中央党史研究室) dar, das mit der am 29. Januar 1980 herausgegebenen Bekanntmachung über die Einrichtung des Zentralen Forschungsbüros für Parteigeschichte (Guanyu chengli zhongyang dang shi weiyuanhui ji qi gongzuo jigou de tongzhi 矢于成立中央党史委员会及其工作机构的通知) aufgebaut wurde. ${ }^{197}$ Es gehört seitdem direkt dem Zentralkomitee der KPCh an und setzt, laut offiziellen Richtlinien, die Standards und Vorgaben für wissenschaftliche Tätigkeiten an staatlichen Universitäten und Ausbildungsstätten, wie den Parteihochschulen. ${ }^{198}$

Nachdem bereits im Jahr 1977 die nationalen Hochschulzugangsprüfungen (Gaokao 高考) wieder eingeführt worden waren, ${ }^{199}$ ist mit der nationalen Bildungskonferenz im April des Jahres 1978 schließlich auch die Grundlage für eine Transformation der chinesischen Universitäten gelegt und damit auch eine Modernisierung des chinesischen Hochschulwesens eingeläutet worden. In seiner Rede zum Auftakt der Konferenz am 22. April betonte Deng Xiaoping die Bedeutung der Intellektuellen für die Gesellschaft und deren Rolle für den Aufbau des Landes in den kommenden Jahren. Dabei wies er auch darauf hin, dass sie ein Teil der Arbeiterklasse und somit auch ein wichtiger Bestandteil der proletarischen Politik seien und er sie, im Gegensatz zum Großteil der Mao-Ära, keinesfalls als Teil der Bourgeoisie oder potentielle Klassenfeinde ansehe:

Lenin hat wiederholt betont, daß die Arbeiter keinen Augenblick vergessen werden, daß sie Wissen als Macht brauchen. Ohne Wissen sind die Arbeiter wehrlos, mit Wissen aber mächtig. Und die Bedeutung dieser Wahrheit tritt heute noch klarer zutage. Wenn wir die Wissenschaft und Kultur unserer Zeit und die neue Technik und die neuen Technologien aller Branchen und Berufe beherrschen und entwickeln und eine höhere Arbeitsprodukti-

196 Liu 2009, S. $108 f$.

197 Nachrichten der Kommunistischen Partei Chinas 中国共产党新闻 1980, http://cpc.people. com.cn/GB/64162/64165/76621/76651/5291818.html.

198 Siehe Zhongguo zhongyang dang shi yanjiu shi 中国中央党史研究室 2019, http://www. zgdsw.org.cn/GB/349944/index.html.

199 An den ersten Prüfungen nach der Kulturrevolution nahmen im Dezember 1977 rund 5,7 Millionen Kandidatinnen und Kandidaten teil. Die Prüflinge konkurrierten um 270.000 Studienplätze. Zur Wiedereinführung der Hochschulzugangsprüfungen siehe Mühlhahn 2019, S. $487 \mathrm{f}$. 
vität als die unter dem Kapitalismus schaffen wollen, wenn wir unser Land zu einem modernen und starken sozialistischen Land aufbauen und im Bereich des Überbaus die bürgerlichen Einflüsse endgültig beseitigen wollen, dann müssen wir Werktätige von hohem wissenschaftlichen und kulturellen Niveau heranbilden und ein mächtiges Kontingent von Intellektuellen der Arbeiterklasse schaffen, die „rot und fachkundig“ sind. Diese Anforderungen entsprechen vollauf der proletarischen Politik. ${ }^{200}$

Und so suchte Deng, so wie es Mao in den Jahren 1956 und 1957 mit der HundertBlumen-Bewegung schon versucht hatte, den Schulterschluss mit den Intellektuellen. ${ }^{201}$ Er wusste, er würde qualifizierte Wissenschaftler benötigen, um sein ambitioniertes Ziel des wirtschaftlichen Aufbruchs Chinas zu erreichen. Dabei dürfte ihm ebenfalls gewahr gewesen sein, dass er den Intellektuellen nach den vielen Jahren der Demütigung etwas anbieten musste, um sie für seine Ziele zu gewinnen. Dies würde das politische Zusammenspiel zwischen Intellektuellen und Politik bzw. zwischen Wissenschaft und Partei in der folgenden Dekade prägen. Und so lockte Deng Xiaoping die Wissenschaftler und Intellektuellen insbesondere an den Hochschulen damit, dass er erstmals seit Ende der 1950er Jahre für sie die Möglichkeit schuf, wissenschaftlich relativ frei zu arbeiten und zu forschen - mit nachhaltigen Konsequenzen.

Zhao Ziyang 赵紫阳, von 1980 bis 1987 Premierminister der VR China, griff diesen Ansatz später noch einmal auf. In seinem Bericht zur Arbeit der Partei, den er während der 1. Sitzung des 6. Nationalen Volkskongresses am 06. Juni 1983 vorgestellt hatte, betonte er, dass die Entwicklung der intellektuellen Ressourcen die höchste Priorität haben müsse, um die Ziele des 6. Fünfjahresplans zu erfüllen oder gar zu übertreffen. Dies müsse auch damit einhergehen, darauf machte er mit Nachdruck aufmerksam, die alte Tendenz, kulturelle Arbeit herabzuwürdigen, zu beenden:

Under the guidance of Marxism-Leninism and Mao Zedong Thought and the principles of integrating theory with practice and of "letting a hundred flowers blossom and a hundred schools of thought contend" people specialized in philosophy and other social sciences should conduct creative research into the major ideological, theoretical and practical problems arising from our socialist modernisation, summarize from a historical perspective the achievements and lessons gained in all fields since the founding of the People's Republic and analytically study and criticize different trends of thought in the world so as to assimilate what is useful and produce research results of high quality. After some years of effort, we will establish a modern, nationwide research network step by step in philosophy and other social sciences that embraces a complete range of disciplines and subjects, each

200 Deng 1985, S. 133.

201 Vgl. Cao 1999, S. $315 \mathrm{ff}$. 
with distinctive characteristics but coordinated in their development, and is rational in geographical distribution..$^{202}$

Das Dokument zur Bildungsreform, welches im Jahr 1985 herausgegeben wurde, enthielt dementsprechend zwei grundlegende Änderungen: Den Universitäten wurde, im Gegensatz zur Chinesischen Akademie der Sozialwissenschaften, die Freiheit über den Inhalt der Lehre zugesprochen, das heißt, die Kontrolle über die Unterrichtsinhalte und -materialen wurde weitgehend ihnen überlassen. Die finale Entscheidungsbefugnis wurde dem Präsidenten der jeweiligen Universität übertragen. Das Dokument sah außerdem die Wiederherstellung der Forschung als zentralen Bestandteil des Universitätswesens vor. Das Forschen war bis dahin der Chinesischen Akademie der Wissenschaften vorbehalten gewesen. Damit einher ging auch eine Wiederbelebung der Geisteswissenschaften und damit auch der Geschichtswissenschaften. ${ }^{203}$ Insgesamt hatte die Peking-Universität zwischen den Jahren 1978 und 1989 drei Präsidenten, keiner von ihnen war Mitglied der KPCh. Der Physiker Zhou Peiyuan 周培源, der zwischen Juli 1978 und März 1981 die Peking-Universität führte, hatte einen großen Teil seiner Ausbildung im westlichen Ausland erlangt und war seit dem Jahr 1952 ein hochrangiges Mitglied der Gesellschaft des 3. September (Jiusanxueshe 九三学社), einer der acht rechtlich anerkannten Parteien in China. ${ }^{204}$ Zhou wurde im Mai 1981 von Zhang Longxiang 张龙翔 abgelöst, der bis zum März 1984 Präsident war. Der Biochemiker, der während der Amtszeit Zhous bereits Vizepräsident war, hatte ebenfalls einen Teil seiner Ausbildung im Ausland erlangt (er wurde 1944 an der Universität Toronto promoviert). ${ }^{205}$ Der Mathematiker Ding Shisun 丁世孙 war schließlich zwischen März 1984 und August 1989 Präsident. Er war Mitglied der Chinesischen Demokratischen Liga (Zhongguo minzhu tongmen 中国民主同盟), ebenfalls einer der in China anerkannten Parteien. ${ }^{206}$ Auch wenn es sich bei den Präsidenten dieser Dekade allesamt um Naturwissenschaftler handelte, ließen sie, als Entscheidungsträger über die Forschung, ein hohes Maß an intellektueller Freiheit in den Geisteswissenschaften zu. Auch wenn es sich bei der Peking-Universität zweifelsohne um eine staatliche Institution handelt, diente sich ein Teil der

202 Zhao 1983, XVIII.

203 Hayhoe 1996, S. 118.

204 Nachrichten der Kommunistischen Partei Chinas 中国共产党新闻 1993, http://cpc.people. com.cn/GB/7301994.html. Während der Kulturrevolution hatte sich Zhou Peiyuan dafür eingesetzt, die chinesischen Hochschulen vom kulturrevolutionären Dogmatismus zu befreien, wofür er heftig kritisiert worden ist, siehe Teiwes und Sun 2007, S. 59.

205 Peking-Universität 北京大学 2017, http://www.pku.org.cn/zt/bjdx120znxq/85672.htm. 206 Renmin Ribao 人民日报 2019, http://en.people.cn/data/people/dingshisun.shtml. 
Wissenschaftler in ihrer Arbeit in jenen Jahren nicht unbedingt den ideologischen Zielen der KPCh an, einige vertraten sogar eine politisch kritische Haltung oder setzten sich für ihre politisch engagierten Studenten ein - Ding Shisun war einer von ihnen. ${ }^{207}$

Bereits seit 1937 ist die People's University of China (Zhongguo renmin daxue 中国人民大学) eine der wichtigsten Institutionen sowohl für die Ausbildung von Parteikadern als auch für die Ausbildung von Parteihistorikern und damit für die Stärkung des offiziellen Narrativs. ${ }^{208}$ Der Schwerpunkt von Forschung und Lehre liegt seit jeher auf den Geistes- und Sozialwissenschaften, auch wenn im Laufe der Jahre immer mehr technische Studiengänge hinzugekommen sind. Die Universität wurde im Jahr 1973 zwischenzeitlich aufgelöst und im Jahre 1978 auf Initiative Deng Xiaopings wiedereröffnet. Sie trägt bis heute das Motto „Die Wahrheit in den Tatsachen suchen“ (shishiqiushi 实事求是), die von Deng ausgegebene Maxime. Sie ist direkt dem Bildungsministerium (jiaoyubu 教育部) angegliedert. ${ }^{209}$

Insgesamt nahmen alle der hier beschriebenen, in jenen Jahren wiedereröffneten und reformierten Institutionen seitdem einen sehr wichtigen Stellenwert für die Ausbildung von Parteihistorikern ein. Insofern nehmen sie auch eine Schlüsselrolle für die nachhaltige Stärkung der offiziellen Narrative und somit für den aus Sicht der Partei korrekten Umgang mit „historischen Fehlern“ wie der Kampagne gegen Rechtsabweichler ein.

Seit dem Jahr 1949 gibt es verschiedene Hierarchieebenen von Parteihistorikern, welche ihre Aufgaben und den Zugang zu Forschungsmaterialien zu sensiblen historischen Themen bestimmen, wie Susanne Weigelin-Schwiedrzik ausführt. Parteihistoriker ersten Ranges nehmen demnach Schlüsselpositionen an der CASS, der Parteihochschule oder an den wichtigsten Universitäten des Landes, wie der People's University of China, ein. Einerseits sind sie für die Ausbildung von Parteikadern zuständig und schreiben auch Lehrbücher, andererseits beraten sie das Zentralkomitee in Fragen zur Geschichte der Partei. Parteihistoriker zweiten Ranges sind häufig Professoren an wichtigen Universitäten oder haben eine hohe Position in der Zentralen Forschungsstelle der KPCh. Sie sind ebenfalls für das Verfassen von Lehrbüchern zuständig. Parteihistoriker dritten Ranges sind junge Wissenschaftler und Dozenten an Universitäten. Sie publizieren in wis-

207 Der damalige Präsident der Peking-Universität musste deswegen kurze Zeit später seinen Posten räumen. The New York Times 1989, https://www.nytimes.com/1989/08/24/world/china-re places-head-of-beijing-university.html.

2081937 wurde sie als Öffentliche Hochschule Shanbei 陕北公学 gegründet. Seit 1949 hat sie ihren Sitz in Peking.

209 Zur Geschichte der Universität seit 1937 siehe Zhongguo Renmin Daxue 中国人民大学 2019, https://www.ruc.edu.cn/history. 
senschaftlichen Zeitschriften oder arbeiten Historikern zweiten Ranges beim Verfassen von Lehrbüchern zu. Historiker zweiten und dritten Ranges haben meist nur Zugriff auf Propagandamaterial, während Parteihistoriker ersten Ranges auch Zugang zu vertraulichen Dokumenten erhalten. Um überhaupt in einen der Ränge aufgenommen zu werden, ist neben der formalen Ausbildung in Parteigeschichte eine regimetreue und loyale Haltung zur Partei eine Grundvoraussetzung. ${ }^{210}$

Einerseits stellten Teile der in den 1980er Jahre reformierten Institutionen die Ausbildung von konservativen Parteikadern sicher und somit auch die Ausbildung von regimetreuen Intellektuellen und Parteihistorikern, die durch ihre Arbeit offizielle Narrative nachhaltig stützen konnten - nicht zuletzt durch die Weitergabe dieser Narrative an Studenten und Schüler. Andererseits konnten sich die offiziellen Narrative dennoch nicht im erwünschten Maße festigen. Anders ausgedrückt, konnte die Übertragung des offiziellen Kanons auf das Kollektiv der chinesischen Bevölkerung zunächst nicht in einem für die KPCh ausreichenden Maße sichergestellt werden. Die institutionellen Grundlagen für den Umgang mit den „historischen Fehlern“ der Partei wie der Kampagne gegen Rechtsabweichler waren möglicherweise zu schwach, um die Kontrolle über die Geschichte ausreichend zu stützen.

Denn trotz des Top-down-Ansatzes im Umgang mit der Parteigeschichte ging die zunehmende Öffnung Chinas in den 1980er Jahren auch damit einher, dass nach und nach westliche Ideen nach China vordrangen und sich insbesondere auch an den Universitäten verbreiteten. Hinzu kam, dass mit der Transformation der Universitäten auch eine Vielzahl an Austauschprogrammen mit ausländischen Universitäten geschaffen wurde. Genutzt wurden diese Programme in den frühen 1980er Jahren typischerweise von Fakultätsmitgliedern mittleren Alters, die häufig später in der Wissenschaft Karriere machten und eine hohe Position an einer chinesischen Universität einnahmen. ${ }^{211}$

Merle Goldman charakterisiert die damalige politische Linie Deng Xiaopings als milden Autoritarismus, der insgesamt eine Lockerung der Kontrollen über die Gemeinschaft der Intellektuellen zur Folge hatte. In jenen Jahren wurden innerhalb Chinas sogar offene Debatten zu den Themen Politik und Kultur in Zeitungen, Fachzeitschriften, akademischen Foren, Konferenzen und auch in Filmen oder im Fernsehen zugelassen. ${ }^{212}$ Dieses politische Klima der 1980er Jahre ließ es $\mathrm{zu}$, dass einige der den staatlichen Institutionen zugehörigen Mitglieder zunehmend auch außerhalb der gesetzten offiziellen Vorgaben agierten und somit

210 Weigelin-Schwiedrzik 1987, S. 82ff.

211 Hayhoe 1996, S. 114 f.

212 Goldman 1996, S. 35 f. 
ein stetig größer werdender Raum für eine alternative Geschichtsschreibung entstand, wie in Kapitel 5 und 6 genauer dargelegt wird. Einen Dissens über den offiziellen Kanon der Bewertung der Verdienste Maos gab es seit 1978 außerdem auch immer wieder aus offiziellen Organen heraus. Hu Jiwei 胡绩伟, der damalige Chefredakteur der Renmin Ribao und ein enger Weggefährte Hu Yaobangs, nutze seine hohe Stellung, um Kritik an der Ikone Mao und der offiziellen historischen Bewertung seiner Leistungen im Parteiorgan abzudrucken. Er selbst übte auch immer wieder Kritik an Mao, welche er ebenfalls über das Parteiorgan verbreitete. ${ }^{213}$ Damit dient er als Beispiel eines zunächst über den offiziell erwünschten Rahmen hinaus agierenden öffentlichen Intellektuellen, der in den nächsten Jahren sukzessive in einen von der Partei nicht mehr tolerierten Bereich eintreten sollte.

Zunächst jedoch schien der Plan der führenden Parteikader um Deng Xiaoping, die Fehler der Vergangenheit, insbesondere die der Ikone Mao Zedong, kollektiv zu vergessen und gemeinsam nach vorne zu blicken, tatsächlich aufzugehen: China legte einen in der Weltgeschichte beispiellosen wirtschaftlichen Aufschwung hin, von dem offenkundig das Land in seiner Gesamtheit zu profitieren schien. Oberflächlich betrachtet war ein Großteil der chinesischen Gesellschaft mit der Umsetzung der Vier Modernisierungen (si ge xiandaihua 四个现代 化) beschäftigt und nicht damit, in die Geschichte zurückzublicken.

\subsection{Die Studierendenproteste 1989 und die Folgen für den offiziellen Diskurs um die Geschichte}

Die 1980er Jahre standen in China ganz im Zeichen der wirtschaftlichen Entwicklung, der Experimente und der zunehmenden Liberalisierung. Die ideologische Bildung des Volkes nahm für die KPCh in diesem Jahrzehnt, insgesamt nur einen untergeordneten Stellenwert ein, denn schließlich war ein Schlussstrich unter die Vergangenheit gezogen worden. Und dennoch sollte das Ende dieses Jahrzehnts eine Zäsur für das China der Reform- und Öffnungspolitik bedeuten.

Das in jenen Jahren entstandene Ungleichgewicht zwischen Markt und Ideologie bzw. ideologischer Bildung war möglicherweise einer der größten politischen Fehler der KPCh im post-maoistischen China, dessen Ausmaß sogar bis in die Gegenwart spürbar ist. Berücksichtigt werden sollte hier allerdings, dass die

$213 \mathrm{Hu}$ Jiwei wurde 1983 im Zuge der Kampagne gegen geistige Verschmutzung (qingchu jingshen wuren 清除精神污染) aufgrund seiner Ansichten und seiner politischen Forderungen nach demokratischen Reformen seines Amtes enthoben. Goldman 2002, S. $513 \mathrm{f}$. 
ideologische Bildung zu jener Zeit wohl auch deshalb vernachlässigt worden ist, weil die Menschen nach mehr als 30 Jahren der politischen Indoktrination durch den Propagandaapparat dieser Form der Bildung müde waren, weshalb sie zunächst wahrscheinlich ohnehin nicht auf fruchtbaren Boden gefallen wäre. Nicht zuletzt deswegen hatte Deng Xiaoping bereits im Jahr 1978 das Zeitalter der revolutionären Massenkampagnen für beendet erklärt. ${ }^{214}$

Insgesamt lassen sich für die Stabilität der Herrschaftslegitimation der KPCh in jenen Jahren drei fatale Entwicklungen erkennen: Erstens ist durch die Vernachlässigung der ideologischen Bildung ein ideologisches Vakuum entstanden, welches nach und nach mit Inhalten gefüllt worden ist, die die Stabilität der Herrschaft der KPCh gefährdeten. Dies wurde auch dadurch begünstigt, dass man die Ikone Mao zwischenzeitlich zwar in Vergessenheit geraten, sie dabei jedoch auch gewissermaßen aus der staatlichen Kontrolle entgleiten ließ. Unter anderem ist in diesen Jahren auch ein Raum für eine alternative Interpretation der Vergangenheit entstanden, wie in Kapitel 5 und 6 dargelegt. Zweitens haben die Machthaber erst viel zu spät erkannt, dass es ideologischer Antworten auf den Widerspruch zwischen Raubtierkapitalismus und Sozialismus bedurfte. Denn auch wenn der wirtschaftliche Aufstieg Chinas den Wohlstand des Landes insgesamt erhöhte, so führte er auf der anderen Seite doch auch zu erheblichen sozialen Ungleichheiten, was insbesondere in einem sozialistischen Land ein Gefahrenpotential für gesellschaftliche Unruhen darstellt. Im Jahr 1985 versuchte Deng Xiaoping diesen politischen Ansatz mit dem berühmten Satz „Lasst einige zuerst reich werden“ (rang yibufen ren xian fu qilai 让一部分人先富起来) zu legitimieren. ${ }^{215}$ Er hatte damals jedoch nicht bedacht, welch nachhaltige Konsequenzen die politischen Entscheidungen später noch für den gesellschaftlichen Zusammenhalt haben würden. Denn, so beschreibt Christian Göbel die gesellschaftliche Lage Chinas der 1980er Jahre, das „Leben der Bevölkerung wurde vor allem durch die Zwänge eines entfesselten Kapitalismus strukturiert“. ${ }^{216}$ All dies führte schließlich, drittens, zu einer wachsenden Unzufriedenheit von Teilen der Bevölkerung. Insbesondere die für den Aufbau des Landes so wichtigen (jungen) Intellektuellen waren unzufrieden mit den politischen Entwicklungen Chinas. Genährt wurde diese Unzufriedenheit auch dadurch, dass die Berufsaussichten für Akademiker ab Mitte der 1980er Jahre zunehmend schlechter wurden. Hinzu kamen eine immer stärker sichtbar werdende Korruption und eine sehr hohe Inflation. ${ }^{217}$ Die aus diesen für die Partei fatalen Entwicklungen folgenden Er-

214 Zur Transformation der Kampagnenpolitik von Mao zu Deng siehe Perry 2011.

215 Siehe Gerth 2017.

216 Göbel 2012, S. 153.

217 Hayhoe 1996, S. 115. 
eignisse zeigen, wie wichtig es generell für die KPCh ist, dass insbesondere in Phasen, in denen ihre Macht volatil zu werden droht, kein ideologisches Vakuum entsteht und dass die Durchsetzung des entsprechenden Kanons zur eigenen Geschichte dabei eine Schlüsselrolle spielt.

Obwohl erste Anzeichen für die wachsende Unzufriedenheit der städtischen Intellektuellen bereits seit dem Jahr 1983 sichtbar geworden sind - insbesondere Studenten und Professoren äußerten sich zunehmend kritisch -, reagierte Peking auf diese Entwicklungen lange Zeit recht passiv. ${ }^{218}$ Auch die Studentenproteste zwischen September 1986 und Januar 1987, welche ausgehend von der Hochschule Hefei (Provinz Anhui) nach und nach auf größere städtische Universitäten, bis hin zur Peking-Universität übergeschwappt waren, veranlasste die Regierung nicht zu einem wirklich konsequenten Einschreiten. ${ }^{219}$

Nach Chen Jie führte die Politik Dengs nach 1976 zu einer sogenannten Dreiglaubenskrise (sanxin weixi 三信危机). Diese beinhaltete eine Krise im Glauben an den Sozialismus (xinxin weiji 信心危机), eine Krise im Glauben an den Marxismus (xinyang weiji 信仰危机) und eine Vertrauenskrise der Bevölkerung in die Partei (xinren weiji 信人危机). ${ }^{220}$ So wurden aus den von der Partei seit den späten 1970er Jahren in weiten Teilen hingenommenen offenen politischen Debatten schließlich für die Führungsspitze nach und nach nicht mehr hinnehmbare Forderungen nach westlichen Konzepten wie Presse- und Meinungsfreiheit und Demokratie. Diese fanden ihren Höhepunkt schließlich in den Studierendenprotesten auf dem Platz des Himmlischen Friedens, welche ab dem Frühjahr 1989, inspiriert von den Reformbestrebungen in der Sowjetunion und ausgelöst durch den Tod Hu Yaobangs am 15. April 1989, die chinesische Führung zunehmend unter Druck setzten und die diese deshalb dazu veranlassten, sie gewaltsam zu beenden. ${ }^{221}$ Nach Einschätzung von Andrew Nathan und Perry Link war die Bewegung innerhalb weniger Wochen auf fast alle Großstädte des Landes und auf fast alle höheren Bildungseinrichtungen übergeschwappt, selbst in Bergwerken und Fabriken begannen die Stimmen der Demokratiebewegung bereits leise zu erklingen. Die Sinologen schätzen, dass landesweit rund 100 Mil-

218 Die konservative Fraktion der KPCh stieß zunächst die Kampagne gegen geistige Verschmutzung (Qingchu jingshen wuran 清除精神污染) an, welche zwischen Oktober und Dezember 1983 durchgeführt worden ist. Diese hatte zum Ziel, die Ausbreitung westlicher Ideen in der Bevölkerung zu unterdrücken. Letztendlich ist sie jedoch nur halbherzig durchgeführt worden. Siehe Miller 1996, S. 45.

219 Goldman 1996, S. 41.

220 Chen 1995.

$221 \mathrm{Zu}$ den genauen Abläufen der Studentenproteste zwischen April und dem 04. Juni 1989 siehe Black und Munro 1993. 
lionen Menschen direkt oder indirekt beteiligt waren. ${ }^{222}$ Dies zeigt, wie schwer die Legitimitätskrise der Partei auf dem Höhepunkt der Proteste im Sommer 1989 gewesen ist, auch wenn die Bewegung im ländlichen China nur wenig Rückhalt hatte.

Deng Xiaoping soll deshalb bereits am 02. Juni 1989, also zwei Tage vor der gewaltsamen Niederschlagung des Aufstandes, während einer geheimen Sitzung der höchsten Parteikader eingeräumt haben, dass der eingeschlagene Weg, den Bildungsinstitutionen ein solch hohes Maß an Freiheiten zu gewähren, ein Fehler gewesen sei, der sich nun räche. In seinem Redebeitrag setzte Deng Xiaoping die Ursachen der Studierendenproteste sowohl in direkten Zusammenhang mit den unterschiedlichen Positionen innerhalb der Partei als auch mit den Versäumnissen in der Bildungspolitik:

Was nun das Thema Fehler betrifft - wir haben tatsächlich welche begangen. Ich sagte vor zwei Jahren, unseren größten Fehler hätten wir auf dem Gebiet der Erziehung gemacht. Wir haben unsere Kinder und Studenten nicht genügend erzogen. Die politische Bildungsarbeit ist stark vernachlässigt worden, und viele Dinge wurden nicht klargemacht. Manche Leute, wie Zhao Ziyang, haben sogar für den Aufruhr Partei ergriffen, und darum ist es umso mehr unsere Schuld, dass das Volk die Dinge missversteht. Wir müssen uns mit nüchternen und kritischen Augen betrachten, die Vergangenheit Revue passieren lassen, während wir in die Zukunft blicken, und aus der Erfahrung lernen, wenn wir gegenwärtige Probleme untersuchen. Wenn wir dies tun, ist es möglich, dass sich etwas Schlechtes in etwas Gutes verkehrt. Wir könnten von diesem Zwischenfall profitieren. Die Mehrheit des Volkes wird nüchtern werden. Wenn wir den Aufruhr niedergeschlagen haben, werden wir hart arbeiten müssen, um all diese verpassten Lektionen in der Erziehung nachzuholen, und das wird nicht einfach sein. Es wird Jahre, nicht Monate dauern, bis die Menschen, die demonstriert und sich in Unterschriftenlisten eingetragen haben, ihre Meinung geändert haben. Wir dürfen den Menschen, die sich dem Hungerstreik angeschlossen, demonstriert oder Unterschriften geleistet haben, keinen Vorwurf machen. Wir sollten uns nur diejenigen vornehmen, die schlechte Absichten hatten oder die bei den Gesetzesverstößen eine führende Rolle spielten. Die Erziehung sollte unser oberstes Ziel sein im Umgang mit den Studenten, auch mit den Studenten, die sich dem Hungerstreik angeschlossen haben. ${ }^{223}$

222 Nathan und Link 2001, S. 3.

223 Ebd., S. 570 f. Bei der hier zitierten Quelle, der Tiananmen-Akte, handelt es sich um eine Sammlung an geheimen, internen Dokumenten der chinesischen Regierung, welche durch einen Informanten mit dem Pseudonym Zhang Liang den Sinologen Andrew J. Nathan und Perry Link zugespielt und von diesen dann gemeinsam mit Zhang im Jahr 2001 zunächst in den USA veröffentlicht worden sind. Das Buch ist bis heute in China zensiert. Die Authentizität dieser Dokumentensammlung gilt unter Wissenschaftlern jedoch als umstritten. Zur Problematik der Authentizität der Dokumente siehe Dittmer 2001. Orville Schell, der das Nachwort der TiananmenAkten geschrieben hat, räumt ein, dass es durchaus problematisch sei, eine Einschätzung zur Authentizität der Dokumente abzugeben, denn die Primärquellen waren für die Herausgeber selbst nicht einsehbar, außerdem sind sie unter nicht eindeutigen Umständen in ihren Besitz 
Damit kritisierte Deng faktisch den Ende der 1970er Jahre eingeschlagenen bildungspolitischen Kurs, der zu großen intellektuellen Freiheiten innerhalb und außerhalb chinesischer Hochschulen geführt hat.

\section{Die Förderung der ideologischen Bildung}

Diese Erkenntnis sollte von entscheidender Bedeutung nicht nur für die Bildungspolitik der kommenden Jahre, sondern insbesondere auch für die offizielle Geschichtsschreibung und damit auch für den Umgang mit den „historischen Fehlern“ der Partei sein. Zunächst wurde jedoch ein scharfer politischer Kurswechsel eingeläutet, der eine massive politische Umerziehung der Jugend zum Ziel hatte, um sie so ideologisch zurückzugewinnen. Das relativ hohe Maß an akademischen und intellektuellen Freiheiten der letzten gut zehn Jahre wurde wieder zunehmend eingeschränkt. Oberste Priorität war es nun, die politische Stabilität wieder zu festigen und die Herrschaftslegitimation der KPCh nachhaltig zu sichern.

Um ihre politischen Maßnahmen an höheren Bildungsinstitutionen auch durchsetzen zu können, setzte die Partei an den wichtigsten Hochschulen des Landes wieder auf ein linientreues Führungspersonal. An der Peking-Universität wurde im August 1989 Ding Shisun, nicht zuletzt wegen seines Einsatzes für seine auf dem Platz des Himmlischen Friedens protestierenden Studenten, offiziell jedoch aus gesundheitlichen Gründen, durch Wu Shuqing 吴树青 ersetzt. Tatsächlich war es in jener Zeit keineswegs ungewöhnlich, dass hochrangige Wissenschaftler der Regierung oppositionell gegenüberstanden oder ihr zumindest nicht treu dienten, wie in Kapitel 5 genauer dargelegt wird. Wu hingegen pflegte als Parteimitglied enge Kontakte zu einigen wichtigen Kadern und so konnte man sicherstellen, dass die bildungspolitischen Maßnahmen der Partei auch umfassend und zuverlässig durchgesetzt werden würden. ${ }^{224}$ Auch hierdurch wurden an einer der wichtigsten Bildungsinstitutionen des Landes die Grundlagen für eine Stärkung der Herrschaftslegitimation der Partei gelegt.

Eine der ersten konkreten politischen programmatischen Maßnahmen zur Umsetzung der Ziele der KPCh war zunächst die Entwicklung eines einjährigen Programms zum militärischen Training mit gleichzeitiger politischer Indoktrina-

gelangt. Dennoch ist er von ihrer Glaubwürdigkeit überzeugt. Zum einen, weil die Dokumente nicht den grundlegenden Kenntnissen der Wissenschaftler widersprochen hätten, und zum anderen, weil im Entstehungsprozess des Buches das Vertrauen zum Kompilator stetig gewachsen sei. Nathan und Link 2001.

224 The New York Times 1989, https://www.nytimes.com/1989/08/24/world/china-replaceshead-of-beijing-university.html. 
tion von Studenten an einer Militärakademie. Insbesondere die Studenten der Eliteuniversitäten sollten damit angesprochen werden und so wurde das Pilotprojekt im Sommer 1990 mit 738 Erstsemestern der Peking-Universität an einer Militärakademie rund 200 Kilometer nördlich von Peking durchgeführt. ${ }^{225}$ Ein entsprechendes Programm wurde kurze Zeit später auch an der Fudan-Universität 复旦大学 in Shanghai umgesetzt. In den kommenden vier Jahren würden alle Studenten dieser beiden Universitäten dieses Umerziehungsprogramm durchlaufen haben. Insgesamt führten bis zum Jahr 1994200 Universitäten ein solches Programm durch, was jedoch auch bedeutet, dass die Mehrheit der damals in China existierenden 1.075 Universitäten, sich nicht daran beteiligte. Auch wenn durchaus kurzfristige positive Effekte eingetreten sein sollen, wurde das Programm Mitte der 1990er Jahre wieder eingestellt, weil es insgesamt zu ineffektiv und zu kostenintensiv gewesen ist. ${ }^{226}$ Fast gleichzeitig wurde zudem die erstmals im Jahr 1963 initiierte Kampagne Vom Genossen Lei Feng lernen (xiang Lei Feng tongzhi xuexi 向雷锋同志学习) ${ }^{227}$ wieder aufgelegt (siehe Abb. 2). Ab dem Spätsommer 1990 sollten sich chinesische Jugendliche nach seinem Vorbild wieder stärker kommunistisch verhalten. Nach Meinung der Parteiführung war dies auch deshalb notwendig geworden, weil eine im August 1990 an einer Sekundarschule in der Provinz Shanxi 山西省 durchgeführte Studie zeigte, dass 48 Prozent der Schüler nicht an den Marxismus glaubten und das, obwohl 81 der 100 befragten Schüler sogar Mitglieder der Kommunistischen Jugendliga (Zhongguo gongchan zhuyi qingnian tuan 中国共产主义青年团) gewesen sind. Die Kampagne sollte sich jedoch schnell als höchst ineffektiv erweisen, nicht zuletzt deshalb, weil Lei Feng nicht zu den Bedürfnissen und Wünschen der Jugendlichen der damaligen Zeit passte. Somit hatte die politische Indoktrination nur geringe Chancen, auf fruchtbaren Boden zu fallen. Und so lief die Kampagne bis Mitte der 1990er Jahre langsam aus. ${ }^{228}$

Die politische Führung des Landes war sich schnell einig, dass es nach dem Sommer 1989 konkreterer Maßnahmen bedurfte, um die politische Indoktrina-

225 Rosen 1993, S. 317.

226 Ebd., S. 318f.

227 Lei Feng (geb. 1940, gest. 1962) war ein Soldat der Volksbefreiungsarmee, der nach seinem Unfalltod von Mao im Jahr 1963 zum nationalen Vorbild und Modellkommunisten erklärt wurde. Er war seitdem bis in die Gegenwart immer wieder Bestandteil von Erziehungskampagnen. Zum Leben von Lei Feng siehe Shi und Lei 2006. Unter einigen westlichen Chinawissenschaftlern ist seine Existenz jedoch höchst umstritten. Siehe zum Beispiel Fraser 1980.

228 Rosen 1993, S. 320 f. 

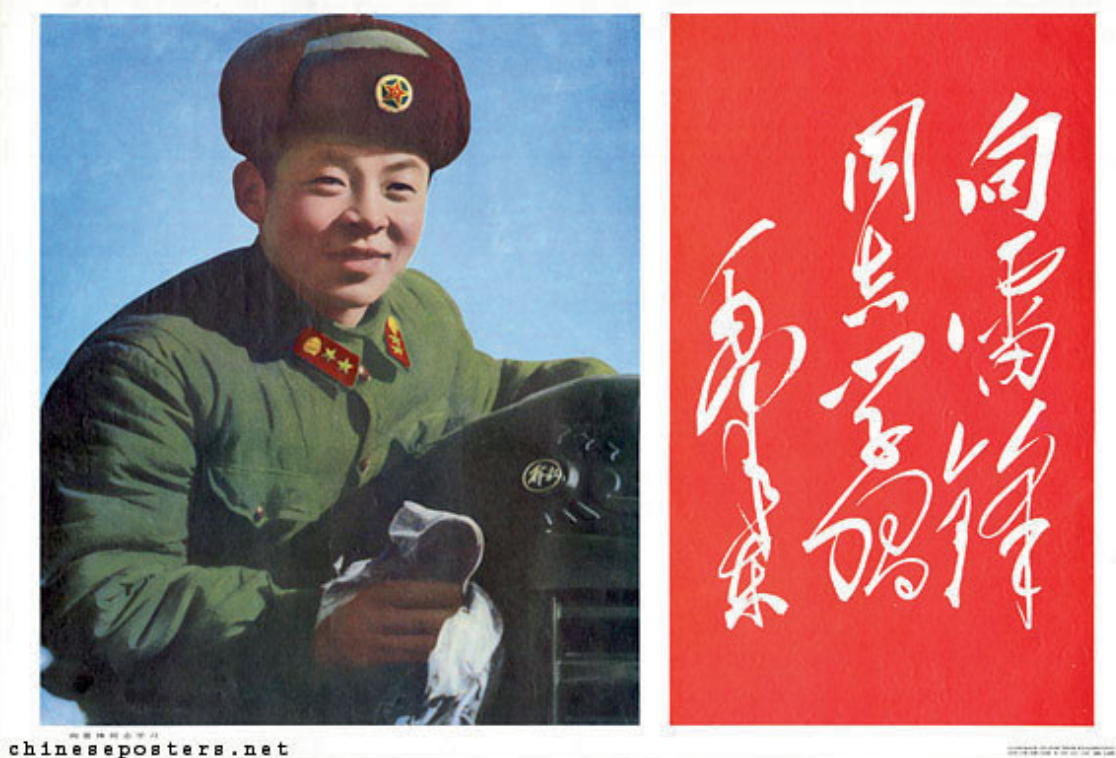

Abbildung 2: „Studiert den Genossen Lei Feng“, 1990 (Quelle: chineseposters.net)

tion der Jugend und deren Glauben in die Partei wieder stärker zu fördern. ${ }^{229}$ Die umfassendste politische Kampagne im Nachklang der Ereignisse des Sommers 1989 würde die Patriotische Bildungskampagne (aiguo zhuyi jiaoyu 爱国主义教育) darstellen, welche Sozialismus und Patriotismus durch entsprechende Maßnahmen, insbesondere an den Bildungseinrichtungen, miteinander verknüpfen sollte. Zur Hauptzielgruppe der Kampagne gehörten neben der Jugend auch Intellektuelle im Allgemeinen. Die Kampagne wurde ab 1991 geplant, ab 1992, direkt nach Deng Xiaopings berühmter Reise durch den Süden Chinas, umgesetzt und erreichte ihren Höhepunkt im Jahr 1995. ${ }^{230}$ Danach ließ die politische Führung die Kampagne langsam auslaufen. Der Schlüssel der Kampagne sollte der Nationalismus (minzhu zhuyi 民族主义) bzw. Patriotismus (aiguo zhuyi 爱国主义) darstellen. Die Grundidee war, die Partei und die Nation ideologisch untrennbar

229 Zunächst herrschte innerhalb der politischen Führung große Uneinigkeit, welche Maßnahmen man ergreifen sollte, um die Legitimität der Partei wieder zu stärken. Während die Konservativen die Uhren zurückdrehen und den Maoismus wiederbeleben wollten, beharrten die Reformer um Deng Xiaoping darauf, weiterhin den Weg der wirtschaftlichen Entwicklung zu gehen. Dieser Dissens führte einige Monate lang zu einer politischen Stagnation. Zhao 1993, S. 289.

$230 \mathrm{Zu}$ Deng Xiaopings Tour durch den Süden siehe ebd. 
miteinander zu verknüpfen, sodass eine Kritik an der Partei als unpatriotisch gelten und somit auf eine ablehnende Haltung in der Bevölkerung stoßen würde. Dabei wurden inhaltlich im Wesentlichen zwei Schwerpunkte gesetzt: erstens die chinesische Tradition und die Geschichte; zweitens die nationale Einheit und die territoriale Integrität. ${ }^{231}$ Die Inhalte sollten durch den Unterricht an Schulen und Universitäten, aber auch durch Print- und Unterhaltungsmedien wie Fernsehen und Kino in die Herzen der Jugendlichen transportiert werden. Der Nationalstolz sollte in jenen Jahren bereits den Kleinsten eingepflanzt werden und war in Bild und Ton in den 1990er Jahren allgegenwärtig. Abbildung 3 zeigt ein Propagandaposter aus dem Jahr 1994, welches zu tausenden an Grundschulen ausgehängt worden ist. Den wichtigsten Stellenwert nahm im Zuge der Kampagne die moderne chinesische Geschichte ein. Das Geschichtsbild, das in jenen Jahren durch die KPCh gestützt worden ist, legte den Fokus einerseits auf ein Opfernarrativ, das heißt, es sollte sich das Bild verfestigen, dass Chinas schmerzhafte Vergangenheit vor allen Dingen den Fehlern des Westens zugeschrieben werden muss. Somit wollte man auch ein weiteres Eindringen westlichen Gedankenguts in die Köpfe der Jugendlichen verhindern. Abbildung 4 zeigt, welche Bilder und Ideen sich die Partei damals konkret zunutze machte. Das Propagandaposter mit dem Titel Wie könnten wir das vergessen? aus dem Jahr 1994 zeigt in zentraler Position eine im Jahr 1860 durch englische Truppen zerstörte Säule des alten Sommerpalastes. Die vier Bilder, die sich an den Rändern des Posters befinden, zeigen (im Uhrzeigersinn von links oben) Szenen aus den Opiumkriegen, die sogenannten Ungleichen Verträge, den Marsch der Vereinigten acht Staaten auf Peking im Jahr $1900^{232}$ und das Massaker von Nanjing 1938 - all dies sind Ereignisse, welche die Demütigungen des chinesischen Volkes beispielhaft zusammenfassen. Am unteren Rand des Bildes ist die Chinesische Mauer abgebildet, was wiederum für die Unerschütterlichkeit und Stärke der chinesischen Nation stehen könnte.

Auf der anderen Seite sollte die Jugend aber auch an die Heldengeschichten der Revolutionäre erinnert werden. Die KPCh wurde hierdurch als einziger und logischer Ausweg aus dem Jahrhundert der Demütigungen (1839-1949; bainian guochi 百年国耻) kanonisiert. ${ }^{233}$ Lehrmittel an Universitäten und Schulen wurden diesem Fokus entsprechend umgeschrieben und hielten ab Mitte der 1990er Jahre Einzug in die Bildungsanstalten. Darüber hinaus wurden Schüler und Studenten dazu angehalten, Geschichtsmuseen sowie historische Stätten, also Erinne-

231 Ebd., S. 295.

$232 \mathrm{Zu}$ den Opiumkriegen, den Ungleichen Verträgen und dem Marsch auf Peking, der den Boxeraufstand beendete, siehe Mühlhahn 2019, S. $92 \mathrm{ff}$.

233 Wang 2008, S. 784. 

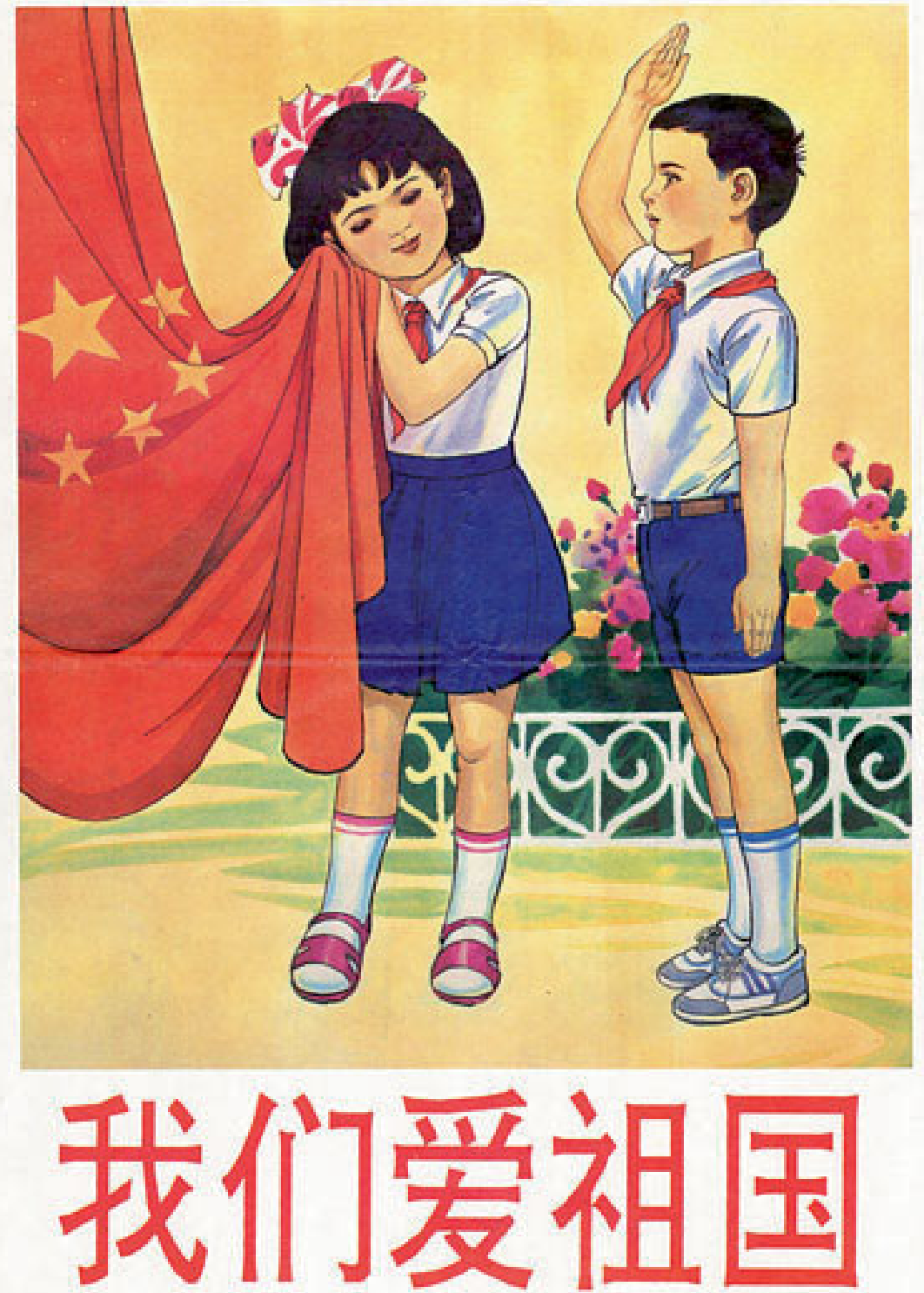

chineseposters.net

Abbildung 3: „Wir lieben unser Heimatland“, 1994 (Quelle: chinesepos-ters.net) 


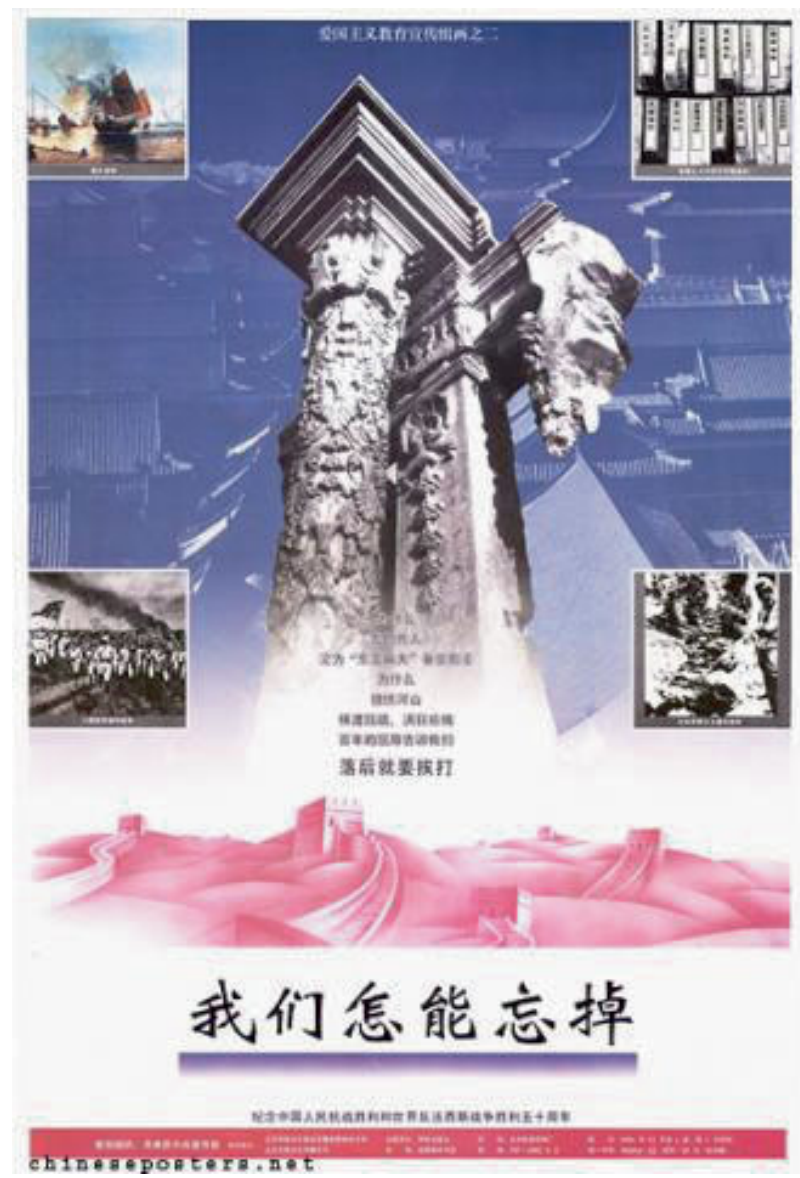

Abbildung 4: „Wie könnten wir vergessen“, 1994 (Quelle: chinesepos-ters.net)

rungsorte, die für die Legitimation der KPCh wichtig waren, zu besuchen. ${ }^{234}$ Die Maxime, dass die KPCh zum Schutz der Nation unverzichtbar sei, sollte sich im kollektiven Gedächtnis etablieren. Die Partei folgte damit der Grundidee, sich die Loyalität der Jugend zu sichern, um ihre Herrschaftslegitimation nachhaltig zu stärken. Politische Theorien des Marxismus-Leninismus und der Mao-ZedongIdeen hingegen wurden während der Jahre der Patriotischen Bildungskampagne

234 Zhao 1993, S. $296 \mathrm{ff}$. 
ausgeklammert, auch wenn sie nicht komplett aus den Lehrplänen gestrichen worden sind. 235

Um dieses Narrativ nicht zu gefährden, wurde auch die Kontrolle über den Umgang mit „historischen Fehlern“ der Partei wieder wichtiger, was wiederum auch mit einer verstärkten Zensur und Repressionen einherging. Oder anders ausgedrückt, machte der von der KPCh geförderte Kanon eine wieder verstärkte Zensur der eigenen „historischen Fehler“ unumgänglich. Zhao Suisheng zählt die ersten zwei Jahre nach den Ereignissen auf dem Platz des Himmlischen Friedens 1989 sogar zu den repressivsten in der Geschichte Chinas seit 1949.236 Getrieben wurden die politischen Entscheidungen nach den Studierendenprotesten 1989 wohl auch durch die allgemeine Situation in Osteuropa, sah die politische Führung Chinas nun einen Großteil der kommunistischen Welt wie ein Kartenhaus zusammenbrechen - ein ähnliches Schicksal sollte ihnen selbst unter allen Umständen erspart bleiben. ${ }^{237} \mathrm{Zu}$ groß dürfte die Angst der chinesischen Machthaber gewesen sein, dass sie sich den Platz in der Geschichte mit den (ehemaligen) Machthabern der Sowjetunion und der DDR würden teilen müssen. Deshalb war es fortan noch wichtiger als in den zehn Jahren zuvor, dass die Vergangenheit der Gegenwart diente. ${ }^{238}$

Die Geschichte sollte auch in Zukunft einen Beitrag zur Aufrechterhaltung der Stabilität leisten. Und somit traten in den Jahren nach dem Tian‘anmenMassaker die konservativen, regimetreuen Historiker wieder verstärkt auf den Plan, nicht nur um die Inhalte der Lehrbücher an Schulen und Universitäten noch stärker den Zielen der KPCh anzupassen, sondern auch um andere wichtige offizielle Schriften zur offiziellen Geschichtsschreibung zu verfassen. Ein kritisches Aufrollen bestimmter Ereignisse der Vergangenheit, wie der Kampagne gegen Rechtsabweichler, sollte dabei möglichst vermieden werden, um die ohnehin schon vorhandene Legitimitätskrise nicht noch weiter zu verschärfen.

Die von Deng Xiaoping eingeleiteten politischen Maßnahmen zur Förderung der ideologischen Bildung als Antwort auf die Studentenproteste wie das Training an der Militärakademie oder die Patriotische Bildungskampagne, dies sei vorweggenommen, sollten sich als nicht nachhaltig erweisen. Als nachhaltig würde sich hingegen das ideologische Vakuum erweisen, welches seit der Generation, die nach der Reform- und Öffnungspolitik aufgewachsen und ausgebildet wurde, entstanden ist. Seitdem tut sich die chinesische Führung schwer, die ideologischen Probleme zu lösen. Dies ist bis ins gegenwärtige China spürbar. Anders

235 Zhao 1998, S. 296.

236 Zhao 1993, S. 289.

237 Siehe Shambaugh 2008b.

238 Vgl. Unger 1993. 
ausgedrückt, führt die Partei spätestens seit dem Jahr 1989 einen stetigen Kampf um die Aufrechterhaltung ihrer Herrschaftslegitimation und somit auch um das kollektive Gedächtnis Chinas.

\subsection{Jiang Zemin: Konsolidierung der Vergangenheit und Bewahrung der Stabilität}

Der Machtübergang von Deng Xiaoping zu Jiang Zemin 江泽民 ging schrittweise und geräuschlos vonstatten, nicht zuletzt deswegen, weil Jiang seit Jahren ein enger Weggefährte Dengs gewesen ist. Bereits seit dem Jahr 1989 bekleidete Jiang das Amt des Generalsekretärs des Zentralkomitees der KPCh. Im Jahr 1993 übernahm er schließlich das Amt des Präsidenten der VR China von Yang Shangkun 杨 尚昆, welches Deng Xiaoping trotz seiner enormen Machtfülle nie innehatte. In den zehn Jahren seiner Präsidentschaft wich Jiang Zemin vom eingeschlagenen politischen Kurs Dengs nicht nennenswert ab und trieb die Reform- und Öffnungspolitik noch weiter voran. Als politische Leitlinie diente in diesen Jahren die von ihm entwickelte Idee der Drei Vertretungen (san ge daibiao 三个代表), wonach sich die KPCh für fortschrittliche Produktivkräfte (Zhongguo xianjin shehui shengchanli de fazhan yaoqiu 中国先进社会生产力的发展要求), eine fortschrittliche Kultur (Zhongguo xianjin wenhua de qianjin fangxiang 中国先进文化的前进方 向) und für die Vertretung der Interessen der Mehrheit der Bevölkerung (Zhongguo zui guangda renmin de genben liyi 中国最广大人民的根本利益) einsetzten sollte. Einige Jahre später wurde diese Idee schließlich auf dem XVI. Parteitag am 08. November 2002 auch in die Parteistatuten aufgenommen. ${ }^{239}$ Konkret bedeutete diese Idee auch, dass die Vertretung durch die Partei nicht mehr nur die Arbeiter, Bauern und Soldaten einschloss, sondern eben auch Unternehmer und Intellektuelle. ${ }^{240}$

Insgesamt stand Jiangs politische Agenda unter dem Motto der Aufrechterhaltung der Stabilität. Er folgte während seiner zehn Jahre als Staatschef stets der von Deng Xiaoping ausgegebenen Maxime „Ohne Stabilität kann nichts erreicht werden“ (meiyou wending, shenme shi ye ganbucheng 没有稳定, 什么事也干不 成). ${ }^{241}$ Dies würde sich sowohl im Umgang mit den Intellektuellen als auch in der Bewertung der „historischen Fehler“ der Partei bemerkbar machen.

239 Siehe Lam 1999.

240 Noesselt 2011, S. 6.

241 Marinelli 2013, S. 113. 
Er sah die Intellektuellen in maoistischer Tradition als Teil der Arbeiterklasse, ohne die der sozialistische Aufbau Chinas nicht möglich wäre. Bildung und Wissenschaft nahmen unter Jiang, ähnlich wie bereits unter Deng, eine Schlüsselposition für die Entwicklung Chinas ein - im Mai 1995 formulierte er die Formel „China durch Wissenschaft und Technik revitalisieren“ (kejiao xingguo 科教兴 国). ${ }^{242}$

Die Zensur wurde an den Universitäten nicht mehr ganz so intensiv betrieben wie in den ersten beiden Jahren nach dem 04. Juni 1989, dennoch sollten die intellektuellen Freiheiten der 1980er Jahre nie wieder zurückkehren. Oder anders ausgedrückt, hatte es den Anschein, dass er den Intellektuellen nicht die Freiheiten der 1980er Jahre zurückgeben konnte, dennoch musste er ihnen ein gewisses Maß an intellektueller Freiheit einräumen, da sie in den politischen Plänen der Partei zum Aufbau des Landes eine zentrale Rolle einnahmen. Ausgeschlossen waren hiervon allerdings politische Diskussionen im öffentlichen Raum, insbesondere solche, die mit Forderungen nach westlichen Konzepten oder ähnlichem einhergingen. Vordergründig schien es in den 1990er Jahren auch immer wieder kurze Phasen der zunehmenden Liberalisierung zu geben, die ein wenig an die Zeit zwischen den Jahren 1978 und 1989 erinnerten. Beispielsweise kamen im Sommer 1998 überraschenderwiese Debatten durch hochrangige KPCh-Mitglieder darüber auf, ob man den städtischen Intellektuellen nicht die Gründung eigener politischer Parteien erlauben könne. Öffentliche Debatten wie diese wurden jedoch auch wieder recht schnell beendet. Willy Wo-Lap Lam hält das plötzliche öffentliche Aufkeimen solcher Debatten für einen politischen Schachzug, um im westlichen Ausland ein gutes Bild abzugeben, stand im Sommer 1998 doch der Besuch des damaligen US-Präsidenten Bill Clinton an, bei dem einige wichtige Wirtschaftsabkommen geschlossen werden sollten. Außerdem hatte Clinton zuvor mehrfach öffentlich angekündigt, auch über das Thema Menschenrechte sprechen $\mathrm{zu}$ wollen. ${ }^{243}$

\section{Jiang Zemins Dilemma zwischen „neuen“ Freiheiten und Zensur}

Die relativen „Freiheiten“ beschränkten sich während der Präsidentschaft Jiang Zemins insgesamt eher auf die akademische Welt. Außerdem sind in den 1990er Jahren in der VR China eine Reihe von Memoiren und Romanen erschienen, die die Kampagne gegen Rechtsabweichler oder die Kulturrevolution aufarbeiten die Herrschaftslegitimation der KPCh sollte jedoch die rote Linie darstellen,

242 Ebd., S. 122.

243 Lam 2014, S. 39. 
welche sowohl in diesen Werken als auch im akademischen Kontext nicht überschritten, also nicht in Frage gestellt werden durfte (siehe Kap. 5). Nur die jüngeren Ereignisse des Tian'anmen-Massakers blieben komplett tabuisiert und das sind sie auch noch bis in die Gegenwart.

Trotz dieses gewissen Maßes an Freiheit, galt auch unter Jiang, dass die Vergangenheit in erster Linie der Gegenwart dienen sollte. Bereits im Mai 1990 hatte er die Forderung formuliert, dass die Intellektuellen die Mao-Zedong-Ideen studieren sollten, auch wenn diese als Teil der von Deng Xiaoping entwickelten Patriotischen Bildungskampagne letztlich weitgehend vernachlässigt worden sind. ${ }^{244}$ Mao sollte nach Jiangs Vorstellungen dennoch wieder vermehrt für den Machterhalt der Partei genutzt werden. Und so setzte er sein Bild wieder etwas häufiger für seine eigenen Zwecke ein, als es in den Jahren 1978 bis 1989 unter Deng Xiaoping der Fall war. Deutlich wird dies beispielsweise durch ein Propagandaplakat (Abbildung 5), welches im Jahr 2000 verbreitet worden ist. Auf diesem sind im Vordergrund Jiang Zemin, Deng Xiaoping und Mao Zedong abgebildet. Den größten Raum nimmt dabei der strahlende Jiang ganz vorne im Bild selbst ein, im Hintergrund sind Symbole des chinesischen Fortschritts wie der Fernsehturm Perle des Ostens (Dongfang Mingzhuta 东方明珠塔) in Shanghai, aber auch traditionelle Gebäude wie der Eingang zur Verbotenen Stadt in Peking zu sehen. Besonders ins Auge fallen jedoch rund ein Dutzend Tauben, die um die drei (ehemaligen) Machthaber herum abgebildet sind. Im internationalen Kontext wird die Taube gemeinhin als Symbol des Friedens betrachtet. In China jedoch steht sie auch für Treue und Langlebigkeit. ${ }^{245}$ Damit vermittelt das Poster ein Bild der Kontinuität und der Stabilität in der jüngsten Entwicklung Chinas von Mao zu Deng und schließlich zu Jiang.

Die Tatsache, dass er sich das Erbe Maos für seinen eigenen Machterhalt zunutze machen wollte, zog noch mehr als zuvor die Notwendigkeit nach sich, dieses zu schützen und die Kontrolle über die Vergangenheit der KPCh im Sinne der Herrschaftslegitimation zu bewahren. Wie entschlossen der Staat während der Präsidentschaft Jiang Zemins reagieren konnte, wenn die rote Linie der Geschichtsschreibung überschritten worden ist, zeigte sich Anfang der 2000er Jahre, als die eigentlich an ausländischen Universitäten tätigen Historiker Xu Zerong, Li Shaomin und Shi Xianmin festgenommen wurden. Offiziell wurde als Haftgrund die Weitergabe von Staatsgeheimnissen angegeben. Sie alle hatten in ihren Veröffentlichungen zur Geschichte der KPCh Archivmaterial verwendet, welches eigentlich nicht für die Öffentlichkeit bestimmt war, ihnen aber über geheime Ka-

244 Marinelli 2013, S. 121.

245 Eberhard 2004, S. 131. 


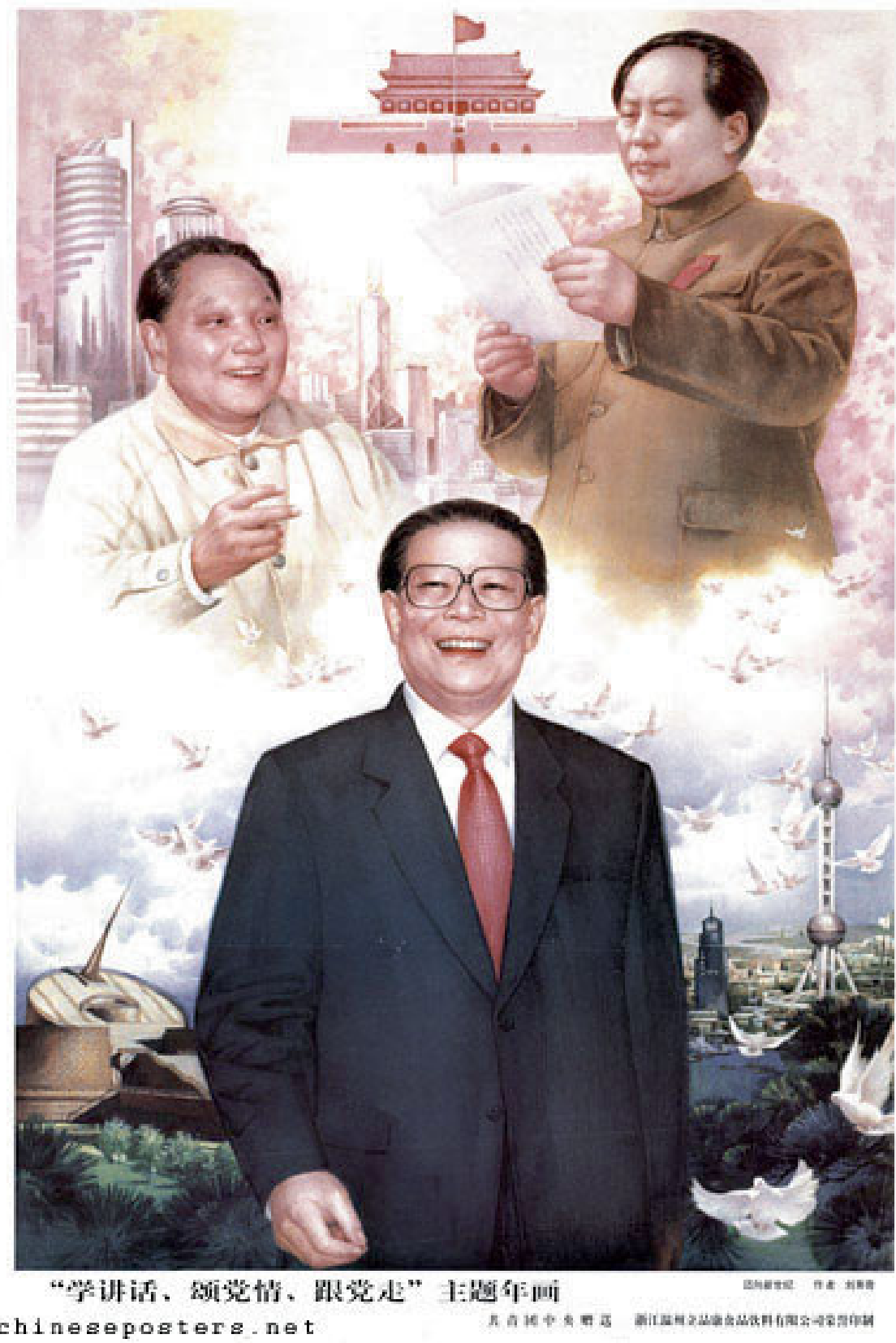

Abbildung 5: „Studiert die Schriften, haltet den Parteigeist hoch und folgt der Partei“, 2000 (Quelle: chineseposters.net) 
näle zugespielt worden war. Xu Zerong, damals Professor an einer Universität in Hongkong, hatte beispielsweise für seine Arbeit zur Rolle der KPCh während des Koreakriegs (1950 - 53) geheime Dokumente zu Militärstrategien eingearbeitet. ${ }^{246}$ Er wurde im Februar 2002 schließlich zu elf Jahren Haft verurteilt. Die anderen Wissenschaftler mussten ebenfalls lange Haftstrafen verbüßen. ${ }^{247}$ In einem offenen Brief an den Präsidenten hatte die Menschenrechtsorganisation Human Rights Watch noch vergeblich die Freilassung der Wissenschaftler gefordert, indem sie ihn darauf hinwiesen, dass China gegen unterzeichnete internationale Menschenrechtsabkommen verstoßen würde. Die Verfasser äußerten in dem Brief auch ihre Sorgen hinsichtlich der massiven Einschränkungen akademischer Freiheiten. ${ }^{248}$

Weitere Maßnahmen zur staatlichen Kontrolle über das kollektive Gedächtnis und der Stärkung der Ideologie sollten die unter Jiang massiven Einschränkungen im Bereich der Pressefreiheit darstellen. Nachdem selbst die größten Parteiorgane des Landes zunehmend über für die Partei negative Geschehnisse wie Korruptionsfälle hochrangiger Beamter berichtet hatten, nahm er die Presse wieder stärker in die Pflicht, die Ziele der Partei zu unterstützen. Entsprechend wurden alle Themen, die die KPCh in ein schlechtes Licht zu rücken drohten, also auch „historische Fehler“ wie die Kampagne gegen Rechtsabweichler, zum Tabuthema für die staatliche Presse. ${ }^{249}$ Die ohnehin schon starken Beschränkungen unterworfene Pressefreiheit wurde somit noch stärker beschnitten - über den 30. Jahrestag des Ausbruchs der Kulturrevolution 1996 durfte ebenso wenig berichtet werden, wie über den 40. Jahrestag des Ausbruchs der Kampagne gegen Rechtsabweichler ein Jahr später. Als Problem für viele Akteure der chinesischen Presselandschaft sollte sich die Tatsache herausstellen, dass es keine klaren gesetzlichen Regelungen gab, was noch erlaubt war und was nicht - dies führte zum Teil zu großen Verunsicherungen unter Journalisten und Redakteuren. Darüber hinaus wurde die Verbreitung ausländischer Zeitungen und Zeitschriften massiv beschränkt. ${ }^{250}$ Im Jahr 1999 wies Jiang zudem darauf hin, dass die Presse in China marxistisch sein müsse. Dementsprechend ging damit auch eine zunehmende institutionelle Kontrolle der Presseorgane einher. Beispielweise musste die erste Seite der Renmin Ribao fortan durch einen hochrangigen Mitarbeiter des Propa-

246 Zur Rolle der KPCh während des Koreakriegs siehe Chen 1994.

247 The New York Times 2002, https://www.nytimes.com/2002/02/03/world/historian-senten ced-to-13-years-in-chinese-prison.html.

248 Human Rights Watch 2002, http://pantheon.hrw.org/legacy/campaigns/china/scholars/let ter.htm.

249 Lam 2014, S. $40 \mathrm{f}$.

250 Ebd., S. $42 \mathrm{ff}$. 
gandaministeriums in der Nacht vor der Veröffentlichung Wort für Wort kontrolliert werden. In den Druck konnte die Zeitung erst gehen, wenn das Ministerium grünes Licht gegeben hatte. Als hinderlich für die Verbreitung des offiziellen Kanons sollte sich jedoch der Reichweitenrückgang der Renmin Ribao herausstellen, was mit dem vermehrten Zugang der Intellektuellen zu alternativen Quellen, insbesondere über das Internet, zusammenhing. ${ }^{251}$

He Qinglian 何清涟, ehemalige Mitarbeiterin der Propagandaabteilung der KPCh in Shanghai, ehemalige Redakteurin der englischsprachigen chinesischen Zeitung Shenzhen Daily und seit Anfang der 2000er Jahre Mitarbeiterin der New Yorker Organisation Human Rights in China, nahm am 24. Juni 2002 an einem Runden Tisch zum Thema „Medienfreiheit in China“ der China-Kommission des US-Kongresses teil. Dort berichtete sie über die systematische Kontrolle der chinesischen Medien, welcher sie in ihrer Zeit als Redakteurin selbst ausgesetzt gewesen sei. Sie berichtete, dass seit Ende der 1990er Jahre jeder einzelne Artikel der auflagenstärksten Zeitungen und Zeitschriften des Landes vor der Veröffentlichung Wort für Wort durch KPCh-Mitarbeiter überprüft würden. Im Gegensatz zu westlichen Medien, zu deren Aufgaben es gemeinhin gehört, die Regierung auch zu kritisieren, sei es Anfang der 2000er Jahre in China genau umgekehrt gewesen: Wenn die Berichterstattungen der Medien in eine falsche Richtung gingen, seien sie heftiger systematischer Kritik durch die Regierung ausgesetzt gewesen:

Then there was a system by the Ministry of Propaganda for a monthly criticism of the media. Every month, a report was prepared and sent to all the different media outlets in the country and it was reported that such-and-such a newspaper made such-and-such a kind of error in such-and-such item of news and what the higher-ranking government officials did to resolve this problem. When the people from the other media outlets saw this, they were supposed to realize what the position of the government was vis-a-vis the media. There was a very good excuse for all this. It was described as "harming the good relationship between the Party and the government”. We should not, therefore, broadcast things that make society look bad. In a free country, the media is expected to criticize the government. In China, it is exactly the opposite: it is the government that criticizes the media. ${ }^{252}$

Dazu gehörten natürlich auch Berichte über die „historischen Fehler“ der Partei seit 1949. Zudem sei es unter dem Jiang-Regime gängige Praxis, Intellektuelle, die mit ihren Arbeiten zu sehr über das Ziel hinausgeschossen seien, der Korruption oder gar der Prostitution oder Zuhälterei zu bezichtigen, um sie mundtot zu ma-

251 Ebd., S. $49 \mathrm{ff}$.

252 U.S. Government Publishing Office 2002, https://www.govinfo.gov/content/pkg/CHRG107hhrg81228/html/CHRG-107hhrg81228.htm. 
chen. ${ }^{253}$ Spätestens seit dem Ende der 1990er Jahre wurden also wieder alle Register gezogen, um Berichte über das „Unerwünschte“ auszumerzen - zumindest in den Bereichen, die der breiten Öffentlichkeit zugänglich waren. Die Kontrolle der öffentlichen Meinung und die damit einhergehende Zensur wird in China bis in die Gegenwart, unter anderem durch das Propagandaministerium, institutionell geregelt.

Was erwünscht war, sollte hingegen mit Unterstützung der (Unterhaltungs-) Medien als Teil des kollektiven Gedächtnisses Einzug in den gesellschaftlichen Kanon halten. In seinem Bericht auf dem XVI. Parteitag am 08. November 2002 machte Jiang Zemin erneut deutlich, welche Rolle Kultureinrichtungen und die Medien für die korrekte ideologische Bildung des chinesischen Volkes spielen sollten und welche Inhalte hierfür kanonisiert werden müssten:

Keep the orientation of advanced culture firmly in hand. In contemporary China, to develop advanced culture means to develop national, scientific and popular socialist culture geared to the needs of modernization, of the world and of the future so as to enrich people's mental world and reinforce their mental strength. We must uphold Marxism-Leninism, Mao Zedong Thought and Deng Xiaoping Theory as our guidelines in the realm of ideology and have the important thought of Three Represents in command of the development of socialist culture. We must keep to the orientation of serving the people and socialism and the principle of letting a hundred flowers blossom and a hundred schools of thought contend and highlight the themes of the times while encouraging diversity. We should continue to arm people with scientific theory, provide them with correct media guidance, imbue them with lofty ideals, and inspire them with excellent works of literature and art. We must exert ourselves to develop advanced culture and support healthy and useful culture, changing what is backward and resisting what is decadent. Literary and art workers should go deep among the masses and into the thick of life so as to contribute to the people more works worthy of the times. The press, publishing, radio, film and television must give correct guidance to the public, and Internet web sites should serve as important fronts for spreading advanced culture. Basing ourselves on the practice of reform, opening up and modernization and keeping abreast of the latest developments in world culture, we must carry forward the fine tradition of our national culture, draw on the strong points of other nations and make innovations in content and form so as to enhance the attraction and appeal of socialist culture with Chinese characteristics. ${ }^{254}$

Auch hier wird deutlich, dass die Ikone Mao wieder stärker für die gegenwärtigen Bedürfnisse Chinas genutzt werden sollte. Betrachtet man die Erinnerungspolitik der Jiang-Jahre genauer, lässt sich beobachten, dass die offizielle Geschichtsschreibung um die eigene Vergangenheit inklusive der „historischen Fehler“ -

253 Ebd.

254 Jiang Zemins Bericht auf dem XVI. Parteitag, Renmin Ribao 人民日报 2002, http://en.peo ple.cn/200211/18/eng20021118_106985.shtml. 
durch ein Zusammenspiel von Kanon und Zensur - unter Jiang Zemin gewissermaßen konsolidiert worden ist. Der korrekte staatliche Umgang insbesondere mit der Kampagne gegen Rechtsabweichler war dabei auch für ihn selbst von äußerster Wichtigkeit, hing sein politisches Schicksal als sein Protegé und Nachfolger doch auch mit dem Erbe Deng Xiaopings zusammen. Weiterhin wurde daran gearbeitet, ein kollektives Gedächtnis zu etablieren, welches die positiven Aspekte der Ikone Mao Zedong verankert. Zuvor war Mao ein wenig in Vergessenheit geraten. Dies führte letztlich dazu, dass während der 1990er Jahre unter den Jugendlichen zwischenzeitlich ein regelrechter Mao-Boom ausgebrochen ist. Auch deshalb galt es, das Bild Maos wieder unter Kontrolle zu bringen. Ein weiterer Aspekt, der hier berücksichtigt werden sollte, ist, dass dieser ohne staatliche Kontrolle potentiell noch immer als Rebellionsfigur dienen konnte. ${ }^{255}$

\section{Eine historische Neubewertung der Ikone Mao Zedong?}

Eines der wichtigsten Zeugnisse über die Bemühungen, ein kollektives Gedächtnis im Sinne der Partei zu etablieren, bzw. über den offiziellen Umgang mit den positiven und negativen Aspekten des Wirkens Mao Zedongs jener Jahre, legt die offizielle Mao-Biografie ab. Der erste Band widmet sich dem Leben Maos von seiner Geburt im Jahre 1893 bis zur Gründung der Volksrepublik China im Jahre 1949. Der erste Teil wurde von dem Parteihistoriker Jin Chongji 金冲及 geschrieben und ist im Jahre 1996 erschienen. Der zweite Teil ist schließlich im Jahre 2003, also zum Ende der Präsidentschaft Jiang Zemins, erschienen. Dieser Teil ist ein Gemeinschaftswerk, welches unter der Leitung des Parteihistorikers Pang Xianzhi 逢先知 und in Zusammenarbeit mit Jin Chongji entstanden ist und die Jahre 1949 bis 1976, dem Todesjahr Maos, abdeckt. Beide Teile wurden durch die Zentrale Forschungsstelle der KPCh (Zhonggong zhongyang wenxian yanjiu shi 中共中央 文献研究室) herausgegeben, was den offiziellen Charakter der Biografie unterstreicht. ${ }^{256}$ Somit kann man sagen, dass dieser Teil der Geschichtsschreibung aus dem Inneren der Partei heraus entstanden ist. Die Ereignisse der HundertBlumen-Bewegung und der Kampagne gegen Rechtsabweichler werden ziemlich ausführlich in zwei Kapiteln und auf insgesamt 122 Seiten behandelt. ${ }^{257}$ Den

255 Vgl. Kroher 2011.

256 Die folgende Analyse bezieht sich auf die im Jahr 2011 erschienene, zweite Auflage, die beide Teile vereint und welche aus sechs Bänden und insgesamt 2768 Seiten besteht. In dieser wird keine Unterscheidung mehr vorgenommen, wer welchen Teil geschrieben hat. Sie wird als gemeinschaftliches Werk Pang Xianzhis und Jin Chongjis ausgegeben. Pang und Jin 2011.

257 Kapitel 56 ,,Über die richtige Behandlung von Widersprüchen im Volk‘, die Berichtigungsbewegung und die Kampagne gegen Rechtsabweichler (Teil 1)“”矢于正确处理人民内部矛盾的问 
weitaus größten Teil nimmt dabei die Beschreibung der Ausgangssituation im China der Jahre 1956 und 1957 ein, welche letztlich als Erklärung und Rechtfertigung für den Ausbruch des Kampfes gegen die Rechtsabweichler dient.

Zunächst gehen die Autoren in Kapitel 56 auf die internationale Situation und die Volksaufstände in Polen (Juni 1956) und Ungarn (Oktober und November 1956) ein. Die Intensivierung der Hundert-Blumen-Bewegung hin zu einem öffentlichen Aufruf zur Kritik an der Partei beschreiben sie klar als Reaktion Maos auf die Sorge, dass sich solche destabilisierenden Vorfälle in China auch ereignen könnten, wenn man dem Auseinanderdriften von Partei und Volk nichts entgegensetzen würde. Die darauffolgenden Überlegungen und Entscheidungen, so betonen es die Autoren mehrfach, seien von Mao gründlich und in aller Sorgfalt abgewogen worden. Gleichzeitig wird immer wieder dargelegt, wie komplex und undurchsichtig die innenpolitische Lage damals gewesen sei und wie schwierig es deshalb für die handelnden Akteure gewesen sei, allen voran Mao, eine adäquate Entscheidung zu treffen.

Pang Xianzhi und Jin Chongji führen dabei auch eine Reihe von Gründen an, die letztlich dazu geführt haben sollen, dass es zu einer (teilweisen) Fehleinschätzung der Situation durch Mao gekommen sei. Dabei weisen sie wiederholt darauf hin, dass es der Partei nur sieben Jahre nach Gründung der Volksrepublik auch an Erfahrung mangelte, wie man mit vermeintlichen Widersprüchen im Volk umgehen solle. Dies zeigt sich insbesondere in der Beschreibung der Proteste zehntausender Arbeiter und Studenten in einigen zentralen und südlichen Provinzen in der zweiten Jahreshälfte 1956:

Die Partei als Ganzes war unvorbereitet und wusste nicht, wie man mit einem solchen Eventualfall umgehen könnte. Es mangelte auch an Erfahrung. Einige Kader waren es gewöhnt, die Dinge auf die alte Art zu regeln, noch immer verhaftet mit alten Praktiken, welche sich während der Revolution als effektiv bewährt hatten, Arbeiter und Studenten aber, behandelten sie so, als wären sie Feinde. Das war so, als würde man Öl ins Feuer gießen. Mao war zutiefst besorgt. ${ }^{258}$

Die von den Autoren verwendeten direkten Zitate unterstreichen immer wieder, dass es nicht nur der Partei an Erfahrung mangelte, sondern dass auch das Volk noch nicht über genügend Erfahrung darüber verfügte, wie man sich innerhalb der neuen marxistischen Gesellschaft stets adäquat zu bewegen habe. Laut einer von den Autoren zitierten Quelle soll Mao am 30. April 1957 während der von ihm

题“和整风反右(上); Kapitel 57 ,,Über die richtige Behandlung von Widersprüchen im Volk‘, die Berichtigungsbewegung und die Kampagne gegen Rechtsabweichler , 矢于正确处理人民内部矛 盾的问题“和整风反右(下), ebd., S. $1565 \mathrm{ff}$.

258 Eigene Übersetzung. Original siehe ebd., S. 1576. 
geleiteten 12. Sitzung der Obersten Staatskonferenz (zuigao guowu huiyi 最高国务 会议) darauf hingewiesen haben, dass Veränderungen Zeit bräuchten und sich eine marxistische Weltanschauung, auch unter den Intellektuellen, somit nicht über Nacht durchsetzen könne:

Wir können nicht erwarten, dass viele Menschen die materialistische Dialektik respektive die marxistisch-leninistische Weltanschauung von heute auf morgen akzeptieren. Die Transformation der Weltanschauung dauert ewig. In diesen Zeiten des großen sozialen Wandels haben die Intellektuellen unter großen Schwierigkeiten zu leiden, insbesondere jene in den Sozialwissenschaften. Dafür gibt es wirtschaftliche Gründe: die wirtschaftliche Grundlage, die einst 5 Millionen Intellektuelle unterstützt hat, ist kollabiert. ${ }^{259}$

Und auch Maos Rede Über die richtige Behandlung der Widersprüche im Volk (guanyu zhengque chuli renmin neibu maodun de wenti 䏌于正确处理人民内部 矛盾的问题), welche er ursprünglich am 27. Februar 1957 gehalten hatte, die jedoch erst am 19. Juni 1957 in der Renmin Ribao nach zahlreichen Überarbeitungen in schriftlicher Form veröffentlicht und damit den Massen zugänglich gemacht worden ist, ${ }^{260}$ enthält in einer ihrer Rohfassungen laut Pang und Jin einen Abschnitt, in dem genau dieser Aspekt unterstrichen wird. In der (unveröffentlichten) Fassung vom 08. Mai 1957 wird darauf hingewiesen, dass sich neben den Intellektuellen auch die Massen noch nicht in Gänze an das neue politische System gewöhnt haben könnten:

Seit der Befreiung sind erst sieben Jahre vergangen und das sozialistische System ist für das Land noch neu. Auch wenn die Massen das neue System begrüßen, sind sie dennoch noch nicht ganz mit ihm vertraut. Und auch die Regierungsangestellten verfügen noch nicht über hinreichend Erfahrung. Mit anderen Worten, es wird noch etwas Zeit benötigt, bis unser sozialistisches System konsolidiert worden ist, bis sich die Massen daran gewöhnt haben und bis das Regierungspersonal neue Erfahrungen erlernt und sich angeeignet hat. ${ }^{261}$

259 Eigene Übersetzung. Original siehe ebd., S. 1636.

260 Hier gilt es jedoch zu bedenken, dass die Analphabetenrate im Jahr der Gründung der Volksrepublik China noch zwischen 80 und 85 Prozent gelegen hat. Zwar genoss die Massenalphabetisierung für die Konsolidierung des neuen sozialistischen Systems für Mao und andere hochrangige Parteikader eine sehr hohe Priorität, jedoch brachten entsprechende Kampagnen in den 1950er Jahren nicht den gewünschten Erfolg, sodass die Alphabetisierungsrate zum Zeitpunkt des Erscheinens des Textes in der Renmin Ribao nicht nennenswert höher gewesen sein dürfte. Die Intellektuellen jedoch, die für den Aufbau des Sozialismus eine entscheidende Rolle spielen sollten, wurden so allerdings sehr wohl erreicht. Henze 1983, S. $300 \mathrm{ff}$.

261 Eigene Übersetzung. Original siehe Pang und Jin 2011, S. 1646. 
Dieser Abschnitt war in der ursprünglichen Fassung vom 27. Februar 1957 noch nicht $\mathrm{zu}$ finden. ${ }^{262}$ Gleichzeitig fehlen in der veröffentlichten, überarbeiteten Fassung einige Passagen, wie zum Beispiel jene, in denen er über die aufkommenden Studierendenproteste spricht. Damit wurde in die offizielle wie auch in die inoffizielle Geschichtsschreibung gleichermaßen eingegriffen, da auch die Autoren der Schriften, die als Teile der inoffiziellen Geschichtsschreibung bewertet werden können, zumeist auf die überarbeitete Fassung zurückgreifen. Mao selbst hat nur wenige Wochen zuvor gesagt, dass die entsprechenden Passagen deshalb herausgestrichen werden müssten, weil er befürchte, dass sie andere anstiften würden, es den Protestierenden gleichzutun, und das Land somit ins Chaos zu stürzen drohte:

\begin{abstract}
Und zum Schluß: Meine Rede, diese Rede von vorgestern, muß in manchen Stellen etwas ergänzt, etwas abgeändert werden; die Genossen, die heute geredet haben, brachten sehr viele Ansichten vor; diese Sache soll nicht in vollem Wortlaut veröffentlicht werden, denn einige Fragen, wie zum Beispiel das Problem der Streiks von Arbeitern und Schulen, sobald das an die Öffentlichkeit gelangte, nun also, dann würde das ganze Land streiken! (Gelächter) Und unsere Kader wären darauf nicht vorbereitet, unsere Genossen ebensowenig. Wenn Sie, meine Genossen aus den Provinzen, nach der Konferenz zurückgekehrt sind, bitte sorgen Sie dafür, daß man auf so etwas eingestellt ist. ${ }^{263}$
\end{abstract}

Insgesamt fällt die überarbeitete Version der Rede etwas kürzer aus als die ursprüngliche Fassung vom 27. Februar 1957. ${ }^{264}$ Dass die Autoren Pang Xianzhi und Jin Chongji die Rohfassungen der einzelnen Überarbeitungsschritte, also die Zwischenschritte bis zum später veröffentlichten Text, ausführlich zitieren und im Sinne Maos nutzen, kann somit ebenfalls als ein direktes Eingreifen in das historische Bild Maos, und damit als Eingriff in die offizielle Geschichtsschreibung der VR China, gewertet werden. Anders ausgedrückt, unterstützen die Autoren mit der Wahl ihrer Quellen einen Kanon, der das durch die Partei vorgegebene Bild Maos stützt. Mit Kritik an der Ikone Mao halten sich die Autoren dementsprechend zurück. In Bezug auf die Fehleinschätzung der Situation des Jahres 1957 jedoch lässt sich in der Biografie eine kurze versteckte Kritik an ihm herauslesen, in der sie diese auf seine Naivität zurückführen: „Zu dieser Zeit war Mao recht naiv bezüglich der Einschätzung möglicher Unruhen; er hat die Situation in China zu optimistisch eingeschätzt; er hat angenommen, dass solch gravierende Zwi-

262 Zum Vergleich des Originaltextes mit der später veröffentlichten Version siehe Schoenhals 1986.

263 Auszug der Schlussworte Mao Zedongs auf der Obersten Staatskonferenz am 02. März 1957. Zit. in Martin 1977, S. 108.

264 Schoenhals 1986, S. 100. 
schenfälle wie in Ungarn hier nicht passieren könnten. “265 Dies ist einer der wenigen analytischen Kommentare der Autoren. Gleichzeitig weist der Hinweis auf Maos Naivität auch einen relativierenden Charakter auf, da er, wie die Autoren betonen, einen starken Glauben in die Loyalität insbesondere der jungen Intellektuellen und Studenten gehegt habe.

Zwar habe sich die Situation um die Hundert-Blumen-Bewegung durch die ausufernde Kritik vieler Intellektueller anders entwickelt als erwartet, jedoch habe Mao, so analysieren es die Autoren, zu keiner Zeit den Überblick über die politische Situation verloren. Mao wird insgesamt als kluger Stratege beschrieben, der im Frühsommer 1957 die Situation dazu genutzt habe, die Partei und die Revolution durch politisches Geschick zu schützen. Die Autoren stützen dabei ganz eindeutig das Narrativ, dass Mao ab Mitte Mai eine Falle gelegt haben soll. Sie unterstreichen damit erneut den Kanon, dass Mao die Partei und die Massen vor großem Unheil bewahrt habe, welches zu jener Zeit von den noch vorhandenen reaktionären Kräften auszugehen drohte, indem er die aktuellen Entwicklungen dazu genutzt habe, „die Schlangen aus ihren Löchern zu holen“ (yinshechudong 引蛇出洞). Dieses Narrativ gilt unter Historikern als umstritten, da es den Kontrollverlust bzw. die völlige Fehleinschätzung der Situation durch Mao verschleiert. Allerdings weist es Ähnlichkeiten mit dem Narrativ vieler Opfer der Kampagne gegen Rechtsabweichler auf. Wie in den Kapiteln 5 und 6 aufgezeigt wird, fühlten sich viele ehemalige Rechtsabweichler, obwohl sie unschuldig gewesen seien, hinterrücks in eine Falle gelockt. Der Unterschied beider Narrative besteht lediglich in der Interpretation der Falle: Während in offiziellen Darstellungen wie dieser von einem geschickten politischen Manöver die Rede ist, wird die ab Mitte Mai 1957 gelegte Falle in einem Großteil der Memoiren ehemaliger Rechtsabweichler eher als politische Niedertracht beschrieben.

Die Autoren stützen sich in ihrer Argumentation unter anderem auf die von Mao entworfene Direktive zum Umgang mit der gegenwärtigen Kritik durch Personen, die nicht Parteimitglied sind (Guanyu duidai dangqian dang wai renshi piping de zhishi 䏌于对待当前党外人士批评的指示), welche er am 16. Mai 1957 mit dem Zentralkomitee diskutiert haben soll. Noch am gleichen Tag soll das gesamte Zentralkomitee Maos Idee unterstützt haben und so sei einstimmig beschlossen worden, die Falle zuschnappen zu lassen, indem reaktionäre Kritiken weiterhin weder beschränkt noch widerlegt werden sollten, mit der Absicht, dem Volk die wahren, abweichlerischen Intentionen der Rechtsabweichler offenzulegen. ${ }^{266}$

265 Eigene Übersetzung. Original siehe Pang und Jin 2011, S. 1644.

266 Ebd., S. 1658. 
Die Beschreibung durch die Autoren vermittelt einerseits erneut das Bild, dass Mao sowie die gesamte Partei stets die Kontrolle und Übersicht behalten hätten, andererseits, dass die Partei letztlich voll und ganz hinter Maos Taktik gestanden habe. ${ }^{267}$ Während die Kritikäußerungen der Hundert-Blumen-Bewegung zwischen Mitte Mai und Anfang Juni ausuferten und in massive Studentenproteste überzugehen drohten, habe er die Gesamtsituation zu jeder Zeit allumfassend im Blick gehabt. Unterstützung habe er dabei auch durch Spitzel erhalten, die von der Partei an die größten Universitäten des Landes geschickt worden seien:

All dies vermittelte einigen Leuten den falschen Eindruck, dass die Kommunistische Partei nicht mehr länger in der Lage gewesen sei, die Situation zu kontrollieren und dass sich die Ereignisse in Polen und Ungarn gerade wiederholen würden. Mao beobachtete sowohl die gesamte Berichtigungsbewegung als auch die öffentlichen Meinungsäußerungen ganz genau und blieb über alle möglichen Kanäle stets informiert. Während der ersten unruhigen Tage schickte er seine Leute fast täglich an die Peking-Universität, die Tsinghua-Universität, die Pädagogische Universität Peking, an die Renmin-Universität sowie andere Universitäten und Hochschulen, um zu lesen, was auf den großen Wandzeitungen geschrieben stand. ${ }^{268}$

Dennoch, so vermitteln es die Autoren, habe Mao mit Sorge auf die Gesamtsituation geblickt.

Deng Xiaoping wird während eines Treffens des Politbüros am 23. Mai 1957 als jemand beschrieben, der sich des Ernstes der Lage zwar bewusst war, jedoch auch besonnen reagierte. So soll er gesagt haben:

Die Frage ist, ob die Situation wirklich so furchtbar ist? Es herrscht große Beunruhigung darüber. Eine ziemlich große Anzahl hochrangiger Kader, Genossen aus Provinz- und Kreisebenen, die an unserer Parteihochschule studieren, zeigen sich sehr besorgt, und das aus guten Gründen. Wer wäre nicht beunruhigt angesichts solcher Schmähungen? Niemand, denke ich mir. So wie auch ich selbst. Während der ersten Tage waren viele von uns verunsichert! Doch dann, als wir mehr reaktionäre Dinge sahen, beruhigten wir uns und fühlten uns besser. Einige fragen sich noch immer, ob ein Aufstand ausbrechen wird. Meiner Einschätzung nach wird das nicht passieren. ${ }^{269}$

Durch die Verwendung dieser Quelle bzw. dieses Zitats von Deng zeichnen die Autoren ihn als abwägenden Denker, der sich zwar beunruhigt gezeigt, dabei

267 Siehe im Gegensatz dazu Zhu Dandans 1956. Mao's China and the Hungarian Crisis, in dem sie beschreibt, wie die Auswertungen der Aufstände in Ungarn im Herbst 1956 zu heftigen innerparteilichen Debatten geführt hätten und dass die Intensivierung der Hundert-Blumen-Bewegung zu einem großen Dissens innerhalb des Zentralkomitees geführt habe, die Partei also keineswegs geschlossen hinter Mao gestanden habe. Zhu 2013.

268 Eigene Übersetzung. Original siehe Pang und Jin 2011, S. 1660.

269 Eigene Übersetzung. Original siehe ebd., S. 1661. 
jedoch nicht kopflos agiert habe. Die entscheidende Rolle Deng Xiaopings im Zusammenhang mit dem Ausbruch der Kampagne gegen Rechtsabweichler, die er auch durch seine Funktion als Generalsekretär des Zentralkomitees innehatte, wird durch die Autoren nahezu komplett negiert. Man muss hier jedoch zweierlei berücksichtigen: Man kann davon ausgehen, dass die Biografie noch zu Lebzeiten Dengs durch die Partei in Auftrag gegeben worden ist - allein die Recherche in den Archiven sowie die Auswertung des sehr umfassenden Quellenmaterials dürfte Jahre in Anspruch genommen haben. Außerdem liegt in einer Biografie der Fokus naturgemäß auf der in ihr beschriebenen Person. Dennoch hätte theoretisch die Möglichkeit bestanden, Maos Verantwortung in dieser Sache als noch geringer darzustellen, zumal der zweite Teil der Biografie im Jahr 2003 und damit rund sechs Jahre nach Dengs Tod im Jahre 1997 erschienen ist. Tatsächlich jedoch ist das Gegenteil davon passiert, Mao wird die alleinige Verantwortung für die politischen Übertreibungen der Jahre 1956 bis 1958 zugeschrieben. Allerdings wird auch immer wieder betont, dass die Partei, nach anfänglichen Diskussionen, hinter den politischen Entscheidungen Maos der Jahre 1957 und 1958 gestanden habe. Hier zeigt sich deutlich, dass die Tatsache, dass der Rahmen der offiziellen, abschließenden Bewertung dieser Kampagne, der mit der Resolution von 1981 gesteckt wurde, durch Deng Xiaoping höchstpersönlich entscheidend mitgestaltet worden ist, die Geschichtsschreibung auch Jahre nach seinem Tod nachhaltig beeinflusste - dies gilt zumindest so lange, wie keine komplette offizielle Neubewertung der Geschichte durch die Partei in Form einer neu ausgearbeiteten Resolution vorgenommen wird.

Aus diesem Grund nimmt die Erklärung der politischen Ausgangsituation inner- und außerhalb Chinas sowie die Einschätzungen der Situation durch Mao den größten Umfang innerhalb der Biografie ein. Der Verlauf und die Durchführung der Kampagne gegen Rechtsabweichler, für die wiederum Deng Xiaoping verantwortlich gewesen ist, werden hingegen nur recht kurz beschrieben. Die Ereignisse ab dem 08. Juni 1957 werden insgesamt auf nur 9 von insgesamt 122 Seiten der zwei Kapitel zu der Hundert Blumen-Bewegung und der Kampagne gegen Rechtsabweichler dargelegt. Das gleiche gilt für die Beschreibung der Konsequenzen und politischen Nachwirkungen, welche auf rund 10 von 122 Seiten abgehandelt werden. Die Erklärung und Rechtfertigung für die Ausmaße des Kampfes gegen die Rechten durch die Autoren beschränkt sich im Wesentlichen auf einen Abschnitt. Die während der Kampagne begangenen Fehler werden zusammenfassend erneut auf die mangelnde Erfahrungen Maos und der Partei zurückgeführt:

Unter sozialistischen Bedingungen kann an der ideologischen Front ein langwieriger und komplexer Kampf bestehen bleiben. Sind bestimmte Voraussetzungen gegeben und entwi- 
ckeln sich diese dann bis zu einem bestimmten Grad, kann sich ein solcher Kampf zu einer politischen Konfrontation entwickeln. Das ist eine Tatsache. Aber Mao und der Partei mangelte es an Erfahrung, wie man einen solchen Kampf zu führen hatte, und Mao selbst überschätzte den Ernst der Bedrohungslage für die Partei und das sozialistische System, die von einer Handvoll rechter Elemente ausging. So ist die fatale Entfaltung der Kampagne gegen Rechtsabweichler zustande gekommen. ${ }^{270}$

Die Beschreibung der Kampagne gegen Rechtsabweichler geht dabei nicht nur in ihrem Umfang insgesamt deutlich über die der Resolution von 1981 hinaus, vielmehr zeigt sich hier, inwiefern die vagen Vorgaben der Resolution durchaus auch Raum für eine deutlich kritischere Betrachtung der Kampagne innerhalb der offiziellen Geschichtsschreibung der kommenden Jahre geschaffen haben:

Die Eskalation der Kampagne gegen Rechtsabweichler hatte schreckliche Konsequenzen. Hunderttausende rechtschaffende talentierte Intellektuelle und Parteimitglieder erlitten unverdiente Demütigungen und Verfolgungen und häufig wurden auch ihre Familien stillschweigend mit hineingezogen. Rückblickend betrachtet, waren die Worte vieler sogenannter Rechtsabweichler häufig nur eine scharfe, aber wohlgemeinte Kritik, welche sich gegen bestimmte Defizite und Fehler in der Parteiarbeit richtete, manchmal hat es sich gar nur um Kritik an bestimmten Basiseinheiten oder ihren Führern gehandelt. Leider wurden solche Kritiken als Beweis für eine Anklage herangezogen. Diese Intensivierung der Kampagne hatte für das politische Leben der Nation verheerende Folgen und hat das Gegenteil dessen bewirkt, was Mao mit der Initiierung der Berichtigungsbewegung erreichen wollte: Anstatt die politische Atmosphäre zu beleben, hat die Kampagne gegen Rechtsabweichler der Hundert-Blumen-Bewegung großen Schaden zugefügt. Das war eine bittere Lehrstunde. ${ }^{271}$

Das heißt, obwohl sie zu einem kritischeren Urteil der Kampagne gegen Rechtsabweichler kommen, bewegen sich die Autoren dennoch innerhalb der Grenzen, die die Resolution vorgegeben hatte, da sie das darin gesetzte Urteil nicht in Frage stellen: Zwar wurde die Kampagne gegen Rechtsabweichler von den Autoren nicht als „korrekt und notwendig“ bewertet, gleichzeitig aber ordnen sie diese auch nicht als Fehler ein - der Begriff „Fehler“ (cuowu 错误) fällt auch hier nicht ein einziges Mal. Und somit sind die Abweichungen von der Resolution durch die etwas deutlichere Kritik an der Kampagne zwar durchaus erkennbar, dennoch kann man nicht von einer Neubewertung dieser durch die Parteihistoriker sprechen. Pang und Jin zitieren direkt unter ihrer eigenen, kurzen Bewertung den entsprechenden Abschnitt der Resolution. Das Zitieren wirkt dabei so, als solle es die in den vorherigen Abschnitten geäußerte Kritik relativieren, indem die Auto-

270 Eigene Übersetzung. Original siehe ebd., S. 1674 f.

271 Eigene Übersetzung. Original siehe ebd., S. 1676. 
ren dadurch demonstrieren, dass die zu Beginn der 1980er Jahre getätigte Einschätzung der Ereignisse und Folgen der Kampagne durch die KPCh, nämlich dass sie zwar übertrieben wurde, zum Schutz der Partei dennoch korrekt und notwendig gewesen sei, auch für sie noch Gültigkeit besitzt.

Obwohl es sich hier zweifelsohne um eine offizielle Darstellung und Bewertung des Lebens und Wirkens Mao Zedongs handelt, kann man die Biografie keineswegs als schlichte Parteipropaganda bezeichnen. Auch wenn es einen bestimmten, von der Partei vorgegebenen Kanon bedient, handelt es sich dennoch um ein sehr umfassend recherchiertes Werk, für das durch die Autoren eine große Vielzahl unterschiedlichster aus dem Parteiarchiv stammender Quellen ausgewertet worden ist. Die Seriosität der in diesem Werk geleisteten Quellenarbeit zeigt sich auch dadurch, dass es wiederum als wichtige Quelle für wissenschaftliche Publikationen einiger international anerkannter Chinahistoriker diente. Als Beispiel sei hier die im Jahr 2011 erschienene Deng-Xiaoping-Biografie des Harvard-Professors Ezra Vogel genannt, welche rund zwei Jahre später auch auf Chinesisch herausgegeben wurde. In dieser dient eben jene Mao-Biografie von Jin Chongji und Pang Xianzhi als wichtige und sehr häufig zitierte Quelle. ${ }^{272}$ Als weiteres Beispiel lässt sich auch die Mao-Biografie des an der Capital University in Columbus (Ohio) lehrenden russischen Historikers Alexander Pantsov nennen, der sich in dieser ebenfalls sehr häufig auf die offizielle Mao-Biografie bezieht. ${ }^{273}$

Die offizielle Linie wird also nicht durch eine Verfälschung historischer Fakten bedient, sondern eher durch das Weglassen von Teilen bestimmter Begebenheiten des jeweiligen historischen Ereignisses. Die Autoren erwähnen zum Beispiel nicht, was den Alltag der Rechtsabweichler nach ihrer Verurteilung in den Zwangsarbeitslagern bestimmen sollte oder welche Verantwortung Deng Xiaoping für die Entwicklungen der Jahre 1957 und 1958 trägt. 2009 sagte Jin Chongji in einem Interview mit Xi Wang hierzu, dass er sich für das Schreiben der Biografie an keinerlei Vorgaben durch die Partei habe halten müssen und er auch niemals einfach so über historische Fakten hinweggehen könne:

The specific work I did at the Research Center, such as writing and editing of the biographies of Mao Zedong, was actually my favorite job. As I set to write these biographies, no one had ever given me any instructions about what to be or not be written or how I should write these biographies. I could sufficiently express my opinion or offer my interpretations based on the historical materials I had reviewed. The position I had defined for myself was: I would only put into words what I believed was in accordance with historical

272 Siehe Vogel 2011.

273 Siehe Pantsov und Levine 2013. 
facts, I would never make a false statement. Whether my conclusions or judgements are correct, I leave them to readers. ${ }^{274}$

Zwar ist dies für einen Parteihistoriker keine überraschende Aussage, wenn man bedenkt, dass er wohl seine hochdotierte Position verlieren würde, würde er öffentlich einräumen, dass er bestimmte, entscheidende historische Aspekte auf Geheiß der Partei zensieren musste, dennoch ist es bemerkenswert, dass er diese Aussage überhaupt tätigt, denn so liest sie sich beinahe wie eine Rechtfertigung seiner Arbeit.

Insgesamt fällt auf, dass der analytische Teil der Biografie nur sehr gering ausfällt. Das Gros des Buches besteht vielmehr aus einer Aneinanderreihung von direkten Zitaten und Quellen ohne lange Bewertungen durch die Autoren. Dadurch gelingt es den Autoren einerseits, deutlich umfangreicher über die historischen Ereignisse und Fehler der Jahre 1949 bis 1976 zu berichten, als es in der Resolution von 1981 der Fall war, gleichzeitig vermeiden sie, von der in dieser vorgenommenen offiziellen Deutung der Vergangenheit abzuweichen. Sie überlassen die Bewertung der historischen Fakten somit den Lesern. Jin Chongji benennt die in dem Buch verwendete Methode als shu er bu lun 述而不论, ${ }^{275}$ „die Fakten darlegen, ohne sie zu bewerten“. ${ }^{276}$

$\mathrm{Zu}$ den „historischen Fehlern“ der Partei sagte Jin Chongji später, dass diese zwar fraglos gemacht worden seien, man diese auch nicht leugnen könne und man über diese durchaus auch sprechen könne, jedoch seien diese später korrigiert worden und müssten als Teil eines Entwicklungsprozesses hin zum gegenwärtigen China angesehen werden:

Surely we have made mistakes and have encountered many difficulties, which we should
not try to avoid talking about. These mistakes had been made during the process of search-
ing for correct ways of development and had been discovered and corrected by the Chinese
people under the leadership of the CCP. They are now our spiritual wealth as we march for-
ward. History cannot be discarded. Without yesterday there would not be today and tomor-
row. As Hu Jintao said, the victory of new nationalist democratic revolution and the estab-
lishment of fundamental socialist system had laid the essential political and systematic

274 Jin und Xi 2009, S. 239.

275 Die Formel shu er bu lun wurde aus dem Lunyu-Zitat shu er bu zuo, xin er hao gu, qie bi wu wo lao Peng 述而不作, 信而好古, 窃比於我老彭 (,Beschreiben und nicht machen, treu sein und das Altertum lieben: darin wage ich mich mit unserem alten Peng zu vergleichen“) abgeleitet. Lunyu, Buch VI. Siehe Die Lehren des Konfuzius 2009, S. $216 \mathrm{f}$.

276 Jin und Xi 2009, S. 240. 
foundations for the development and progress of today's China. This is an objective and truthful assessment of modern China's development. ${ }^{277}$

Damit deutet er an, dass die Geschichte der VR China immer auch der Gegenwart dienen müsse. Eine intensivere Aufarbeitung „historischer Fehler“, ebenso wie ein komplettes Öffnen der Archive, würde, seiner Einschätzung nach, die Meinung der Bevölkerung zur Vergangenheit Chinas und der Partei ohnehin nicht mehr ändern, da sich diese bereits nachhaltig verfestigt habe. ${ }^{278}$

Zusammenfassend lässt sich feststellen, dass Jiang Zemin zwar wieder zunehmend Bilder der Ikone Mao für seinen Machterhalt zu nutzen versuchte, jedoch gelang es ihm nicht wirklich, die „positiven“ Aspekte Maos für seine Zwecke zum Volk zu transportieren. Damit einher gingen aber dennoch Maßnahmen, um die Kontrolle über die Geschichte der Partei und ihre „historischen Fehler“ nicht $\mathrm{zu}$ verlieren. Auffällig ist außerdem, dass es ihm scheinbar nicht gelang, eine Ideologie zu formen, die das Volk einbezog. Die wirtschaftliche Entwicklung stand deutlich im Fokus jener Jahre, ein Umstand, der dazu führte, dass ihm häufig vorgeworfen wurde, dass er sich mit seiner Politik nur den Eliten andiene. ${ }^{279}$

\subsection{Die Präsidentschaft Hu Jintaos - ein Zwischenspiel?}

Der Machtwechsel von Jiang Zemin zu Hu Jintao gestaltete sich geräuschlos und zumindest nach außen hin scheinbar konfliktfrei. Hu stand schon lange als Nachfolger Jiang Zemins fest, denn er war bereits im Jahr 1992 von Deng Xiaoping als Nachfolger Jiangs auserkoren worden. Die Partei war sich über den „Thronfolger“ einig und wählte Hu im Jahr 1998 zum Vizepräsidenten der VR China, bevor er im Jahr 2003 schließlich das Amt des Staatspräsidenten antrat. ${ }^{280} \mathrm{Zu}$ nächst waren sowohl eine Reihe von Intellektuellen in China als auch einige westliche Beobachter in der Phase des Machtübergangs von Jiang zu Hu recht optimistisch, dass er einen liberaleren politischen Kurs als sein Vorgänger einschlagen würde und dass damit auch wieder mehr intellektuelle und gesellschaftliche Freiheiten einhergehen würden. Ideologisch vermittelte Hu Jintao während der ersten Wochen seiner Präsidentschaft, die unter dem Motto der sogenannten Wissenschaftlichen Entwicklung (kexue fazhan guan 科学发展观)

277 Ebd., S. 244.

278 Ebd., S. 240.

279 Xing 2009, S. 221.

280 Zum Machtübergang von Jiang Zemin zu Hu Jintao siehe Bo 2007, S. 17 ff. 
stand, überraschenderweise zunächst den Eindruck, China würde weiter nach links rücken - nicht zuletzt wegen seiner Die Menschen zuerst-Agenda (yi ren wei ben 以人为本). Diese sollte eine Antwort auf die zunehmende Spaltung der postmaoistischen Gesellschaft darstellen, welche neben der Korruption nach und nach zu einem immer größer werdenden Problem für die Stabilität der Herrschaft der KPCh wurde. ${ }^{281}$ Die Idee hinter diesem ideologischen Konzept war, sowohl das Bild zu vermitteln, dass das Regime im Interesse der überwältigenden Mehrheit des chinesischen Volkes handelt, als auch, dass von dem stetig wachsenden Wohlstand alle Chinesen, ob Arbeiter, Bauern oder Intellektuelle, profitieren. ${ }^{282}$ Dies ging auch mit konkreten politischen Maßnahmen einher wie dem Programm zur Erhöhung ländlicher Einkommen. ${ }^{283}$ In der Zeit des Machtübergangs bediente er sich für eine kurze Zeit sogar maoistischer Bilder und Phrasen, weshalb er in jener Phase als Populist bezeichnet worden ist. Als Beispiel sei an dieser Stelle seine Pilgerreise nach Xibaipo 西柏坡im Dezember 2002 genannt, einer wichtigen Stätte der kommunistischen Revolution im Norden der Provinz Hebei. Sie diente zwischen 1947 und 1948 vorrübergehend als Hauptquartier der KPCh. Außerdem wurde hier im März 1949 die bedeutende 2. Plenarsitzung des 7. Zentralkomitees der KPCh abgehalten. ${ }^{284} \mathrm{Hu}$ besuchte dort im tiefsten Winter ältere Dorfbewohner und ältere ehemalige Parteikader in ihren bescheidenen Häusern. ${ }^{285}$ Indem die Bilder seines Besuchs durch die staatlichen Medien ins Volk transportiert worden sind, machte er sich die Erinnerungsorte der Kommunistischen Revolution zunutze. Gleichzeitig kann man dies auch als Versuch deuten, Volksnähe zu demonstrieren, um - im Gegensatz zu seinem Vorgänger - nicht nur als Politiker der Eliten wahrgenommen zu werden.

Allerdings hatten andere führende Parteimitglieder des Regimes um Hu Jintao und seinen Ministerpräsidenten Wen Jiabao 温家宝 kein Interesse an einer Wiederbelebung eines sehr linken oder gar populistischen Pfads. Die in den ersten Monaten seiner Amtszeit angestimmten populistischen Töne waren alsbald wieder verklungen und so sollte der wirtschaftliche Aufbau des Landes auch unter $\mathrm{Hu}$ die höchste Priorität genießen. ${ }^{286}$ Dennoch dürfte den Machthabern jener Jahre auch bewusst gewesen sein, dass es zur Sicherung der Herrschaftslegitimation der KPCh einer festen ideologischen Grundlage bedurfte, für den Fall,

281 Fewsmith 2005, S. 2.

282 Li 2008b, http://theory.people.com.cn/GB/82288/83849/83857/7374564.html.

283 Fewsmith 2005, S. 3.

284 Zur 2. Plenarsitzung des 7. Zentralkomitees siehe Mao 1956, S. 57 ff.

285 Renmin Ribao 人民日报 2004, http://unn.people.com.cn/GB/22220/34430/34443/2567086. html.

286 Xing 2009, S. 223. 
dass das Wirtschaftswachstum einmal nicht mehr so üppig ausfallen sollte. Notwendig geworden ist dies nicht nur aufgrund der zunehmenden gesellschaftlichen Spaltung, auf die Konservative und Intellektuelle in den vergangenen Jahren vermehrt mahnend hingewiesen hatten, sondern unter anderem auch durch die fortschreitende Globalisierung und die rasende Entwicklung des Internets. ${ }^{287}$ Deshalb lässt sich unter ihm eine pragmatische Reform und Modernisierung einer Parteiideologie erkennen, die darauf beruht, den Marxismus an die Gegebenheiten der modernen sozialen Marktwirtschaft in China anzupassen. Hierfür wurde im Jahr 2005 unter anderem eine neue Akademie für Marxismus gegründet, welche unter der Schirmherrschaft der CASS stand. Im Gegensatz zu seinem Vorgänger sollte durch seine nach außen getragene politische Agenda, auch wenn sie in der Praxis nahezu komplett auf den wirtschaftlichen Aufbau ausgerichtet war, zumindest der Eindruck von sozialer Gerechtigkeit und Gleichheit entstehen. Dies war auch deshalb besonders wichtig, da ausgerechnet in dem Teil der Bevölkerung, in der die KPCh traditionell den meisten Rückhalt erhielt, nämlich unter den Arbeitern und Bauern, die meisten Verlierer der Reform- und Öffnungspolitik zu finden waren. ${ }^{288}$

Die Die Menschen zuerst-Agenda sowie seine gesamte politische Leitlinie umfasste dabei ausdrücklich nicht die Verknüpfung seiner eigenen Legitimität mit der Ikone Mao Zedong. Er bediente sich eher des Teils der Geschichte, der die Entwicklung der gesamten Partei bzw. die Entstehung des Kommunismus in China im Blick hatte. Welch untergeordnete Rolle das Bild Maos während seiner beiden Amtszeiten spielen sollte, zeigt sich beispielhaft anhand zweier Propagandaposter, die anlässlich des 60. Gründungstages der Volksrepublik China im Jahr 2009 verwendet worden sind. Sie zeigen eine Militärparade anlässlich des Jubiläums, welche wie traditionell üblich am Platz des Himmlischen Friedens und am Haupteingang der Verbotenen Stadt vorbeiführte, der von einem überlebensgroßen Gemälde von Maos Konterfei geziert wird. Auf beiden Postern (Abb. 6 und 7) ist dieses Bild kaum zu erkennen - wenn man nicht genau wüsste, wer darauf abgebildet ist, würde man ihn auf den Postern auch nicht wahrnehmen. Dies vermittelt den Eindruck, als hätten die Künstler absichtlich darauf verzichtet, $\mathrm{Hu}$ Jintao, der auf beiden Bildern im Vordergrund in einer offenen Staatskarosse zu sehen ist, zu deutlich mit dem Bild Mao Zedongs in Verbindung zu bringen.

Dies zeigte sich auch in seiner Rede anlässlich eben jenes Gründungsjubiläums der VR China am 01. Oktober 2009. In dieser betont er die Errungenschaften des chinesischen Volkes während der letzten 60 Jahre, welche, trotz diverser

287 Holbig 2009, S. $41 \mathrm{f}$.

288 Ebd., S. 50 ff. 


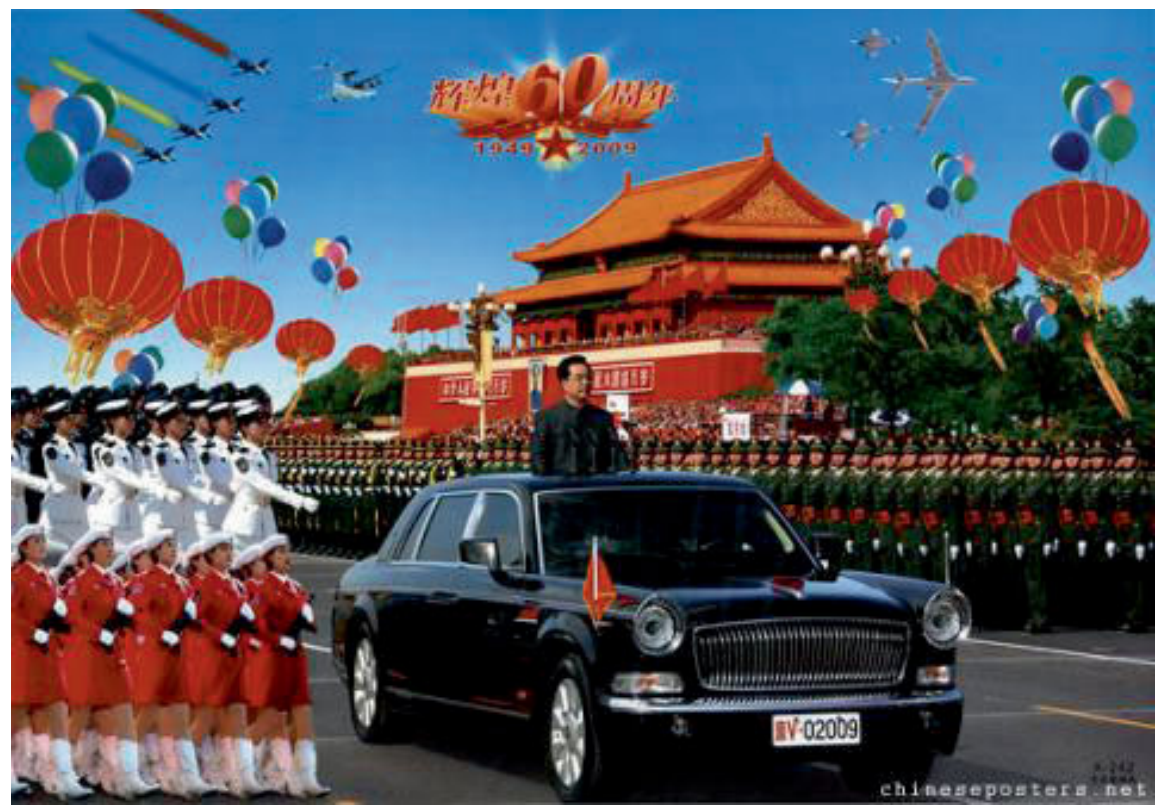

Abbildung 6: Der 60. Jahrestag der Gründung der VR China I, 2009 (Quelle: chineseposters.net)

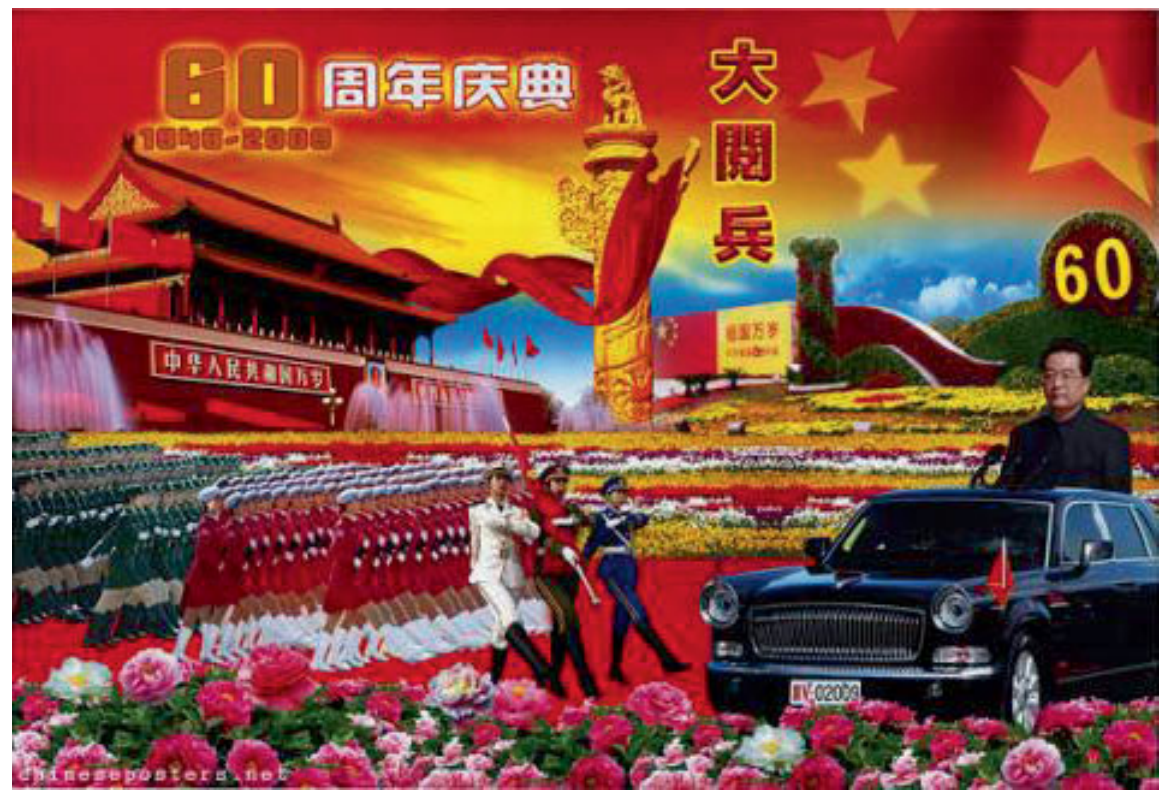

Abbildung 7: Der 60. Jahrestag der VR China II, 2009 (Quelle: chineseposters.net) 
Rückschläge, erfolgreich verlaufen seien. Mao Zedong räumt er dabei keine höhere Stellung als dem chinesischen Volk oder seinen Erben Deng Xiaoping und Jiang Zemin ein, stattdessen stellt er ihn auf eine Stufe mit ihnen und bewertet die Ikone als Teil eines Kollektivs:

\begin{abstract}
Während der vergangenen 60 Jahre hat das eifrige und weise chinesische Volk aller ethnischer Gruppen unter der Führung des zentralen Führungskollektivs mit dem Genossen Mao Zedong, dem Genossen Deng Xiaoping und dem Genossen Jiang Zemin im Zentrum und dem Zentralkomitee seit dem XVI. Parteitag mit einem Herz und einer Seele hart gearbeitet, dabei Krisen, Wendungen und Risiken aller Art bewältigt und bemerkenswerte Erfolge erzielt. Sie haben dabei ein Erfolgslied geschrieben, das aufzeigt, wie man durch stetiges Streben immer stärker werden kann. Heute ragt ein sozialistisches China über den Osten, welches sich an der Modernisierung, der Welt und der Zukunft ausrichtet. ${ }^{289}$
\end{abstract}

In seiner Rhetorik stellt er also die Leistung des gesamten Volkes für den Aufbau des Landes in den Mittelpunkt, was noch einmal seinen neuen pragmatischen ideologischen Ansatz unterstreicht. Die Mao-Zedong-Ideen bleiben sogar in Gänze unerwähnt.

Deutlich wird dieser Ansatz im Umgang mit der Ikone Mao jener Jahre auch in der Bewertung der Vergangenheit während der Feierlichkeiten zum 90. Gründungsjubiläum der KPCh am 01. Juli 2011. Während dieser zog er in seiner Rede Verbindungen zur Xinhai-Revolution (Xinhai geming 辛亥革命) von 1911, die das Ende der Qing-Dynastie und somit auch das Ende der Unterdrückung des chinesischen Volkes einläuten sollte. Er beschrieb dieses Ereignis als Grundlage für die Gründung der KPCh rund zehn Jahre später. ${ }^{290}$ Eine besondere Stellung unter den historischen Persönlichkeiten der letzten 90 Jahre wird Mao Zedong nicht zugesprochen - vielmehr stellt $\mathrm{Hu}$ ihn, ähnlich wie in seiner Rede zum 60. Gründungsjubiläum der VR China, als Teil der revolutionären Entwicklung auf die gleiche Stufe wie Zhou Enlai 周恩来, Deng Xiaoping oder Chen Yun 陈云:

At this moment when we are marking the 90th anniversary of the founding of the CPC, we
cherish the memory of Mao Zedong, Zhou Enlai, Liu Shaoqi, Zhu De, Deng Xiaoping, Chen
Yun and other proletarian revolutionaries of the older generation who contributed so much
to China's revolution, development, and reform and to the founding, consolidation, and
growth of the CPC. We cherish the memory of revolutionary martyrs who gave their lives
in founding, defending, and building New China. We also cherish the memory of all the
forerunners who struggled tenaciously for the independence and liberation of the Chinese

289 Eigene Übersetzung. Original siehe Hu 2009, http://cpc.people.com.cn/GB/64093/64094/ 10152026.html.

290 Noesselt 2011, S. 5. 
nation in modern times. Their tremendous contributions to China and the Chinese nation will go down in the annals of history. ${ }^{291}$

Zwar wurde Mao Zedong in der gesamten Rede sechsmal namentlich erwähnt, viermal davon jedoch im Zusammenhang mit den Mao-Zedong-Ideen, die seit der 1981er Resolution als Teil der Staatsideologie kanonisiert worden sind. Seine Fehler blieben unerwähnt, gleichzeitig unterließ Hu Jintao es jedoch auch, seine Verdienste für die Republik explizit über die Verdienste anderer führender Kader jener Jahre zu stellen. Insgesamt machte er sich Mao als legitimierenden Faktor kaum zunutze, auch wenn dies nicht bedeuten soll, dass er ihn komplett negierte. Vielmehr scheint es so, als wäre Mao in den Hu-Jahren als eines von vielen wichtigen Puzzleteilen der jüngeren chinesischen Geschichte bewertet worden.

Die Tatsache, dass Mao als legitimierender Faktor während der Präsidentschaft $\mathrm{Hu}$ Jintaos während offizieller Veranstaltungen in einem relativ geringen Umfang erwähnt worden ist, bedeutet allerdings keineswegs, dass die Arbeit der Parteihistoriker oder gar die offizielle Bewertung der „historischen Fehler“ der Partei in jenen Jahren keinen wichtigen Stellenwert gehabt hätte. Bereits im Jahr 2008 betonte $\mathrm{Hu}$ in einer Rede beispielsweise, dass es von höchster Wichtigkeit sei, die öffentliche Meinung zu steuern. Dem Erziehungs- und Propagandasystem schrieb er dabei eine Schlüsselrolle zu. ${ }^{292}$

Der Kampf um das kollektive Gedächtnis bzw. die Stärkung des offiziellen Kanons wurden während der Hu-Jahre durch zwei wichtige Ereignisse geprägt: die Wiedereröffnung des Nationalmuseums in Peking nach einer fast zehnjährigen Umbauphase im April 2011 mit seiner Ausstellung zur Weg der Wiederbelebung (fuxing zhi lu 复兴之路) ${ }^{293}$ und die Veröffentlichung der offiziellen Geschichte der Kommunistischen Partei durch die Zentrale Forschungsstelle für Parteigeschichte rund zwei Monate später.

291 Rede zum 90. Jubiläum der Gründung der KPCh, Hu 2011, http://pg.china-embassy.org/eng/ xwdt/t835962.htm.

292 Vgl. Göbel 2012, S. 166.

293 Die Ausstellung existierte bereits zuvor. Sie wurde im Zuge des Umbaus jedoch erheblich erweitert und modernisiert. Im Jahr 2011 wurde die Ausstellung schließlich wiedereröffnet. Zur Geschichte und zum Umbau des Nationalmuseums siehe Yang 2011, http://culture.people.com. cn/GB/87423/15512378.html. 


\section{Das Chinesische Nationalmuseum als Blaupause der nationalen Erinnerungskultur}

Die Ausstellung Weg der Wiederbelebung beleuchtet die Gesichte Chinas von 1840 bis zum Jahr 2011. Thematisch liegt der Fokus auf Chinas Entwicklung von einem durch Imperialisten gedemütigten Staat hin zum Aufstieg zu neuer Größe. Während der zehnjährigen Umbauphase soll es, so gaben es anonyme Zeugen zu Protokoll, immer wieder zu Diskussionen um die Art der Darstellung der Vergangenheit der Partei gekommen sein. Das Konzept wurde daraufhin immer wieder verändert und ursprünglich geplante Ausstellungsteile - teilweise auch zu „historischen Fehlern“ - mussten umgestaltet werden oder wurden ganz gestrichen. ${ }^{294}$ Diese Diskurse können dahingehend interpretiert werden, dass die Ausstellung nicht nur als eine visuelle Darstellung der 1981er Parteiresolution angesehen werden kann, sondern dass mit ihr ein weiterer Versuch unternommen worden ist, innerhalb der Partei ein Konsens über die Darstellung der eigenen Vergangenheit zu finden. Anders ausgedrückt, kann die Ausstellung, ebenso wie die Resolution von 1981, als kleinster gemeinsamer Nenner im offiziellen Diskurs um die Vergangenheit der KPCh angesehen werden. Anlässlich des 40. Jubiläums des Auftakts der Reform- und Öffnungspolitik des Jahres 2018 wurde noch eine sehr umfangreiche Erweiterung der Ausstellung vorgenommen, welche sich jedoch vornehmlich auf die Erfolge Chinas unter Xi Jinping bezieht. Seine Vorgänger Jiang Zemin und $\mathrm{Hu}$ Jintao, aber auch Deng Xiaoping, der einst das Fundament für Chinas wirtschaftlichen Aufstieg legte, bleiben darin nicht mehr als eine Randnotiz.

Die Kommunistische Partei nimmt in der Ausstellung Weg der Wiederbelebung eindeutig die Rolle des Schicksalswenders ein, der den entscheidenden Impuls für die Befreiung des Volkes setzte und ohne den der Wiederaufstieg Chinas zur Weltmacht nicht möglich gewesen wäre. Dementsprechend wird die Ausstellung mit den folgenden Worten eingeleitet:

The Chinese nation is a great nation whose people are industrious, courageous, intelligent and peace loving and have made indelible contributions to the progress of human civilization. For generations and generations, the Chinese people have been pursuing a dream of national strength and prosperity. "The Road to Rejuvenation" is a permanent exhibition showcasing the explorations made by the Chinese people from all walks of life who, after being reduced to a semi-colonial, semi-feudal society since the Opium War of 1840, rose in resistance against humiliation and misery, and tried in every way possible to rejuvenate the nation. The Exhibition also highlights the glorious history of China under the leadership of the Communist Party of China (CPC), in which all the ethnic groups joined

294 Johnson 2011, https://www.nytimes.com/2011/04/04/world/asia/04museum.html?pagewan ted=all\&mtrref=undefined\&gwh=05 A01AD570DC0BC46EE35891F997D8DF\&gwt=pay. 
forces to achieve national independence and liberation and strove to build a strong and prosperous country for the well-being of the people. The exhibition therefore clearly demonstrates the historical course of the Chinese people of choosing Marxism, the CPC and the socialist road and the reform and opening-up policy, and China's firm determination in building socialism with Chinese characteristics, through adherence to this great banner, this special road and this theoretical system. Today, the Chinese nation is standing firm in the east, facing a brilliant future of great rejuvenation. The long-cherished dream and aspiration of the Chinese people will surely come to reality. ${ }^{295}$

Ähnlich lauten auch die Worte auf dem Plakat, welches die Schlussworte der Ausstellung enthält. Hier wird noch einmal betont, dass der Aufstieg Chinas ohne die KPCh nicht möglich gewesen wäre und dass der Sozialismus chinesischer Prägung (Zhongguo tese shehui zhu yi 中国特色社会主义) der einzige Weg in die Zukunft Chinas darstelle.

Die Kampagne gegen Rechtsabweichler wird in der Ausstellung vollständig zensiert. Sie wird kein einziges Mal erwähnt - im Gegensatz zur Kulturrevolution, die zwar nicht viel Raum einnimmt, jedoch anhand einer Fotografie, die eine Massenkundgebung der Roten Garden auf dem Platz des Himmlischen Friedens im Sommer 1966 zeigt, zumindest Erwähnung findet, indem sie als „zehnjähriges Chaos“ beschrieben wird. Als Aufarbeitung des „historischen Fehlers“ kann man diese Darstellung jedoch keinesfalls betrachten. Das Foto befindet sich in dem Ausstellungsteil zur Geschichte Chinas nach 1949, in dem es auch einen kleinen Abschnitt gibt, in dem allgemein und vage auf Rückschläge im Prozess des sozialistischen Aufbaus eingegangen wird und in dem (theoretisch) Platz für eine Aufarbeitung der „historischen Fehler“ der Partei wäre. Der Abschnitt Die Erkundung des sozialistischen Aufbaus (shehui zhuyi zai tansuo zhong quzhe fazhan 社会主义建设在探索中曲折发展) wird entsprechend mit ein paar sehr allgemein gehaltenen Worten eingeleitet:

Nach der Einrichtung des sozialistischen Systems trat das neue China in jeder Hinsicht in eine Phase des sozialistischen Aufbaus ein. Die KPCh leitete das Volk aller chinesischer Ethnien auf den mühsamen Weg, die Gesetze der sozialistischen Entwicklung bis hin zum großen Ziel der „Vier Modernisierungen“ zu ergründen. Im Zuge der Gestaltung eines unabhängigen und umfassenden Industrie- und Wirtschaftssystems, welches das wichtige Fundament für das Material und die Technologie der sozialistischen Modernisierung legen würde, hat es seine Eigenständigkeit entdeckt und Schwierigkeiten überwunden. ${ }^{296}$

295 Das Chinesische Nationalmuseum 中国国家博物馆 2019.

296 Eigene Übersetzung. Original siehe Ausstellung Weg der Wiederbelebung. Das Chinesische Nationalmuseum 中国国家博物馆 2019. 
Die Ausstellung nimmt nur ein einziges Mal indirekt Bezug auf die Kampagne gegen Rechtsabweichler, indem lediglich ein Aspekt, der mit ihr in Zusammenhang steht, erwähnt wird, nämlich Maos berühmte Rede Über die richtige Behandlung der Widersprüche im Volk. Unter dem in einem Schaukasten ausgestellten gedruckten Exemplar der für das Volk überarbeiteten und veröffentlichten Fassung der Rede (siehe Abb. 8), findet sich eine kurze, ebenfalls sehr allgemein gehaltene Beschreibung:

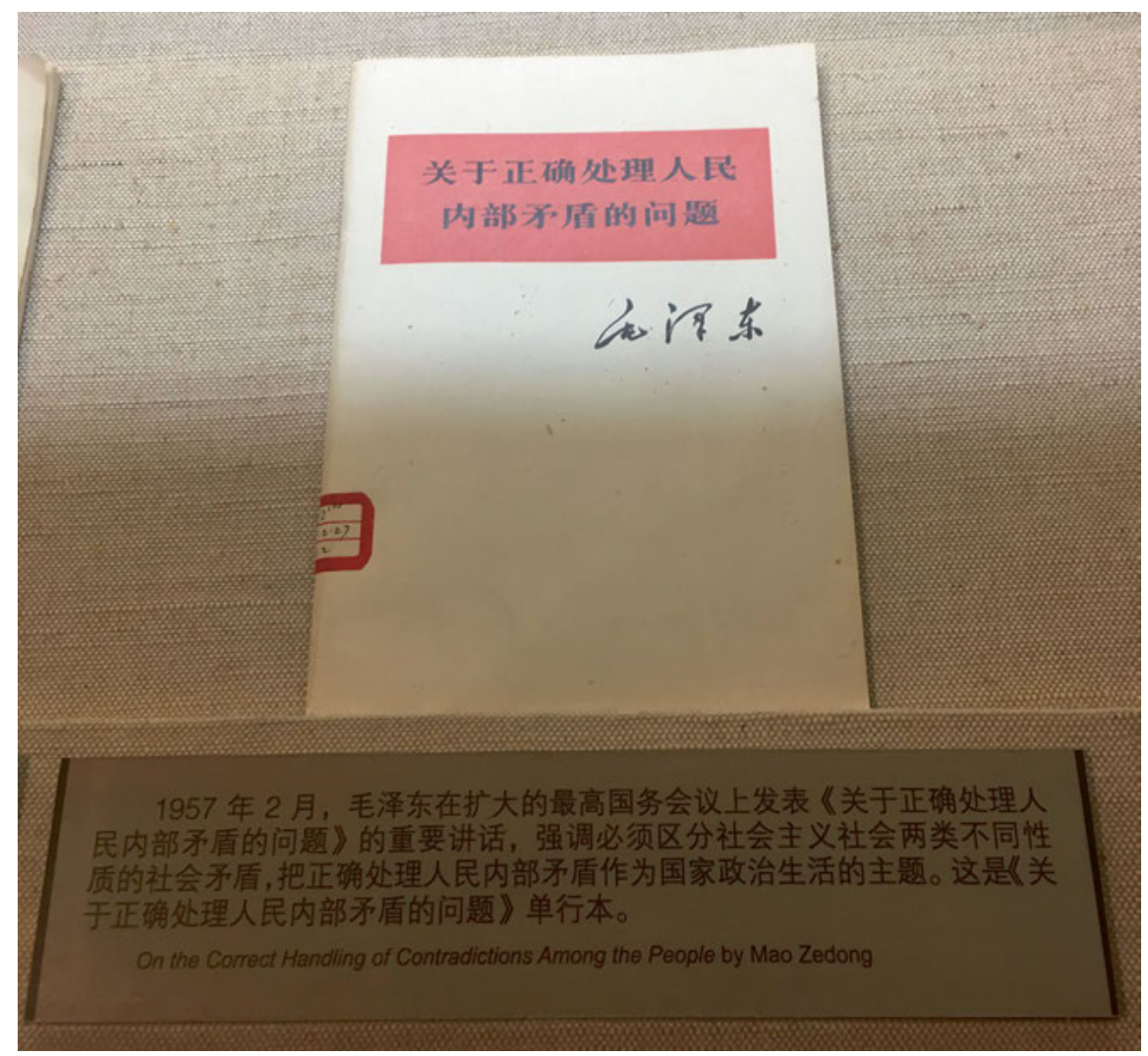

Abbildung 8: „Über die richtige Behandlung der Widersprüche im Volk“ (Das Chinesische Nationalmuseum, eigene Fotografie, November 2017)

Im Februar 1957 hielt Mao Zedong beim erweiterten Staatsrat die wichtige Rede „zum korrekten Umgang mit Widersprüchen im Volk“ und betonte die Notwendigkeit, im Sozialismus zwischen zwei unterschiedlichen Arten von sozialen Konflikten zu unterscheiden. Der korrekte Umgang mit den Widersprüchen der Menschen wurde zum zentralen Thema des po- 
litischen Lebens des Landes. „Zum korrekten Umgang von Widersprüchen im Volk“ ist ein einzelnes Buch. ${ }^{297}$

Darüber hinaus fand kein weiterer Aspekt, der auch nur entfernt mit der Kampagne gegen Rechtsabweichler in Zusammenhang steht, Einzug in die Ausstellung - das heißt, auch die Umerziehung durch Arbeit im Laogai-System oder die „Rehabilitierungen“ der sogenannten Rechtsabweichler werden nicht erwähnt. Insgesamt stehen in diesem Ausstellungsabschnitt - im Sinne der Stärkung des offiziellen Kanons - die Verdienste der Partei im Vordergrund. Dementsprechend werden die Erfolge der Partei während der Jahre 1957 und 1958 betont. Dargestellt wird hier anhand einer Fotografie, die die Eröffnung einer neuen Fabrik in Peking im Jahr 1956 zeigt, unter anderem, dass sich die Elektronikindustrie zwischen den Jahren 1956 bis 1965 rasant entwickelt habe und dass in jener Zeit der große Fortschritt von der Nachahmung von Elektroartikeln bis hin zur Selbstkonstruktion vollzogen worden sei. Außerdem geht die Ausstellung auf die Erfolge in der Entwicklung landwirtschaftlicher Maschinen ein, wie zum Beispiel des ersten chinesischen Traktors der Marke Dongfanghong 东方红, der im Juli 1958, also kurz nach Beginn der Kampagne gegen Rechtsabweichler, erstmals vom Band lief und einen wichtigen Stellenwert in der landwirtschaftlichen Produktion einnehmen sollte.

Das Chinesische Nationalmuseum nimmt einen sehr hohen Stellenwert im Kampf um das kollektive Gedächtnis ein, da es ein wichtiger Ort für die Darstellung der offiziellen Geschichtsschreibung ist und als Teil der nationalen Erinnerungskultur bzw. als Erinnerungsort dient. Durch die Ausstellung hat die Partei zudem eine Möglichkeit geschaffen, den staatlichen Kanon auf anschauliche Art und Weise ins kollektive Gedächtnis des Landes zu transportieren. Dem Besucher wird die Alternativlosigkeit der Führung Chinas durch die Kommunistische Partei wiederholt vor Augen geführt. Durch die gewählte Form der Darstellung der Vergangenheit liegt die Vermutung auf der Hand, dass sich die Partei erhofft, diese als einen legitimitätsfördernden Faktor einsetzen zu können. Die wichtigste Zielgruppe für eine nachhaltige Festigung des kollektiven Gedächtnisses nach staatlichem Gusto dürfte die Jugend Chinas sein. Meiner eigenen Beobachtung nach sind es vor allem Schülerinnen und Schüler, die den Großteil der Ausstellungsbesucher ausmachen. So konnte ich während meiner beiden letzten mehrtägigen Besuche des Nationalmuseums im November 2017 und im März 2019 beobachten, dass mehrere Schulklassen die Ausstellung als Teil des Geschichts-

297 Eigene Übersetzung. Original siehe Ausstellung Weg der Wiederbelebung. Das Chinesische Nationalmuseum 中国国家博物馆 2019. 
unterrichts besuchten und während ihres Gangs durch die Ausstellung dabei von der Lehrerin ausgeteilte Fragebögen bearbeiteten. Vertreten waren alle Altersklassen, von Grund- bis Mittelschülern (siehe Abb. 9 und 10). Damit zeigt sich, wie $\mathrm{Hu}$ Jintaos Aufforderung, dass die Erziehungsinstitutionen als Steuerelement fungieren sollen, auch gegenwärtig noch in die Praxis umgesetzt wird. Besucht man die Ausstellung hingegen am Wochenende, ist dieser Teil des Museums äußerst spärlich besucht, während sich in den Ausstellungsräumen zum Beispiel zum alten China (gudai Zhongguo 古代中国) ein sehr hoher Besucherandrang beobachten lässt. Die enorme Reichweite des staatlichen Kanons lässt sich auch anhand der Besucherzahl belegen, welche nach offiziellen Angaben im Jahr 2018 bei rund 8 Millionen gelegen haben soll. Dies bedeutet, wenn man den Zahlen Glauben schenken mag, dass täglich rund 30.800 Menschen das Museum besuchen. ${ }^{298}$ Welch hohe Bedeutung dieser Ausstellung fortan auch für die Inszenierung des Staatsapparates zukommen sollte, zeigte sich unter anderem am 29. November 2012, als Hu Jintaos Nachfolger Xi Jinping eben jene Ausstellung als Ort für die Vorstellung seiner politischen Idee des Chinesischen Traums (Zhongguo meng 中国梦) wählte. Während seiner Rede wies er außerdem darauf hin, welch hohen Stellenwert die Vergangenheit für die Gegenwart und für die Zukunft Chinas einnehmen würde. ${ }^{299}$ Ian Johnson sieht die Ausstellung als ein auffälliges Symbol für die Bemühungen der KPCh, die Kontrolle über das Narrativ ihrer eigenen Geschichte zu behalten und abweichende Meinungen zu unterdrücken. Für den Hongkonger Professor Hung Chang-tai gehe es der Partei mit der Inszenierung der Ausstellung nicht um ihre Vergangenheit, sondern einzig und allein darum, ihr gegenwärtiges Image zu verbessern. ${ }^{300}$

\section{Die „neue“ Geschichte der Kommunistischen Partei Chinas}

Der offizielle Umgang mit der eigenen Vergangenheit jener Jahre zeigt sich im Besonderen auch durch die ebenfalls im Jahr 2011 von der Zentralen Forschungsstelle für Parteigeschichte herausgegebene Geschichte der Kommunistischen Partei Chinas (Zhonggguo gongchandang lishi 中国共产党历史), die eine umfassende Bewertung der historischen Ereignisse zwischen den Jahren 1949 und 1978 und damit auch der „historischen Fehler“ der Partei darstellt. Dass die

298 China Daily 2019, http://www.chinadaily.com.cn/a/201903/05/WS5c7e72fea3106c65c34ecf Od.html.

299 Die Zentralregierung der Volksrepublik China 中华人民共和国央人民政府 2012, http:// www.gov.cn/ldhd/2012-11/29/content_2278733.htm.

300 Johnson 2011, https://www.nytimes.com/2011/04/04/world/asia/04museum.html?pagewan ted=all\&mtrref=undefined\&gwh=05 A01AD570DC0BC46EE35891F997D8DF\&gwt=pay. 


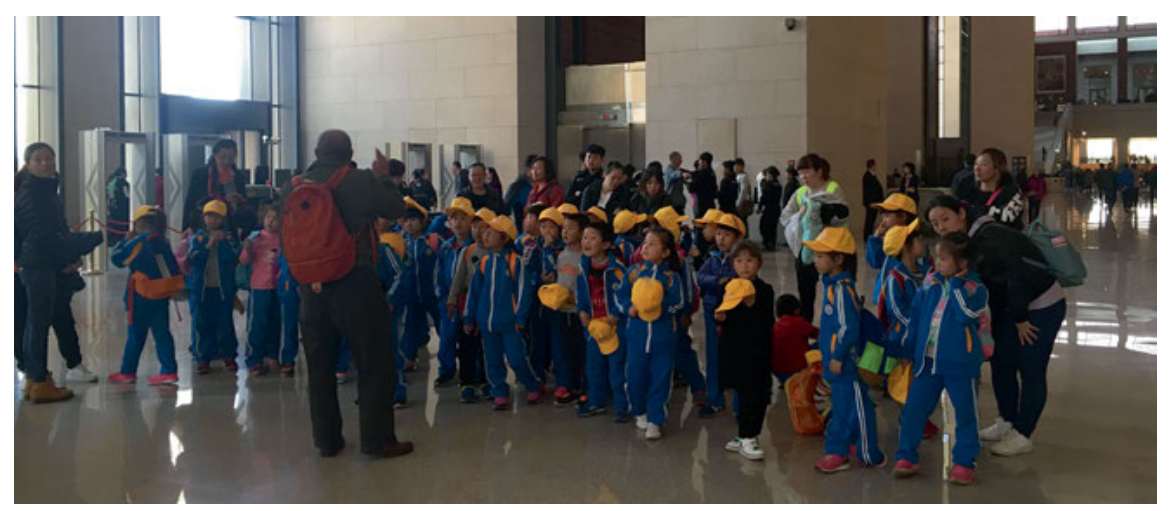

Abbildung 9: Schülerinnen und Schüler einer Pekinger Grundschule im Chinesischen Nationalmuseum (eigene Fotografie, November 2017)

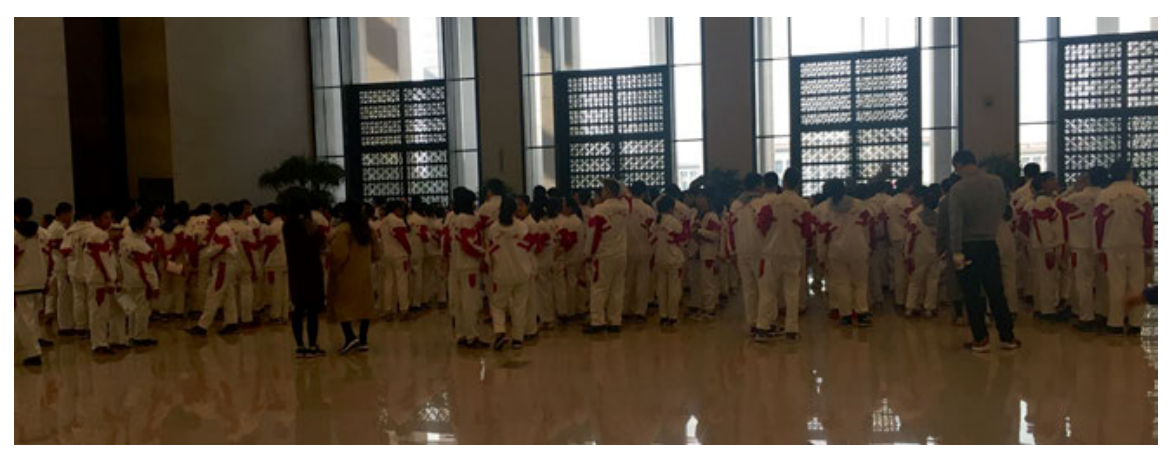

Abbildung 10: Schülerinnen und Schüler einer Pekinger Mittelschule im Chinesischen Nationalmuseum (eigene Fotografie, November 2017)

Veröffentlichung auf das 90. Jubiläum der Gründung der KPCh fiel, dürfte dabei kein Zufall gewesen sein. Im Buch, welches aus zwei Bänden und insgesamt 1.074 Seiten besteht, werden keine Einzelautoren angegeben, stattdessen wird es als Gemeinschaftswerk der Forschungsstelle ausgegeben. Man kann davon ausgehen, dass eine ganze Reihe von führenden Parteihistorikern in die Entstehung miteingebunden gewesen ist. Der Entstehungszeitraum umfasste insgesamt 16 Jahre - er erstreckte sich also sowohl über die Präsidentschaft Jiang Zemins als auch über die Hu Jintaos. Dabei musste das Buch insgesamt viermal intensiv umgeschrieben werden, bis es von den Behörden freigegeben wurde ${ }^{301}$ - dies zeigt

301 Renmin Ribao 人民日报 2011, http://en.people.cn/90001/90776/90785/7401558.html. 
noch einmal, wie schwierig es auch im gegenwärtigen China ist, einen Konsens über die offizielle Bewertung der Vergangenheit zu finden.

Für den an der Entstehung beteiligten Parteihistoriker Shi Zhongquan 石仲泉 war der schwierigste Teil des Buches nicht etwa der, der die zehn Jahre der Kulturrevolution behandelt, sondern der Abschnitt über die Berichtigungsbewegung der Partei und die Kampagne gegen Rechtsabweichler der Jahre 1957 und 1958. In einem Interview, das Shi im Jahr 2011 der Renmin Ribao gab, verwies er darauf, dass auch Xi Zhongxun, der Vater des damaligen Vize-Präsidenten Xi Jinpings und Nachfolgers Hu Jintaos, im Zuge des Kampfes gegen die Rechten öffentlich angegriffen worden sei. Obwohl er bereits nach 1976 offiziell rehabilitiert wurde, wird seine öffentliche Diffamierung in dem Buch erneut ausdrücklich als Fehler bezeichnet und so erfährt er posthum noch einmal auf einer anderen Ebene eine Rehabilitierung. ${ }^{302}$ Die Aussage des Parteihistorikers unterstreicht erneut den besonderen Stellenwert der Kampagne gegen Rechtsabweichler im offiziellen historischen Diskurs und damit auch für das kollektive Gedächtnis.

Im Zuge der Veröffentlichung im Jahr 2011 äußerte sich der Parteihistoriker und Professor der Zentralen Parteihochschule Yan Shuhan 严书翰 ebenfalls in der Renmin Ribao, indem er darauf hinwies, dass es zur richtigen Attitüde einer reifen Partei gehöre, weder das Erreichte in übertriebener Art und Weise zu glorifizieren, noch solle man in der Geschichtsschreibung die eigenen Misserfolge und Fehler leugnen. Und für den Parteihistoriker Feng Xianzhi 逢先知 stellt das Buch dementsprechend einen differenzierten Umgang mit den Fehlern der KPCh dar, indem es diese tiefgreifend analysiere, ohne die Partei dabei einer zu vereinfachten oder diffamierenden Kritik zu unterwerfen. ${ }^{303}$

Wie stellt sich nun der Umgang mit der Kampagne gegen Rechtsabweichler in dieser offiziellen Bewertung des Jahres 2011 tatsächlich dar? Insgesamt umfasst das Kapitel zur Berichtigungsbewegung und zur Kampagne gegen Rechtsabweichler (Quan dang zhengfeng he fanyoupai douzheng 全党整风和反右派斗争) 40 Seiten und ist in drei Abschnitte unterteilt. Der erste Abschnitt befasst sich mit Theorien zu Widersprüchen in der sozialistischen Gesellschaft und im zweiten Abschnitt folgt eine Analyse der berühmten Rede Maos Über die richtige Behandlung der Widersprüche im Volk und der daraus folgenden Maßnahme der Berichtigungsbewegung innerhalb der Partei. Der dritte Abschnitt thematisiert auf zwölf Seiten schließlich die Kampagne gegen Rechtsabweichler an sich, welcher Gegenstand der folgenden analytischen Betrachtung sein wird.

302 Higgins 2011, https://www.washingtonpost.com/world/in-china-a-long-path-of-writing-thecommunist-partys-history/2011/05/16/AGDfMECH_story.html?noredirect=on\&utm_term=.5932 89e7af46.

303 Renmin Ribao 人民日报 2011, http://en.people.cn/90001/90776/90785/7401558.html. 
Der Abschnitt zur Kampagne gegen Rechtsabweichler beginnt zunächst damit, den 08. Juni 1957 mit Erscheinen des Renmin Ribao-Artikels „Warum ist das so?", wie in der offiziellen als auch in der inoffiziellen Geschichtsschreibung gemeinhin anerkannt, als offiziellen Beginn der Kampagne zu deklarieren. Die Autoren räumen entsprechend des offiziellen Narrativs der 1981er Resolution ein, dass die Kampagne, auch wenn sie übertrieben worden sei, insgesamt notwendig gewesen sei. Bemerkenswert sind jedoch die Gründe, die die Autoren für die Übertreibungen heranziehen. Während in der offiziellen Mao-Biografie noch ausgeführt worden war, dass die Ausuferung der Kampagne auch in Zusammenhang mit einer gewissen Naivität Maos gestanden habe, wird dieser Aspekt hier komplett ausgelassen. Wiederholt wird hingegen betont, dass die Übertreibungen jener Jahre auch dem Umstand geschuldet gewesen seien, dass sich der Sozialismus in China noch im Aufbau befunden und sich auch der Klassenkampf noch auf seinem Höhepunkt befunden habe. ${ }^{304}$ Deshalb, so werden hier die Fehler jener Jahre erklärt, sei es für alle an der Umsetzung der Kampagne beteiligten Parteikader in dieser Phase äußerst schwierig gewesen, eine klare Unterscheidung zwischen Regimefeind und Kritiker vorzunehmen - die Ausführungen machen hier deutlich, dass es dem noch jungen System Ende der 1950er Jahre auf allen Ebenen an Erfahrung mangelte. ${ }^{305}$

Mangelnde Erfahrung wird durch die von den Autoren ausgewählten Quellen auch für die als Rechtsabweichler verurteilten als mildernder Umstand geltend gemacht - denn nicht nur der Staatsapparat und die Machthaber, auch das gesamte Volk habe sich in den 1950er Jahren noch unsicher im neuen System bewegt. Die Darstellungen des Buches suggerieren, dass dieser Umstand den damaligen Machthabern durchaus bewusst gewesen sei, und deshalb hätten sie auch Verständnis für die Reaktionen vieler Menschen gezeigt. Zhou Enlai soll sich hierzu bereits am 14. September 1957 entsprechend geäußert haben:

Es sollte darauf hingewiesen werden, dass es unausweichlich ist, dass in der Phase zwischen der Gründung des neuen China bis zur Vollendung der sozialistischen Transformation und der Verwirklichung solch tiefgreifender Veränderungen in der kurzen Zeitspanne von nur sieben Jahren unterschiedliche Reaktionen aller Klassen der Gesellschaft hervorgerufen werden. Die Menschen müssen diesen Prozess beobachten und immer wieder Anpassungen an diese Veränderungen vornehmen. Ob sie die Führung der Kommunistischen Partei Chinas und den sozialistischen Weg wollen, ist ein Prozess in den Köpfen der Menschen, der noch nicht vollständig abgeschlossen ist. ${ }^{306}$

304 Zentrale Forschungsstelle für Parteigeschichte 中共中央党史研究室 2011, S. 452.

305 Ebd., S. 456.

306 Eigene Übersetzung. Original siehe ebd., 459-460. 
Dies ist insofern bemerkenswert, als dass diese Darstellung von dem in der Resolution formulierten Narrativ abweicht, dass die KPCh im Jahr 1949 auf einer Welle der Begeisterung vom gesamten chinesischen Volk („Das chinesische Volk war aufgestanden!“) zum Sieg im Bürgerkrieg gegen Chiang Kai-sheks Guomindang 国民党 getragen worden und dass nahezu das gesamte Volk von den Ideen der KPCh überzeigt gewesen sei. ${ }^{307}$

Deutlich betont wird in diesem Kapitel der Zusammenhalt der höchsten Parteiebene in der Entscheidungsfindung um die Durchführung der Kampagne: Mao Zedong selbst wird dabei zwar als treibende Kraft, jedoch nicht als alleiniger Entscheidungsträger porträtiert. So wird ausdrücklich dargelegt, dass das Zentralkomitee am 26. Juni 1957 einstimmig und ohne Dissens im Rahmen des Nationalen Volkskongresses für die herausgegebene Direktive zur Bekämpfung und Isolation der bourgeoisen Rechten (Guanyu daji guli zichan jieji youpai fenzi de zhishi 矢于打击孤立资产阶级右派分子的指示) gestimmt habe. Etwaige Debatten und Uneinigkeiten während des Volkskongresses um die Durchführung der Kampagne werden nicht erwähnt. Unterstrichen wird der Zusammenhalt der damaligen Führungsriege zudem, indem die Autoren darlegen, dass die Kampagne in jenen Tagen auch durch den im Volk stets beliebten damaligen Premierminister Zhou Enlai unterstützt worden sei. In seiner Rede während des Volkskongresses soll er betont haben, dass der Aufbau des Sozialismus sich zwar auf einem guten Wege befinde, die bourgeoisen Rechten diesen Aufbau seiner Einschätzung nach jedoch zu unterwandern drohten: „Die Rechten wollen unser Land substantiell vom Weg des Sozialismus auf den Weg des Kapitalismus ziehen.“308

Deng Xiaopings zentrale Rolle in der Planung und Durchführung der Kampagne wird von den Autoren nahezu komplett negiert, auch wenn er, wie sie darlegen, als Teil des Kollektivs und wichtiger Vertreter des Führungszirkels alle Entscheidungen mitgetragen habe. In diesem Zusammenhang verweisen die Autoren auf seinen Bericht zur Berichtigungsbewegung und zur Kampagne gegen Rechtsabweichler, welchen er im Zuge des 3. Plenums des 8. Zentralkomitees (20. September - 09. Oktober 1957 in Peking) vorgetragen hat. Dabei soll er sich klar für den eingeschlagenen Weg des Kampfes gegen die Rechtsabweichler eingesetzt haben:

307 Siehe Resolution über einige Fragen zur Geschichte der KP Chinas seit 1949 1981, S. 9 ff. 308 Eigene Übersetzung. Original siehe Zentrale Forschungsstelle für Parteigeschichte 中共中央 党史研究室 2011, S. 451. 
Wenn wir in dieser Debatte keinen vollständigen Sieg davontragen können, können wir den Weg nicht weitergehen. Nur wenn wir diese Debatte gewinnen, wird dies die sozialistische Transformation und den sozialistischen Aufbau unseres Landes bedeutend voranbringen. ${ }^{309}$

Andererseits wird die Darstellung seines Einsatzes für die Kampagne durch die Autoren jedoch dadurch abgemildert, dass sie ihm anhand der von ihnen verwendeten Quellen auch die Rolle des Mahners zuschreiben, der bereits während des Plenums vor einer übertriebenen Durchführung des Kampfes gewarnt haben soll:

Der Kampf gegen die Rechten sollte bis zum Ende geführt werden. Es ist notwendig, sich weiterhin den rechten Emotionen zu widersetzen, jedoch ist es nun auch notwendig, der Gefahr der exzessiven und einfachen Grobheit vorzubeugen. Es ist notwendig, eine strikte Differenzierung zwischen den extremen Rechtsabweichlern, den Rechtsabweichlern und den gemäßigten Rechtsabweichlern vorzunehmen und dabei genau die Kategorisierung der einzelnen Einheiten $\mathrm{zu}$ beachten und diese, wenn notwendig, stetig anzupassen. ${ }^{310}$

Die Autoren lassen in ihrer Einschätzung zur historischen Rolle Deng Xiaopings seine Schlüsselposition in der Umsetzung der politischen Entscheidungen der Jahre 1957 und 1958 insgesamt weitgehend unerwähnt. Berücksichtigt werden sollte hier, wie wichtig das Erbe Deng Xiaopings auch für die Stabilität der Macht $\mathrm{Hu}$ Jintaos gewesen ist, denn so ging auch er den einst von Deng beschrittenen Pfad der auf Wirtschaftswachstum ausgerichteten Politik konsequent weiter. Auch durch die wiederholte Betonung des Zusammenhalts der KPCh jener Jahre, die Fokussierung auf das Kollektiv, ebenso wie durch das durch die Autoren transportierte Verständnis für die Fehltritte sowohl der Partei als auch des Volkes, kann man im Umgang mit der Kampagne gegen Rechtsabweichler den scheinbar angestrebten Nutzen der Vergangenheit für die Gegenwart herauslesen.

$\mathrm{Hu}$ Jintao wollte den Herausforderungen der zunehmenden Spaltung der Gesellschaft entgegentreten und den gesamtgesellschaftlichen Zusammenhalt sowie die Bindung zwischen Volk und Partei stärken. Auch wenn sich die Herausforderungen der schwindenden Legitimität der Partei im Volk, ausgelöst u.a. durch die zunehmend sichtbar werdende Korruption, aber auch durch ein zunehmendes Auseinanderdriften verschiedener Flügel innerhalb der Partei, allein durch die Geschichtsschreibung nicht lösen lässt, ist es für die Legitimität der KPCh dennoch von größtem Vorteil, positive Bilder und Narrative ins Volk zu

309 Eigene Übersetzung. Original siehe ebd., S. 455.

310 Eigene Übersetzung. Original siehe ebd., S. 455. 
transportieren. ${ }^{311}$ Deshalb spiegelt sich $\mathrm{Hu}$ Jintaos politische Agenda also durchaus auch in der offiziellen Geschichtsschreibung jener Jahre wider - Zusammenhalt ist gleichermaßen auch ein Zeichen für Stabilität, welche für die KPCh zu Beginn der 2000er Jahre erneut ins Wanken geriet. Ähnlich wie in der Mao-Biografie, steht die Kanonisierung des Zusammenhalts dabei teilweise jedoch in einem klaren Widerspruch zu anderen (inoffiziellen) Quellen, die darlegen, dass die Parteiführung in ihren Entscheidungsfindungen während der Jahre 1956 bis 1958 keineswegs an einem Strang gezogen hat - tatsächlich war diese Phase eher geprägt von intensiven Debatten und einem fast unlösbar erscheinenden Dissens, wobei sich Mao letztlich durchsetzen konnte. ${ }^{312}$

Der letzte Teil des Kapitels zur Kampagne gegen Rechtsabweichler befasst sich schließlich mit den Konsequenzen der Kampagne - sowohl für das ganze Land als auch für die Opfer an sich. Zunächst erfährt sie jedoch noch einmal eine Rechtfertigung, was eine der wenigen analytischen Einschätzungen der Autoren selbst darstellt:

Die Fakten zeigen, dass die feindseligen Kräfte, die sich gegen das sozialistische System und gegen die Parteiführung richteten, tatsächlich vorhanden waren. Es war richtig und notwendig, entschlossen gegen die grassierenden Angriffe durch eine sehr kleine Anzahl von Rechtsabweichlern zu kämpfen, es war korrekt und notwendig, die breite Masse der Parteimitglieder und des Volkes zu erziehen. Der Kampf gegen die Rechten hat die Grundlagen für die Menschen in der Mitte der Gesellschaft gelegt und das neu etablierte sozialistische System stabilisiert. Hätten wir diese Art von Kampf aufgegeben und die Angriffe einer sehr kleinen Zahl von Rechten nicht eindeutig abgewehrt, hätte dies zu ernsthaften Wirrungen in den Gedanken und in der Politik geführt. In dieser Hinsicht ist die Erfahrung der Partei von langfristiger Wirkung. Dennoch wurde aufgrund der Übertreibungen in der Einschätzung der Lage der Klassenkämpfe und der Angriffe der Rechten durch die Partei sowie des Einsatzes der strategischen politischen Mobilisierung der Massen in der revolutionären Periode die Entwicklung des Kampfes nicht sorgfältig genug kontrolliert. Der Kampf gegen die Rechten wurde stark übertrieben. ${ }^{313}$

Die Kampagne gegen Rechtsabweichler wird auch in diesem Buch, entsprechend der Resolution von 1981, eindeutig nicht als „historischer Fehler“ anerkannt. Dennoch gehen die Autoren auf Fehler ein, die während der Kampagne gemacht

$311 \mathrm{Zu}$ den unterschiedlichen Fraktionen der Partei jener Jahre, welche insbesondere im Zuge des Machtübergangs von Hu Jintao zu Xi Jinping deutlich zu Tage getreten sind, siehe Li 2016, S. $77 \mathrm{ff}$.

312 Zum Dissens der Parteispitze um die politischen Entscheidungsfindungen zwischen 1956 und 1958 siehe Zhu 2013.

313 Eigene Übersetzung. Original siehe Zentrale Forschungsstelle für Parteigeschichte 中共中央 党史研究室 2011, S. 455f. 
worden sind. Auch wenn dies ein wenig über die Resolution hinausgeht, fordern sie diese dennoch nicht in Gänze heraus. Recht deutlich gehen die Autoren zum Beispiel auf die Folgen der falschen Verurteilungen von Rechtsabweichlern für sie selbst, aber auch für den Staat respektive für den sozialistischen Aufbau ein:

Viele Freunde, die schon seit langem mit der Partei zusammengearbeitet hatten, viele talentierte Intellektuelle, eine Vielzahl von politisch enthusiastischen und unreifen jungen Menschen, wie auch eine Reihe von loyalen Genossen, die fälschlicherweise als Rechtsabweichler eingestuft wurden und deshalb eine lange falsche Behandlung und viel Elend ertragen mussten, konnten für den sozialistischen Aufbau nicht eingesetzte werden. Dies war nicht nur eine Tragödie für sie und ihre Familien selbst, sondern auch für das gesamte Land und die Partei. Die übertriebene Ausweitung des Kampfes gegen die Rechten hat die Partei zurückgeworfen am Anfang des Weges der Errichtung eines auf China zugeschnittenen sozialistischen Pfades. Hinsichtlich des Parteiaufbaus hatte dies negative Auswirkungen auf die gesamte Partei, was Mao Zedongs subjektiven Wunsch, durch die Berichtigungsbewegung eine lebhafte politische Situation zu kreieren, widersprach. Bezüglich der Wirtschaft wurden einige nützliche Erkenntnisse der landwirtschaftlichen Genossenschaften, die für die Produktion im ländlichen Raum geeignet sind, während des Kampfes gegen die Rechten kritisiert; neue Ideen für die Wiedereinführung einer Privatwirtschaft wurden ebenfalls aufgegeben und die Kritik richtete sich auch an die als reaktionär angesehene Geschwindigkeit der wirtschaftlichen Entwicklung. Bezüglich der politischen Ideologie und des kulturellen Lebens wurde der Aufbau der sozialistischen Demokratie und des Rechtssystems, die Umsetzung der Idee „Lasst hundert Blumen blühen, lasst hundert Schulen miteinander wetteifern“ und die beiden Leitlinien „langfristiges Zusammenleben und gegenseitige Kontrolle" sehr stark beeinträchtigt. ${ }^{314}$

Trotz der recht ausführlichen Aufzählung der Fehler kommen die Autoren dennoch zu dem Ergebnis, dass, obwohl in einem gewissen Maße jene Fehler gemacht worden, diese jedoch insgesamt wichtig für die zukünftige Entwicklung der Partei gewesen seien, da sie einen wichtigen Lerneffekt darstellten. ${ }^{315}$

Zusammenfassend lässt sich feststellen, dass die Kampagne gegen Rechtsabweichler auch in dieser offiziellen Veröffentlichung keiner Neubewertung unterzogen wurde, das heißt, der gesteckte Rahmen der Resolution von 1981 wurde auch hier nicht verlassen. Im Vergleich zur Mao-Biografie wird die kollektive Entscheidungsfindung des gesamten Führungszirkels in den Jahren 1957 und 1958 noch stärker betont. Ähnlichkeiten zwischen diesen beiden wichtigen Veröffentlichungen der offiziellen Geschichtsschreibung lassen sich auch bezüglich des Shu er bu lun-Ansatzes feststellen. Zwar lässt sich hier bei weitem nicht eine solche Vielzahl von Aneinanderreihungen von direkten Zitaten aus Parteidoku-

314 Eigene Übersetzung. Original siehe ebd., S. $460 \mathrm{f}$.

315 Ebd., S. 462. 
menten finden - die Quellen werden eher in zusammenfassender Form wiedergegeben -, dennoch werden auch hier zumeist nur die Fakten dargelegt, erkennbare Argumente und Analysen der Autoren findet man hingegen nur selten. Das offizielle Narrativ wird auch hier eher durch die Auswahl der Quellen geformt als durch die analytische Betrachtung der Parteihistoriker.

Zweifelsohne handelt es sich dennoch um eines der wichtigsten Dokumente der Parteigeschichte der 2000er Jahre, nicht zuletzt deswegen, weil es eine entscheidende Rolle im Kampf um das kollektive Gedächtnis spielt. Es ist kurz nach seiner Veröffentlichung zu einem Standardwerk geworden, welches vor allem im Unterricht an Universitäten eingesetzte wird - es hat also einen besonderen und direkten Einfluss auf das Geschichtsbild von Millionen junger Chinesinnen und Chinesen. Allein durch die Verkaufszahl hat es einen enormen Einfluss auf das kollektive Gedächtnis - laut offiziellen Angaben sind allein während der ersten vier Monate der Veröffentlichung 1.000.000 Exemplare verkauft worden. ${ }^{316}$

Im Zuge der Veröffentlichung im Jahr 2011 ist jedoch auch Kritik durch chinesische Historiker aufgekommen. Yang Kuisong 杨奎松 gab gegenüber der Washington Post zu Protokoll, dass er sich für das Buch nicht interessiere, da es sich dabei nur um Politik und Propaganda handele. ${ }^{317}$ Der berühmte Professor der Peking-Universität dient damit nicht nur als Beispiel dafür, dass es innerhalb Chinas durchaus einen Dissens über die offizielle Geschichtsschreibung gibt, sondern auch dafür, dass Kritik teilweise sogar aus staatlichen Institutionen heraus vorgetragen wird, was die wichtigste Universität des Landes zweifelsohne ist.

\section{Der Wind beginnt sich zu drehen}

Neben der Förderung des offiziellen Kanons gab es während der Präsidentschaft $\mathrm{Hu}$ Jintaos, wie oben bereits erwähnt, auch Phasen, in der der Staatsapparat die Maßnahmen der Zensur verschärfte. Insgesamt nahm der Druck auf die Intellektuellen, die von den offiziellen Vorgaben zur Darstellung der Vergangenheit zu stark abwichen oder aber unerwünschte gegenwärtige Diskurse, z. B. um Themen wie Menschenrechte oder Demokratie, in die Öffentlichkeit trugen, im Laufe der Präsidentschaft $\mathrm{Hu}$ Jintaos sukzessive zu.

$\mathrm{Hu}$ Ping 胡本, ein bedeutender Intellektueller des post-maoistischen Chinas, auf dessen Rolle im Kampf um das kollektive Gedächtnis insbesondere in Kapitel 5

316 Renmin Ribao 人民日报 2011, http://en.people.cn/90001/90776/90785/7401558.html.

317 Higgins 2011, https://www.washingtonpost.com/world/in-china-a-long-path-of-writing-thecommunist-partys-history/2011/05/16/AGDfMECH_story.html? noredirect=on\&utm_term $=.5932$ 89e7af46. 
noch genauer eingegangen wird, gab während eines Runden Tischs der ChinaKommission des US-Kongresses zum Thema „Öffentliche Intellektuelle in China“ am 10. März 2005 zu Protokoll, dass intellektuelle Freiheiten in China, seiner Einschätzung nach, bereits kurz nach dem Amtsantritt $\mathrm{Hu}$ Jintaos dramatisch eingeschränkt worden seien, auch wenn es oberflächlich betrachtet zunächst anders ausgesehen haben mag. In seinem Redebeitrag begründet er dies damit, dass die Partei zum Schein absichtlich eine Atmosphäre der Lockerung geschaffen habe, um einen besseren Überblick über die Situation zu erhalten. Er wies außerdem darauf hin, dass es keine einheitlichen Regeln gebe, was gesagt werden kann und was nicht. Dies hätte, so Hu, eine Ungleichbehandlung der in der Öffentlichkeit agierenden Intellektuellen zur Folge, die sich nur schwer durchschauen lasse - einige würden verschont, wohingegen andere hart sanktioniert würden. In seinen Ausführungen zum gegenwärtigen Vorgehen der Partei zog er sogar Parallelen zur Kampagne gegen Rechtsabweichler:

Yes, on the surface it seems that the intelligentsia are very active in today's China. On the Internet, even in the official media, discussion [sic] certain public issues is quite open and even quite lively. Some dissidents express themselves without fear, and nothing happens, they sit at home, quite well. But what I must bring to your attention is the principle being implemented by authorities in China today, that principle is "all people are not equal before the law". When the authorities handle issues related to expression and speech, there is no single standard measure used. The standards vary by person, by time, and by place. When the authorities oppress the intellectuals, they often consider a multitude of factors, such as; do you have any position within the establishment? Are you known internationally? What's your social network of "connections" like? And so on. We cannot draw the conclusion based solely from the situation of a few well-known dissidents that freedom of speech in China has expanded greatly. Again, we cannot forget that the means the Chinese Communists use to squash freedom of speech have taken on many forms over the years. For example, during the Anti-Rightist movement only a handful of the over 500,000 Rightists were actually imprisoned and sentenced, some Rightists were fired from their jobs and sent to the countryside to do manual labor. Some were demoted, had their salaries cut, or were forced to move to other posts. Some Rightists were permitted to show their faces in the official media to say a word or two. The situation today is the same. ${ }^{318}$

Die Zunahme des staatlichen Drucks auf die intellektuellen Freiheiten betraf auch den Umgang mit der Kampagne gegen Rechtsabweichler, deren Beginn sich im Jahr 2007 zum 50. Mal jährte. Wenig überraschend gab es keine Erwähnung der Opfer oder Worte des Gedenkens der Partei anlässlich des runden Jahrestags dieses finsteren Kapitels der chinesischen Geschichte. Doch der Staatsapparat

318 U.S. Government Publishing Office 2005, https://www.govinfo.gov/content/pkg/CHRG109hhrg20180/html/CHRG-109hhrg20180.htm. 
ging noch weiter und versuchte, möglichst alle Stimmen, die über diesen „historischen Fehler“ öffentlich sprechen wollten, zum Schweigen zu bringen. Anlässlich des Jahrestags hatten sich rund 1.500 Opfer und ihre Angehörigen zusammengeschlossen und eine Petition an das Zentralkomitee der KPCh gerichtet, in der sie forderten, dass sich die Partei öffentlich zu den Fehlern der Jahre 1957 und 1958 bekennen und den Opfern darüber hinaus eine angemessene Kompensation zahlen solle. Die Partei ging, wenig überraschend, nicht auf diese Forderungen ein und reagierte, indem sie die Veröffentlichung von Memoiren von Zeitzeugen untersagte und $\mathrm{zu}$ diesem Zeitpunkt auch eine Reihe anderer Werke, die „historische Fehler“ der Partei zum Thema hatten, auf die schwarze Liste setzte. ${ }^{319}$

Rund einen Monat nach dem 50. Jahrestag des Beginns der Kampagne hielt $\mathrm{Hu}$ Jintao eine Rede, in der er über die historische Leistung Mao Zedongs sprach. In dieser erwähnte er zwar, dass Mao durchaus auch Fehler gemacht habe, vor allem aber betonte er demonstrativ, dass seine Leistungen für das Land und die Partei insgesamt deutlich überwiegen:

It is true that Mao Zedong made gross mistakes in his later years, but when his life is judged as a whole, his indisputable contributions to the Chinese revolution far outweigh his mistakes, and his merits are primary and his errors secondary. He is still held in great respect by the Chinese people. The CPC gave an all-round evaluation of all his revolutionary activities and thought in a resolution adopted by its Central Committee five years after his death. Mao Zedong Thought, the development of Marxism in China, is still the guiding ideology of the CPC. ${ }^{320}$

Damit unterstrich Hu unmissverständlich, dass der grobe Rahmen der Resolution von 1981 nach wie vor Gültigkeit besaß und zu starke Abweichungen von der Partei nicht toleriert werden würden - insbesondere dann, wenn ihre eigene Herrschaftslegitimation in Frage gestellt wird. Berücksichtigt werden sollte auch, dass die Olympischen Spiele ihre Schatten voraus warfen, die im Sommer 2008 in Peking ausgetragen werden würden. Die Partei hatte in dieser Phase sicherlich kein Interesse daran, dass das öffentliche Bild des chinesischen Staates, ausgelöst durch eine öffentliche Debatte über die „historischen Fehler“ der Partei, vor diesem Großereignis Schaden nimmt. Angesichts der Tatsache, dass der Großteil der Rechtsabweichler rund 20 Jahre zur Umerziehung durch Arbeit im LaogaiSystem verbracht hatte, hätte dies inner- und außerhalb Chinas möglicherweise

319 Asia Sentinel 2007, https://www.asiasentinel.com/politics/righting-maos-wrongs/. $320 \mathrm{Hu}$ 2007, http://www.chinadaily.com.cn/china/2007-07/10/content_5424810.htm. 
auch Debatten über das System der Zwangsarbeit nach sich ziehen können, welches auch im Jahr 2008, wenn auch in etwas veränderter Form, noch existierte.

$\mathrm{Zu}$ einer Verschärfung der Zensur bzw. zu einer strikteren Kontrolle der Medien und des Internets kam es insbesondere nach den Unruhen in Tibet im März 2008, bei der die Demonstranten die Rückkehr des Dalai Lama aus dem Exil sowie die Unabhängigkeit Tibets forderten. Die zunächst friedlichen Demonstrationen gingen nach einigen Tagen in gewaltsame Unruhen über, in die sowohl die tibetische Seite, aber vor allem auch der chinesische Staatsapparat involviert war. ${ }^{321}$ Dies zog insbesondere in den westlichen Medien einen sehr chinakritischen Diskurs nach sich - sogar ein Olympiaboykott wurde in einigen Ländern diskutiert. Diese Diskurse sollten so wenig wie möglich bei der chinesischen Zivilbevölkerung ankommen. Während der Olympischen Spiele selbst wurden die Zensurmaßnahmen vorrübergehend wieder gelockert, wohl auch, um den westlichen Besuchern und Journalisten nicht noch mehr Angriffsfläche zu bieten. ${ }^{322}$

Insgesamt hat sich $\mathrm{Hu}$ Jintao das Bild der Ikone Mao für seine eigene Präsidentschaft kaum zunutze gemacht, das heißt, er verknüpfte seinen eigenen Machtanspruch etwas weniger mit dem Bild Maos als sein Vorgänger Jiang Zemin während der letzten Phase seiner Präsidentschaft. Das heißt allerdings nicht, dass die Leistungen Mao Zedongs aktiv negiert worden und die „historischen Fehler“ der Partei Freiwild für die Historiker gewesen wären, die außerhalb des offiziellen Bereichs agierten. Der Schutz der offiziellen Narrative nahm auch unter $\mathrm{Hu}$ grundsätzlich einen wichtigen Stellenwert ein.

Ebenso lässt sich feststellen, dass sich auch in den Jahren 2003 bis 2013 eine starke Förderung des offiziellen Kanons durch die Partei im Sinne der Stärkung ihrer Herrschaftslegitimation erkennen lässt - nicht zuletzt durch die Neueröffnung der Ausstellung Der Weg der Wiederbelebung im Chinesischen Nationalmuseum und der Veröffentlichung der Geschichte der Kommunistischen Partei durch das Zentrale Forschungsbüro für Parteigeschichte. Die Förderung des offiziellen Kanons stützte sich auch hier auf die Errungenschaften der gesamten Partei. Eine umfassende Neubewertung der Kampagne gegen Rechtsabweichler im Besonderen und der „historischen Fehler“ der Partei im Allgemeinen, fand auch in dieser Phase nicht statt, auch wenn gewisse Räume für Kritik an der Kampagne, die die Resolution offengelassen hat, in dem von der Zentralen Forschungsstelle für Parteigeschichte herausgegebenen Buch genutzt worden sind.

$321 \mathrm{Zu}$ den Ursachen und zum Verlauf der Unruhen in Tibet im März 2008 siehe Smith 2010. 322 Zum Chinabild und zur Berichterstattung westlicher Medien vor und während der Olympischen Spiele 2008 siehe Becker 2011. 
Die akademische Welt schien, trotz der Intensivierungen der Repressionen von Intellektuellen oder der immer wieder aufkommenden Verschärfung von Zensurmaßnahmen, zunächst weitgehend verschont $\mathrm{zu}$ bleiben. Natürlich bewegten sich auch die Historiker, die sich mit sensiblen Themen wie der Kampagne gegen Rechtsabweichler beschäftigten, innerhalb gewisser Grenzen, welche im post-maoistischen China mal enger und mal weiter waren. Dennoch genossen sie in dieser Phase - gemessen an den politischen Umständen - relativ große Freiheiten. Der Zugang zu Archiven war sowohl für chinesische als auch für westliche Wissenschaftler grundsätzlich - mit gewissen Einschränkungen - möglich. Wie in Kapitel 5 dargelegt, ermöglichte dies wiederum auch in den zehn Jahren unter der Führung $\mathrm{Hu}$ Jintaos und Wen Jiabaos, die Weiterentwicklung und Verbreitung einer alternativen Gesichtsschreibung innerhalb der VR China, die zwar in Konkurrenz zu den offiziellen Narrativen stand, aber dennoch von staatlicher Seite toleriert werden konnte.

Dies sollte sich jedoch im Laufe des zweiten Jahrzehnts des 20. Jahrhunderts radikal ändern. Erste Schatten warf bereits das 6. Plenum des 17. Zentralkomitees voraus, welches am 18. Oktober 2011 eine Reform des Kultursystems (wenhua tizhi gaige 文化体制改革) verabschiedete. Dieser Beschluss sah eine kulturelle Umstrukturierung zur intensiveren Förderung des Sozialismus chinesischer Prägung vor. Dadurch sollte auch der Marxismus in der Bevölkerung wieder populärer werden, vor allem in der jungen Generation. Außerdem sah die Reform eine verstärkte Förderung des Patriotismus vor. Für die konkrete Umsetzung wurde nun vor allem die akademische Welt in die Pflicht genommen, wobei die Geisteswissenschaften die wichtigste Rolle einnehmen sollten. Weiterhin besagt der Beschluss, dass auch die Medien in einem noch stärkeren Maße eine Schlüsselposition für die Steuerung der öffentlichen Meinung haben müssten. Die Möglichkeit der breiten Streuung dieser Maßnahmen durch die Medien sollte der „Förderung der sozialen Harmonie“ (cuijin shehui hexie 促进社会和谐) dienen, wie es im Beschluss wortwörtlich heißt. Zur Unterstützung dieser neuen ideologischen Offensive sah der Beschluss weiterhin vor, noch stärker als zuvor auf Maßnahmen zur Zensur des Internets zurückzugreifen. ${ }^{323}$ Und somit wurden gegen Ende der Präsidentschaft Hus erste Grundlagen für eine starke Intensivierung des Drucks auf die Geschichtswissenschaften gelegt.

Im Zuge des XVIII. Parteitags der KPCh, der den Machtübergang formal besiegelte, blickte Hu Jintao am 09. November 2012 in seinem Bericht auf seine

323 Die Zentralregierung der Volksrepublik China 中华人民共和国央人民政府 2011, http://www. gov.cn/jrzg/2011-10/25/content_1978202.htm. 
vergangene Amtszeit zurück. Dabei gab er auch einen Ausblick auf den zukünftigen politischen Umgang mit der ideologischen Bildung:

\begin{abstract}
Der Glauben der Kommunisten an den Marxismus, den Sozialismus und den Kommunismus ist ihre politische Seele und ihre geistige Säule, um jeder Prüfung standzuhalten. Wir sollten der Entwicklung der Parteitheorie oberste Priorität einräumen, da diese entscheidend ist für den Aufbau der Partei. Wir sollten dem Marxismus-Leninismus, die Mao-Zedong-Ideen, das System der Theorien des Sozialismus chinesischer Prägung und die Idee der wissenschaftlichen Entwicklung gründlich studieren und praktizieren. Wir sollten eine lernende Parteiorganisation aufbauen, Parteimitglieder und Parteikader in unserem gemeinsamen Ideal des Sozialismus chinesischer Prägung ausbilden und sie dazu ermutigen, diesem unermüdlich zu folgen. Wir sollten die Ausbildung im Sinne des Kerns des Parteigeistes intensivieren, die Parteigeschichte studieren und umfangreiche Lehren aus den Lektionen der beiden Parteiresolutionen zu gewissen Fragen in der Geschichte ziehen. Wir sollten die guten Traditionen und den Stil der Partei vorantreiben und die Parteimitglieder und Kader erziehen und anleiten, eine korrekte Weltanschauung, eine korrekte Einstellung zu Macht und Karriere zu etablieren und Engagement zu entwickeln; sie sollten in die Lage versetzte werden, bei bedeutenden Themen richtig und falsch zu unterscheiden. ${ }^{324}$
\end{abstract}

Diese Worte waren gewissenmaßen ein dezenter Vorgeschmack auf die Geschichtspolitik seines Nachfolgers Xi Jinping und die massive Zunahme des Drucks auf Intellektuelle der kommenden Jahre.

\title{
4.5 Xi Jinpings Kampf gegen den historischen Nihilismus
}

Der Kampf um die Deutungshoheit der Geschichte steht seit dem Amtsantritt Xi Jinpings sichtbar unter dem Motto „Kampf gegen den historischen Nihilismus“ (lishi xuwu zhuyi 历史虚无主义), welcher schon vor seiner Präsidentschaft seine Schatten voraus warf, auch wenn man nicht ahnen konnte, dass dies eine Zäsur für die alternative Geschichtsschreibung inner- und außerhalb Chinas bedeuten würde. Gemeint ist damit ein stark verschärftes Vorgehen gegen Narrative, die dem Ansehen der Partei schaden, was insbesondere die „historischen Fehler“ der Partei wie die Kampagne gegen Rechtsabweichler betrifft. Andererseits schließt er jedoch auch eine Förderung des gewünschten Kanons und eine intensive ideologische Bildung des Volkes, insbesondere aber der Jugend, mit ein. Der Kampf gegen den historischen Nihilismus besteht also aus zwei Seiten einer Medaille. Seit dem Jahr 2013 lässt sich somit auch eine deutliche Zuspitzung des Kampfes um das kollektive Gedächtnis beobachten.

324 Eigene Übersetzung. Original siehe Hu 2012, http://cpc.people.com.cn/n/2012/1118/c6409419612151-12.html. 


\section{Vorbereitungen zum Kampf gegen den historischen Nihilismus}

Erste Grundlagen für die Veränderungen im Umgang mit der eigenen Geschichte sind bereits während der Präsidentschaft $\mathrm{Hu}$ Jintaos ab 2010 und damit noch vor der Reform des Kultursystems im Oktober 2011 von Xi Jinping, damals Vizepräsident, höchstpersönlich gelegt worden. Am 21. Juli 2010 hielt er eine wegweisende Eröffnungsrede auf der Arbeitskonferenz zur Geschichte der KPCh (quanguo dang shi gongzuo huiyi 全国党史工作会议), welche an der Zentralen Parteihochschule abgehalten wurde. In dieser betonte er, dass es von äußerster Wichtigkeit sei, dass sich die gesamte Partei geschlossen gegen die falschen Tendenzen, die Geschichte zu verunglimpfen oder zu verfälschen, einsetzt. Dabei stellte er die fünf zentralen Themen der Parteigeschichte heraus: Erstens, die stetige Verbesserung des Verständnisses für die Bedeutung der Parteigeschichte; zweitens, das Beharren auf der Maxime „die Wahrheit in den Tatsachen suchen“, um die Geschichte der Partei zu studieren und zu verbreiten; drittens, die Verbesserung der Lehr- und Lernfähigkeit der Parteigeschichte; viertens, die Verbesserung des wissenschaftlichen Niveaus der Parteigeschichtsschreibung; und fünftens, der Ausbau der Führungsrolle der Parteigeschichte. ${ }^{325}$ Im Anschluss daran soll eine interne Diskussionsrunde über die von Xi Jinping angesprochene Problematik stattgefunden haben. Teile der Inhalte der Diskussion wurden im Jahr 2017 geleakt. Es lässt sich jedoch nicht mit Sicherheit feststellen, ob es sich bei dem Leak tatsächlich um authentisches Material oder um eine Fälschung handelt. ${ }^{326}$ Dennoch ist es durchaus aufschlussreich, einen Blick darauf zu werfen, da man diesen Leak auch als Zeichen des innerparteilichen Widerstands gegen die im Jahr 2010 eingeleiteten Veränderungen in der Geschichtspolitik deuten kann - möglicherweise sogar dann, wenn es sich dabei um eine Fälschung handeln sollte.

An der Diskussion sollen rund 30 Professoren teilgenommen haben, darunter einige über die Grenzen Chinas anerkannte Historiker. Darin werden die Hintergründe und Intentionen des kommenden Kurswechsels hin zu einem wieder stärker werdenden Top-down-Ansatz im Umgang mit der Geschichte der KPCh

325 Nachrichten der Kommunistischen Partei Chinas 中国共产党新闻 2010.

326 Die Herausgeber der in Kalifornien ansässigen Nachrichten-Website China Digital Times, wo die Auszüge aus dem Gespräch veröffentlicht worden sind, geben an, dass sie den Leak für authentisch halten. Dennoch gibt es unter Chinawissenschaftlern auch einige, die Zweifel an der Authentizität äußern, andere hingegen halten die Auszüge der Diskussion durchaus für authentisch. Siehe zum Beispiel Hundman 2018. Die Frage nach dem genauen Ursprung der hochgeladenen Quelle wollten die Herausgeber nicht beantworten. Die Anfrage bei einem der Teilnehmer der Diskussion per E-Mail, ob der Leak authentisch ist, blieb unbeantwortet. Betrachtet man die politische Entwicklung seit 2013 bezüglich des Umgangs mit den „historischen Fehlern“ der Vergangenheit, ist es dennoch denkbar, dass das Gespräch so stattgefunden haben könnte. 
und ihren „historischen Fehlern“ deutlich. Der Verlauf der Diskussion kann einen möglichen Hinweis darauf geben, weswegen ein Umdenken im Umgang mit den „historischen Fehlern“ der Partei politisch notwendig geworden ist. Ganz allgemein wird die tiefe Sorge vor einem drohenden Legitimitätsverlust der Partei zum Ausdruck gebracht. Die Diskutanten sollen sich weitgehend einig gewesen sein, dass es zu einem Dominoeffekt kommen könnte, wenn man über einen bestimmten „historischen Fehler“ spricht, der möglicherweise wiederum eine unkontrollierte Rebellion des Volkes gegen die Partei nach sich ziehen könnte. Die Folgen, die ein Aufwühlen der Vergangenheit haben könnte, soll demnach von einem der Diskutanten, Professor $\mathrm{Hu}$, als besonders drastisch einschätzt worden sein:

Nach der Gründung der Nation glaubten die einfachen Leute alle, egal was unsere Partei sagte, dass es wahr ist, und wenn jemand sagte, die Partei hat einen Fehler gemacht, hat das ganze Land ihn verachtet und bestraft. Das war der Erfolg unserer Propagandaarbeit und ist eine Tradition, die wir nicht ablegen können. Was glauben diese Bürger heute leicht? Jede Information, die ungünstig ist für unsere Partei. Und ein Bürger wird diese Information an zehn weitere weitergeben und diese zehn dann an hundert weitere, dann gerät es außer Kontrolle und dann wird daraus eine Rebellion. Unter diesen Umständen sollte die Regierung den einfachen Bürgern nicht alles über unsere Partei preisgeben, und solange Professoren oder andere bekannte Persönlichkeiten kein Exempel statuieren, werden uns alle vertrauen; ein paar Worte werden einen schlechten Einfluss haben, sprechen wir hundert Sätze, können wir das nicht wieder gut machen. In Anbetracht der nationalen Umstände, können wir mit den einfachen Leuten nicht über die Geschichte unserer Partei sprechen und niemals sollten wir uns öffentlich zu den sogenannten „Ereignissen“ bekennen. Bekennt man sich zu einer Sache, werden sie zehn weitere Fragen stellen und das wird die Partei in Verlegenheit bringen. Gemäß dem Sprichwort „Gute Nachrichten dringen nicht durch und schlechte Nachrichten verbreiten sich wie ein Lauffeuer“ wird es sich dadurch, dass es angesprochen wird, zu unzähligen Verbrechen multiplizieren. Deshalb befürworte ich die Rede von Präsident Xi aus voller Überzeugung, deren Geist uns sagt, was gesagt werden muss, und nicht das sagt, was nicht gesagt werden sollte..$^{327}$

Der Leak der Diskussion suggeriert, dass viele Parteihistoriker, und damit diejenigen, die einen entscheidenden Anteil an der Weiterentwicklung und Weitergabe offizieller Narrative haben, schon vor seiner Amtsübernahme hinter Xi Jinpings Agenda gestanden haben, auch zukünftig Stillschweigen über die „historischen Fehler“ der Partei zu bewahren. Kritische Stimmen sollen dazu demnach nicht erhoben worden sein. Man sollte jedoch nicht unberücksichtigt lassen, dass die von den Wissenschaftlern in der Diskussion geäußerte Zustimmung nicht zwangsläufig bedeutet, dass sie auch tatsächlich hinter dem geschichtspoliti-

327 Eigene Übersetzung. Original siehe China Digital Times 中国数字时代 2017. 
schen Kurs Xi Jinpings stehen. Man sollte bedenken, dass es in solchen Diskussionsrunden durchaus ein erhebliches Risiko darstellen dürfte, sich in der Parteiöffentlichkeit kritisch zu äußern oder gar einen Paradigmenwechsel im offiziellen Umgang mit der Geschichte der KPCh zu fordern. Der eingeschränkte Zugang zu zweifelsfrei authentischen Aufzeichnungen solcher Debatten stellt eine enorme Herausforderung für die Einschätzung der tatsächlichen Stimmungslage der Parteihistoriker bzw. der hohen Parteikreise dar.

\section{Die staatliche Toleranz schwindet}

Auch wenn sich die Authentizität der oben diskutierten Debatte nicht mit Sicherheit bestätigen lässt, kann man jedoch spätestens seit dem Jahr 2013 deutlich beobachten, dass sich die Toleranz des Staatsapparats gegenüber inoffiziellen Narrativen sukzessive verringerte, und so ging Chinas Erinnerungspolitik seit dem Jahr 2013 in den „Kampf gegen den historischen Nihilismus“, also den Feldzug gegen den öffentlichen Diskurs um die „historischen Fehler“ der Partei, über. Dies wurde spätestens durch das interne Dokument Nummer 9 - Kommuniqué zur aktuellen Lage im Bereich der Ideologie deutlich, welches im April 2013 innerhalb der Partei zirkulierte und einige Monate später geleakt wurde. Es beinhaltet „sieben Dinge, über die nicht gesprochen werden soll“ (qige bu yao jiang 七个不 要讲). Neben Aspekten westlicher Diskurse und Ideen ist eines dieser Dinge das öffentliche Sprechen über die „historischen Fehler“ der Partei und ihrer wichtigsten Persönlichkeiten, welches die Herrschaftslegitimation der KPCh gefährde. $^{328}$

Auf diese Direktive folgte eine Reihe von Maßnahmen, durch die die Verbreitung unerwünschter Narrative die Geschichte der KPCh betreffend sukzessive unterdrückt worden ist und von denen Intellektuelle und deren Arbeiten seitdem gleichermaßen betroffen sind. Xi Jinpings politischer Kurs sollte fortan den gesamten öffentlichen Diskurs um die Geschichte beeinflussen, so auch der an staatlichen Bildungseinrichtungen, insbesondere an den Hochschulen. Im Zuge dessen wurden die Hochschulleitungen schließlich dazu angehalten, westliche Lehrbücher aus den Bibliotheken und den Curricula zu verbannen. Immer mehr unerwünschte Schriften, die einen zu kritischen Blick auf die chinesische Geschichte werfen, landen seitdem auf dem Index. Beispielsweise wurden die bis dato tolerierten Bücher und Aufsätze Mao Yushis 茅于轼, Honorarprofessor am

328 Im Gegensatz zu der zuvor zitierten Diskussion gilt die Authentizität dieses Dokuments als unbestritten. Document 9: A ChinaFile Translation 2013, http://www.chinafile.com/document-9chinafile-translation. 
Unirule Institut für Wirtschaft, einem liberalen Pekinger Think Tank, ${ }^{329}$ seit dem Jahr 2014 konsequent verbannt. In einigen von ihnen hatte er sich auch kritisch mit der Politik Maos auseinandergesetzt und die offizielle Parteigeschichtsschreibung in Frage gestellt. ${ }^{330}$ Professorinnen und Professoren wurden immer stärker unter Druck gesetzt, wenn sie „historischen Nihilismus“ betrieben und/ oder westliche Ideen förderten bzw. verbreiteten. Einer von ihnen war der Journalismusprofessor Qiao Mu 乔木, der aufgrund dessen im Sommer 2014 seines Postens an der Peking Universität enthoben und in die Bibliothek strafversetzt wurde. Er selbst gab an, dass die Partei ihm keinen Grund für seine berufliche Degradierung genannt habe, dieser aber Warnungen vorausgegangen seien, dass er über jene unerwünschten Themen nicht mehr öffentlich, das heißt vor allem vor Studierenden, sprechen solle. ${ }^{331}$

Seit 2013 lässt sich zudem beobachten, dass der Zugang zu Archiven immer weiter eingeschränkt worden ist. Dies führte dazu, dass es immer schwieriger geworden ist, neue Forschungen zu „historischen Fehlern“ der Partei durchzuführen, wovon auch die westliche Chinaforschung massiv betroffen ist. Auch VPN-Verbindungen, mit denen man die „Große chinesische Firewall“ umgehen konnte, wurden zunehmend geblockt. VPN-Anbieter benötigen seitdem eine staatliche Genehmigung. ${ }^{332}$

Der veränderte Umgang mit weiten Teilen der inoffiziellen Geschichtsschreibung, die zuvor durch die Partei toleriert worden sind, wurde insbesondere deutlich sichtbar, als die Geschichtszeitung Yanhuang Chunqiu 炎黄春秋 zur Zielscheibe im Kampf gegen den historischen Nihilismus geworden ist. In der seit dem Jahr 1991 monatlich erscheinenden Zeitung mit einer Auflage von 200.000 Heften ließ sich eine von der offiziellen Geschichtsschreibung abweichende Darstellung von „historischen Fehlern“ der Partei erkennen (siehe Kapitel 5.2). ${ }^{333}$ Yanhuang Chunqiu galt bis dato als liberalstes Magazin innerhalb Chinas und genoss lange Zeit sogar die Unterstützung von einer Reihe ehemals hochrangiger Parteikader. ${ }^{334}$ Einer von ihnen war Xi Zhongxun 习仲勋, Xi Jinpings

329 Das Institut wurde im Sommer 2018 von den chinesischen Behörden geschlossen. Siehe Buckley 2018, https://www.nytimes.com/2018/07/11/world/asia/china-unirule-institute.html.

330 The China Story 2018, https://www.thechinastory.org/key-intellectual/mao-yushi-\%E8\%8C $\% 85 \% \mathrm{E} 4 \% \mathrm{BA} \% 8 \mathrm{E} \% \mathrm{E} 8 \% \mathrm{BD} \% \mathrm{BC} /$.

331 Philipps 2015, https://www.theguardian.com/world/2015/aug/06/china-xi-jinping-crack down-liberal-academics-minor-cultural-revolution.

332 Lam 2015, S. 38.

333 Eine Analyse des Umgangs mit der Kampagne gegen Rechtsabweichler in Yanhuang Chunqiu erfolgt in Kapitel 6.

334 Yu 2016, https://thediplomat.com/2016/07/the-death-of-a-liberal-chinese-magazine/. 
Vater, ein wichtiger Vertreter der ersten Führungsgeneration der VR China, der sich Ende der 1970er und zu Beginn der 1980er Jahre für die Rehabilitierung von Rechtsabweichlern einsetzte und später das Tian'anmen-Massaker öffentlich kritisierte. ${ }^{335}$ Im Juli 2016 jedoch wurde das gesamte Redaktionsteam um den Mitgründer des Magazins Du Daozheng 杜导正 durch ein von der chinesischen Regierung ernanntes neues Redaktionsteam, bestehend aus Angehörigen der Chinesischen Hochschule der Künste (Zhongguo meishu xueyuan 中国美术学院), ersetzt. Im Zuge dessen wurden die Redaktionsräume tagelang von Mitarbeitern der Hochschule und der chinesischen Polizei besetzt, da die bisherigen Herausgeber zunächst nicht kampflos das Feld räumen wollten. ${ }^{336}$ Du Daozheng verglich dieses Vorgehen später mit Methoden aus der Zeit der Kulturrevolution. ${ }^{337}$ Das fortan von der Chinesischen Hochschule der Künste herausgegebene Magazin machte kurz nach der Übernahme öffentlich bekannt, dass es sich inhaltlich fortan an den staatlich erwünschten Leitlinien orientiere:

Diese Ausgabe wird, ebenso wie die folgenden, den Zielen „Die Wahrheit in den Tatsachen suchen, geradlinig zu schreiben, die Geschichte als Lektion zu verstehen und diese weiter voranzutreiben“ dienen; sie wird ihren ursprünglichen Stil, ihr Genre und Layout beibehalten, genauso wie die Abonnements und Vertriebswege. ${ }^{338}$

Eine kritische Auseinandersetzung mit der Geschichte der KPCh lässt sich seitdem, wenig überraschend, in der Geschichtszeitung nicht mehr erkennen.

\section{Xi Jinpings Weg in die Vergangenheit}

Doch wie lassen sich die Gründe dieses Strategiewechsels in der Erinnerungs- und Geschichtspolitik und die seit Xi Jinpings Amtsantritt immer stärker werdende Intoleranz gegenüber einer alternativen Betrachtung der Vergangenheit erklären?

Eine Begründung für den strengeren Umgang mit dem politischen Erbe der KPCh und ihrer Akteure lieferte Xi Jinping im Frühjahr 2015 selbst mit seinem Verweis darauf, dass man aus dem Umgang der Sowjetunion mit Stalin, welcher

\footnotetext{
335 Lam 2015, S. 40.
}

336 Siehe offizielle Mitteilung vom 02. August 2016, Yanhuang Chunqiu 炎黄春秋 2016b, http:// www.yhcqw.com/html/wenzjc/2016/1021/16102118361789DHJ102351JB77K03884I198.htm.

Das Dokument ist online nicht mehr zugänglich, liegt jedoch zur Einsicht im Privatarchiv der Autorin bereit.

$337 \mathrm{Yu}$ 2016, https://thediplomat.com/2016/07/the-death-of-a-liberal-chinese-magazine/.

338 Eigene Übersetzung. Original siehe Yanhuang Chunqiu 炎黄春秋 2016a, http://www.yhcqw. com/html/wenzjc/2016/1021/1610211736358BH0610222DA9CEE5413 J46 J9.html. Das Dokument ist online nicht mehr zugänglich, liegt jedoch zur Einsicht im Privatarchiv der Autorin bereit. 
seiner Meinung nach entscheidend zu ihrem Untergang beigetragen habe, Lehren ziehen müsse:

\begin{abstract}
Warum ist die Sowjetunion zusammengebrochen? Warum ist die Kommunistische Partei der Sowjetunion kollabiert? Ein wichtiger Grund war der sehr intensive ideologische Kampf, der die sowjetische Geschichte, die Geschichte der Partei sowie Lenin und Stalin komplett negierte und letztlich in den historischen Nihilismus und ins Chaos geführt hat, was wiederum die Führung der Partei auf allen Gebieten und über die Armee untergraben hat. Am Ende hat sich so eine große Partei wie die Kommunistische Partei der Sowjetunion in alle Winde verstreut und der große sozialistische Staat ist auseinandergefallen. Das sollte uns eine Lehre sein! [...] Der Schlüssel des historischen Nihilismus ist die wesentliche Negierung der Vormachtstellung des Marxismus, der historischen Notwendigkeit des Sozialismus chinesischer Prägung sowie die Negierung der Führung der Kommunistischen Partei Chinas. ${ }^{339}$
\end{abstract}

Doch Xis Hinweis, dass man aus der Vergangenheit lernen müsse, erklärt seine verschärfte Geschichtspolitik nur unzureichend. Tatsächlich wurde der Schutz der Vergangenheit seit dem Amtsantritt Xi Jinpings noch wichtiger als zuvor, weil er sich die Geschichte und die Ideologien Mao Zedongs und Deng Xiaopings, der beiden Hauptakteure der Kampagne gegen Rechtsabweichler, deutlich stärker zunutze machte als seine beiden Vorgänger Jiang Zemin und Hu Jintao. Insbesondere lassen sich seit seinem Amtsantritt eine starke Revitalisierung der MaoZedong-Ideen bzw. bestimmter Aspekte des Maoismus und eine stärkere Fokussierung auf den Sozialismus chinesischer Prägung beobachten. Die politische Ideologie Xi Jinpings basiert jedoch nicht einfach nur auf dem „Maoismus“, vielmehr werden für diese ganz bestimmte Bilder und Narrative der chinesischen Geschichte miteinander kombiniert, so auch die positiven Aspekte der historischen Erben der wichtigsten Figuren der modernen chinesischen Geschichte Mao Zedong und Deng Xiaoping. Garniert wird dies darüber hinaus auch noch mit einer Prise wiederbelebtem Konfuzianismus. ${ }^{340}$ Im Zuge dessen ist es jedoch wichtig zu verstehen, dass dies nicht mit einer Widerbelebung eines „echten“ Maoismus einhergeht, vielmehr hat Xi Jinping, seit 2013 nach außen hin sichtbar, nach und nach seinen eigenen „-ismus“ kreiert, mit dem er eine neue Ära einläutete und der sich selektiv auf bestimmte Aspekte, Ideen, Bilder, Narrative und manchmal sogar Methoden der Ikone Mao Zedong bezieht. Das vorläufige Ergebnis dessen wurde im Oktober 2017 während des XIX. Parteitags der KPCh in Form der Xi-Jinping-Ideen zum Sozialismus chinesischer Prägung für eine neue Ära

339 Eigene Übersetzung. Original siehe Nachrichten der Kommunistischen Partei Chinas 中国共 产党新闻 2016, http://theory.people.com.cn/n1/2016/0214/c112851-28121586.html.

340 Zur Widerbelebung des Konfuzianismus unter Xi Jinping siehe Perry 2015. 
(Xi Jinping xin shidai Zhongguo tese shehui zhuyi sixiang 习近本新时代中国特色 社会主义思想) präsentiert und in die Verfassung aufgenommen. ${ }^{341}$

Betrachtet man die politischen Ideen und Konzepte der Präsidentschaft Xi Jinpings genauer, lässt sich feststellen, dass die Aspekte des Maoismus, die darin Einzug finden, sich im Wesentlichen auf den organisatorischen Maoismus der Yan'aner Jahre (1937-45) beziehen und nicht auf die späteren ikonoklastischen Ideen Maos während der Kulturrevolution. Stattdessen werden die von Xi wiederbelebten Aspekte des Maoismus durch einige Ideen Deng Xiaopings der Reformära komplementiert. Der Yan'aner Maoismus wurde während des VII. Parteitags der KPCh im Jahr 1945 durch Liu Shaoqi als Leitprinzip der KPCh implementiert. Während des Parteitags betonte Liu Shaoqi auch die Bedeutung des Konzepts der Massenlinie (qunzhong luxian 群众路线). In diesem Zusammenhang betonte er, dass die Partei und die Massen eng verbunden sein müssten, um die revolutionären Ziele zu erreichen:

Die andere Seite ist, daß die Vorhut der Massen wirklich enge Beziehungen zu den Massen herstellen muß. Sie muß auf jedem Gebiet für die Interessen des Volkes eintreten, zu allererst auf politischem Gebiet. Sie muß dem Volk gegenüber die richtige Haltung einnehmen und es mit den richtigen Methoden führen. Nur so kann die Vorhut mit den Massen eng verbunden sein; andernfalls besteht die Gefahr, daß die Vorhut von den Massen isoliert wird. In diesem Fall wäre sie aber keine Vorhut des Volkes. Sie würde nicht nur bei der Aufgabe versagen, die Massen zu befreien, sondern auch Gefahr laufen, vom Feind vernichtet zu werden. Das bedeutet, daß die Vorhut der Massen in ihrer gesamten Arbeit den Massen gegenüber eine vollkommen klare Linie befolgen muß. ${ }^{342}$

Ein weiterer Aspekt, der eine wichtige Rolle im organisatorischen Maoismus, insbesondere für die Umsetzung der Massenlinie, jener Jahre einnahm, ist das Konzept der Kritik und Selbstkritik, welches für die Verbesserung der Parteiarbeit hervorgehoben wurde. Auch dieses wurde von Liu Shaoqi gefördert. In seiner berühmten Rede Wie man ein guter Kommunist wird aus dem Jahr 1939 betonte er:

[...] we must modestly listen to the opinions and criticisms of our comrades and of the masses, carefully study the practical problems in our lives and in our work and carefully sum up our experiences and the lessons we have learned so as to find an orientation for our own work. ${ }^{343}$

341 Hua 2018, http://www.qstheory.cn/wp/2018-03/08/c_1122505081.htm.

342 Liu 1954, S. 45.

343 Liu 1964, S. 43. 
Seit dem Amtsantritt Xi Jinpings lässt sich eine deutliche rhetorische und politische Wiederbelebung dieser Ideen, die der Verbesserung der Parteiarbeit dienen soll, beobachten. Die von ihm angestrebten Verbesserungen des Arbeitsstils der Partei ähneln in ihrer Konzeption den Berichtigungsbewegungen der Jahre 1942- 44 und 1957. Bereits im Juni 2013 betonte er in einer Rede vor hochrangigen Mitgliedern der Zentralregierung und der Provinzregierungen die Wichtigkeit des Konzepts der Massenlinie und des Prinzips der Kritik und Selbstkritik für die Verbesserung der Parteiarbeit und der Beziehung zwischen Partei und Volk. ${ }^{344}$

Die Xi'sche Wiederbelebung einer Parteiorthodoxie maoistischer Prägung schließt dabei jedoch, wie bereits erwähnt, die „späten“ Ideen Maos der Kulturrevolution klar aus - Xi lässt keinerlei Bestrebungen erkennen, die Klassenkämpfe oder Massenbewegungen der Jahre 1966 bis 1976 wiederzubeleben. Im Dezember 2012 betonte er sogar, dass es für die positiven Entwicklungen der letzten 30 Jahre von entscheidender Bedeutung gewesen sei, aus den negativen Erfahrungen der Kulturrevolution zu lernen:

Die gegenwärtig geltende Verfassung wurde erarbeitet, wobei man gemäß dem Kurs, den Richtlinien und der Politik, welche auf dem 3. Plenum des XI. ZK etabliert wurden, die positiven und negativen Erfahrungen beim Aufbau des Sozialismus zusammenfasste, aus den bitteren Lehren der zehnjährigen Kulturrevolution sowie Erfolgen und Misserfolgen des internationalen Sozialismus Lehren zog und sich auf die neuen Erfordernisse für die Reform und Öffnung, die sozialistische Modernisierung und die Intensivierung des Aufbaus der sozialistischen Demokratie und des Rechtssystems einstellte. ${ }^{345}$

Die kulturrevolutionären „Störungen“ würden seinem pragmatischen wirtschaftlichen Kurs klar im Wege stehen. Und so lässt sich im Gegensatz dazu in Xis politischer Agenda neben einer selektiven Verwendung des Yan'aner Maoismus auch ein Nutzen der Deng-Xiaoping-Theorien erkennen. ${ }^{346}$ Diesbezüglich betonte er 2012, dass die Weiterentwicklung Chinas sich an den Anleitungen der DengXiaoping-Theorie und der fortwährenden Aufgabe der Reform und Öffnung orientieren müsse:

344 Nachrichten der Kommunistischen Partei Chinas 中国共产党新闻 2013, http://cpc.people. com.cn/n/2013/0619/c64094-21888765-2.html. Vgl. Zhao 2016.

345 Xi 2014, S. $166 \mathrm{f}$.

346 Deng Xiaoping wurde zwischenzeitlich selbst zum Opfer der Kulturrevolution. Aufgrund seines pragmatischen wirtschaftlichen Kurses wurde er heftig kritisiert und zunächst unter Hausarrest gestellt und zwischen 1969 und 1973 in den Bezirk Xinjian in der Provinz Jiangxi verbannt. Siehe Vogel 2011, S. $49 \mathrm{ff}$. 
Reform und Öffnung sind immer im Fluss und nie abgeschlossen. Ohne sie wäre China weder das, was es heute ist, noch hätte unser Land eine Zukunft. Widersprüche in der Reform und Öffnung können nur durch die Reform und Öffnung selbst gelöst werden. Um sie voranzutreiben, müssen wir den Geist des XVIII. Parteitags umfassend umsetzen, uns unerschütterlich von der Deng-Xiaoping-Theorie, den wichtigen Ideen der Drei Vertretungen und dem Wissenschaftlichen Entwicklungskonzept leiten lassen, aktiv auf die lauten Stimmen und sehnlichsten Erwartungen des Volks hinsichtlich der Vertiefung der Reform und Öffnung reagieren, einen gesellschaftlichen Konsens erzielen und die Reformen in allen Bereichen und Bindegliedern koordiniert vorantreiben. ${ }^{347}$

Anlässlich des 110. Jahrestags der Geburt Deng Xiaopings betonte Xi Dengs selbstlose Hingabe für öffentliche Belange. Er hob zudem hervor, dass der Chinesische Traum der nationalen Wiederbelebung nur durch die Blaupause der sozialistischen Modernisierung Deng Xiaopings erreicht werden könne. ${ }^{348}$ Mit anderen Worten kann man Xis Konzept des Chinesischen Traums, zumindest in Teilen, als Weiterentwicklung der Politik Deng Xiaopings betrachten.

Die Wiederbelebung bestimmter Teile der Erben Maos und Dengs können als Teil einer gut durchdachten politischen Strategie angesehen werden. Dies bedeutet noch lange nicht, dass Xi tatsächlich ein Maoist ist. Vielmehr haben bestimmte politische Entwicklungen der letzten Jahre gewisse Veränderungen der politischen Ideologie als Basis der politischen Legitimität der KPCh notwendig gemacht. Der Aufbau der Xi'schen Ideologie muss dabei als Prozess betrachtet werden, der auf einem Überdenken der modernen chinesischen Geschichte beruht. Diese Entwicklung erreichte ihren vorläufigen Höhepunkt rund um den XIX. Parteitag im Herbst 2017. Xi Jinping beschrieb in seinem Bericht das neue historische Narrativ als Aufstieg des chinesischen Volkes, dem es demnach gelungen sei aufzustehen (zhan qilai 站起来), reich (fu qilai 富起来) und schließlich mächtig (qiang qilai 强起来) zu werden. ${ }^{349}$ Dies lässt sich als neue Einteilung der Geschichte der VR China und der KPCh in drei Zeitabschnitte interpretieren, welche sich direkt auf Mao Zedong (aufstehen), Deng Xiaoping (reich werden) und Xi Jinping selbst (mächtig werden) beziehen. Dies suggeriert, dass Xis Amtsübernahme, genauso wie der Ausbau seiner Macht, als logische Weiterentwicklung bzw. als legitimiertes Erbe der bis dato mächtigsten Führer der VR China Mao Zedong und Deng Xiaoping angesehen werden muss. Über seine Vorgänger Jiang Zemin und $\mathrm{Hu}$ Jintao scheint Xi in dieser neuen historischen Zeitrechnung einfach hinwegzugehen. Jiang Shigong, Professor an der juristischen Fakultät der Peking-

347 Xi 2014, S. 83.

348 Xi 2017, S. 11.

349 Xi 2018, http://www.xinhuanet.com/english/special/2017-11/03/c_136725942.htm. 
Universität, hat in diesem Zusammenhang darauf hingewiesen, dass es innerhalb und außerhalb der Partei bis dato Kräfte gegeben habe, die die Reformen Dengs dafür verwendet haben, um die Mao-Ära zu negieren und umgekehrt. ${ }^{350}$ Xis Bericht während des XIX. Parteitags machte somit deutlich, dass er dem nihilistischen gegenseitigen Ausspielen Maos gegen Deng ein Ende setzen würde.

\section{Xi Jinping - ein Vorzeigekommunist auf den Spuren Maos}

Diese Entwicklungen gingen sogar mit einem Wiederaufkeimen eines Populismus maoistischer Prägung und mit einem Hauch durch Xi selbst inszenierten Personenkults einher. Bereits seit 2012 lässt sich beobachten, dass Xi Jinping konsequent ein öffentliches Bild von sich selbst kreiert, welches ihm das Image eines bescheidenen, volksnahen und vorbildlichen Kommunisten verleihen soll. So ging seine 2012 angestoßene Anti-Korruptionskampagne mit einer Kampagne gegen Verschwendung einher, einer Maßnahme zur Bekämpfung von Extravaganz und Bürokratismus durch hochrangige Parteikader. Xi erhielt für sein entschlossenes Vorgehen gegen extravagante Banketts und seine öffentliche Demonstration von Bescheidenheit zu jenem Zeitpunkt ein hohes Maß an öffentlicher Anerkennung. ${ }^{351}$ Im Zuge dessen verstand er es auch geschickt, sich als bescheidenen Maoisten zu inszenieren, indem er sich im Dezember 2013 öffentlichkeitswirksam in einem einfachen Baozi-Laden selbst in die Schlange stellte, ein einfaches Gericht aß und sein Tablett anschließend auch selbst wieder wegräumte. Diese Bilder wurden durch die sozialen Medien in China schnell zu einem viralen Hit. ${ }^{352}$

Zunehmend machte er sich ganz bestimmte Bilder und Narrative zunutze, um seine Zuneigung zu den einfachen Menschen in China zum Ausdruck zu bringen und um seine heroischen Taten maoistischer Art ins kollektive Gedächtnis der chinesischen Bevölkerung zu pflanzen. In seinem 2014 erschienenen Buch China regieren (tan zhiguo li zheng 谈治国理政) wird er als bescheidener Held beschrieben, der als gebildeter Jugendlicher während der Kulturrevolution auf dem

350 Jiang 2018, https://www.thechinastory.org/cot/jiang-shigong-on-philosophy-and-history-in terpreting-the-xi-jinping-era-through-xis-report-to-the-nineteenth-national-congress-of-the-cсp/. 351 Zhu et al. 2017, S. 349.

352 Xinhuanet 新华网 2013, http://www.xinhuanet.com/politics/2013-12/28/c_118748144.htm. Im Anschluss daran ist eine Art Hype um das „Gericht des Vorsitzenden“ (zhuxi taocan 主席套餐) entstanden. Seitdem kann man das einfache Gericht, das Xi Jinping damals in der Öffentlichkeit $a ß$, in eben jenem Laden für 21 Renminbi kaufen, ebenso wie in einigen anderen einfachen Restaurants in Peking. Liu 2016, http://www.81.cn/jmywyl/2016-02/09/content_6890662.htm. 
Land wahre Wunderdinge vollbracht hat, um der armen Landbevölkerung zu helfen:

Dieser Xi Jinping, der eine Strecke durch bergiges Gebirge von fünf Kilometern mit fünfzig bis hundert Kilo Weizen eine lange Zeit, ohne die Schulter dabei zu wechseln, zu Fuß bewältigen konnte, imponierte den Dorfbewohnern und erwarb sich nach und nach ihr Vertrauen. ${ }^{353}$

Auch nach dem Beginn seiner politischen Karriere habe er die einfachen Menschen auf dem Land nie vergessen und so keine Mühen gescheut, sich um ihre Belange zu kümmern:

Dem Volk misst Xi Jinping das größte Gewicht bei. Die Basis war der Ort, zu dem ihn seine Reisen am häufigsten führten. 1988 bekleidete Xi Jinping das Amt des Sekretärs des Parteikomitees des Bezirks Ningde, Provinz Fujian. Damals zählte Ningde zu den achtzehn ärmsten Gebieten Chinas. Um die Dörfer dort zu erreichen, musste Xi oft mehrere Tagesreisen mit dem Geländewagen auf unwegsamen Bergpfaden zurücklegen. Der Wagen holperte auf diesen Fahrten derart, dass er nicht einmal gerade sitzen konnte, und manchmal konnte er vor Schmerzen nicht mehr aussteigen. In abgelegene Bergregionen, die nicht an das Verkehrsnetz angeschlossen waren, gelangte er nur zu Fuß über gefährliche Bergpfade. Einmal führte ihn eine seiner Touren in eine Gemeinde namens Xiadang. Nachdem er morgens um halb acht aufgebrochen war, erreichte er die Gemeinde erst nach zwölf Uhr mittags. Vor Ort wurde er von der Bevölkerung herzlich und feierlich empfangen. Die Dorfbewohner lobten ihn als den „ranghöchsten Funktionär, der jemals hierhergekommen ist“. Während seiner Amtszeit in Ningde half Xi einigen Tausend Bauern beim Umbau von Strohhütten und den Fischern beim Hausbau am Meeresufer, damit sie auf dem Meer fischen und an der Küste wohnen und so in Ruhe und Frieden arbeiten und leben konnten. ${ }^{354}$

Während er das historische Erbe Deng Xiaopings eher für die Legitimierung seiner Wirtschaftspolitik einsetzt, liegt der Gedanken nahe, dass die von Xi geschaffenen Bilder und die mit seiner Person verknüpften positiven Assoziationen des maoistischen Erbes dafür verwendet werden, die Herzen des Volkes für sich zu gewinnen. Dabei scheint er insbesondere das einfache Volk bzw. die Verlierer der Reform- und Öffnungspolitik anzusprechen. Mao dabei nicht nur als Sinnbild für Bescheidenheit, sondern auch für Gerechtigkeit und Gleichheit für sich einzusetzen, ist in einer Zeit rasant wachsender sozialer Ungleichheiten ein nicht zu unterschätzender Faktor. ${ }^{355}$ Die von oben eingesetzten und konstruierten Narrative der ehemaligen Machthaber Mao und Deng stellen somit scheinbar ein

353 Xi 2014, S. 533.

354 Ebd., S. 536.

$355 \mathrm{Zu}$ den wachsenden sozialen Ungleichheiten in China siehe Zheng 2011, S. $293 \mathrm{ff}$. 
Gleichgewicht dar, das an die politischen Notwendigkeiten des gegenwärtigen Chinas angepasst worden zu sein scheint.

Das Problem dabei ist, dass dieser Nutzen bestimmter Teile der historischen Erben Maos und Dengs ein zweischneidiges Schwert darstellt, da somit ein Sprechen über die „historischen Fehler“ Xis eigene Legitimität untergraben könnte. Und somit macht die Konstruktion seiner Ideologie es noch mehr als zuvor notwendig, die Kontrolle über die Vergangenheit zu behalten, womit sich also die schwindende Toleranz gegenüber alternativen Narrativen erklären lässt. Denn auch wenn er sich nur auf Teile der Bilder Maos oder der Mao-Zedong-Ideen bezieht, ist es dennoch notwendig, den „gesamten“ Mao und sein historisches Erbe zu beschützen. Das gleiche gilt für das historische Erbe Deng Xiaopings. Dies macht nochmals deutlich, weswegen insbesondere die Kampagne gegen Rechtsabweichler nicht Einzug in einen breiten öffentlichen Diskurs finden sollte. Unterstützung erhielt er hierfür öffentlich immer wieder auch aus offiziellen Institutionen heraus, wie zum Beispiel im Jahr 2013, als der damalige Vizedirektor der CASS Li Shenming 李慎明 öffentlich kundtat, dass im Zuge der Kampagne gegen Rechtsabweichler nicht eine einzige Person politisch verfolgt worden sei, auch wenn 500.000 Menschen als Rechtsabweichler gebrandmarkt worden seien. In diesem Zusammenhang kritisierte er auch die diffamierende Berichterstattung über die Kampagne durch Zeitzeugen oder Wissenschaftler. ${ }^{356}$

\section{Die ideologische Bildung der Jugend}

Der Kampf gegen den historischen Nihilismus geht also nicht nur mit einem repressiven Umgang mit der Geschichte, sondern auch mit einer Förderung des erwünschten Kanons durch eine intensivierte ideologische Bildung der Bevölkerung einher. Am deutlichsten nach außen hin sichtbar wird dies insbesondere durch den in den vergangenen Jahren in ganz China umfangreichen und deutlich zunehmenden Einsatz von Propagandapostern. In Peking etwa werden durch sie von der Partei erwünschte Botschaften, wie zum Beispiel ein verstärkter Patriotismus, die Errungenschaften durch die KPCh und die Alternativlosigkeit ihrer Vormachtstellung für die weitere Entwicklung des Landes oder aber die Wichtigkeit des Sozialismus chinesischer Prägung, in das Volk transportiert (siehe Abb. 11).

Die primären Zielgruppen der staatlichen Maßnahmen der ideologischen Bildung dürften jedoch die Generationen Y und Z darstellen, also jene Genera-

356 Li 2013a, https://www.scmp.com/news/china/article/1237558/not-single-person-persecutedanti-rightist-movement-says-vice-director. 


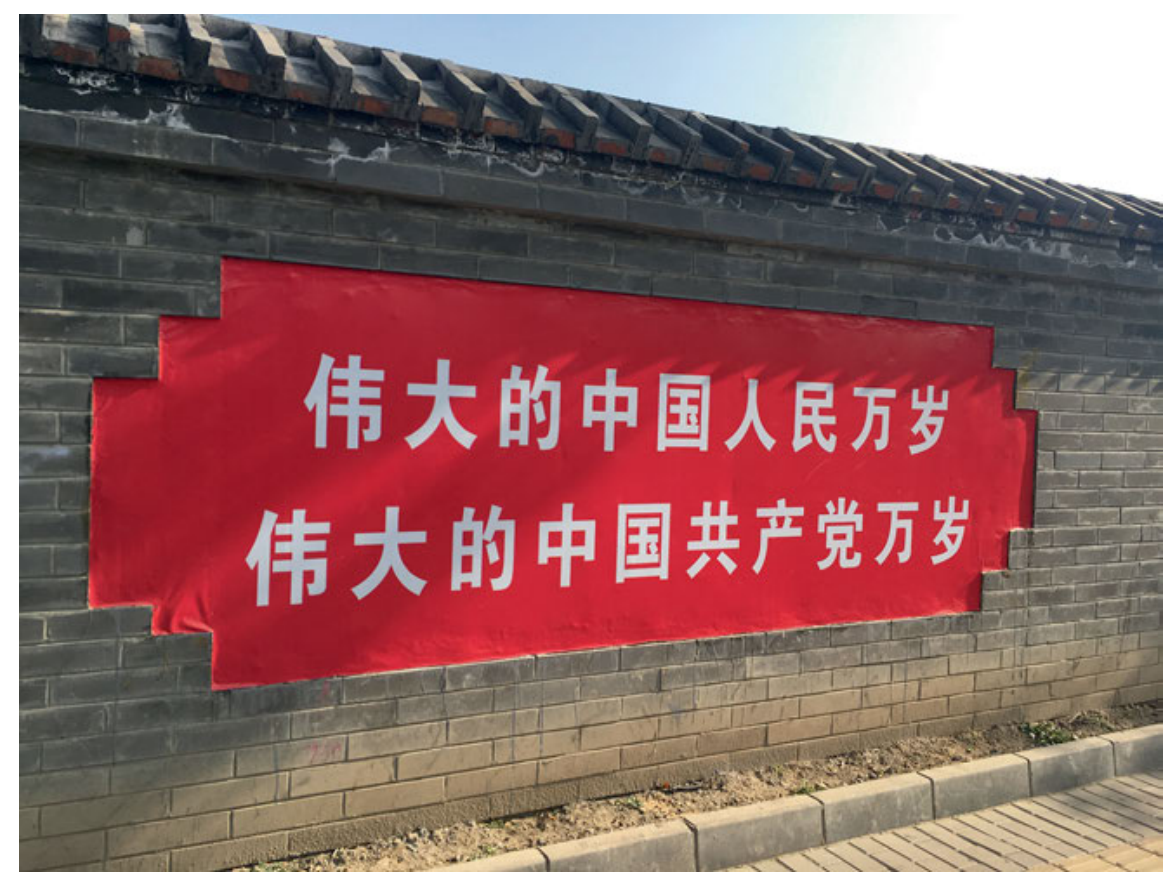

Abbildung 11: „Lang lebe das große chinesische Volk, lang lebe die große Kommunistische Partei“ (eigene Fotografie, Peking, November 2017)

tionen, die nach dem Beginn der Reform- und Öffnungspolitik geboren wurden. Innerhalb dieser Generationen ist durch die Vernachlässigung der ideologischen Bildung ab den 1980er Jahren ein ideologisches Vakuum entstanden. Die Ideen des Marxismus oder das Konzept des Sozialismus chinesischer Prägung hat in ihrer Ausbildung eine weitgehend untergeordnete Rolle gespielt. Dieses ideologische Vakuum scheint die Partei zur nachhaltigen Festigung ihrer Herrschaftslegitimation seit dem Amtsantritt Xi Jinpings gezielt schließen zu wollen. Somit lässt sich seit 2013 beobachten, dass eine intensivierte ideologische Bildung in den Hochschulen, aber auch in den Massenmedien stattfindet. Als Beispiel hierfür lässt sich die fünfteilige Fernsehshow Marx hat recht (Makesi shi dui de 马 克思是对的) anführen, welche anlässlich des 200. Jahrestags der Geburt Karl Marx' im Frühjahr 2018 von dem chinesischen Fernsehsender CCTV ausgestrahlt und zuvor wochenlang intensiv beworben wurde. Das Format stellte eine Mi- 
schung aus politischer Indoktrination, Talkshow und Quizshow dar. Die offizielle Website der Show beschreibt sie als Programm mit theoretischer Tiefe, welches der Jugend ein korrektes Gefühl infiltriere. ${ }^{357}$ Im Herbst desselben Jahres, also pünktlich vor dem XIX. Parteitag, wurde außerdem die Fernsehshow Sozialismus ist cool (Shihuizhuyi youdian chao: xin shidai xue Xi dahui 社会主义有点潮 : 新 时代学习大会) ausgestrahlt, welche ebenfalls die Förderung der korrekten ideologischen Bildung der Jugendlichen zum Ziel hatte. Dieses Format ging jedoch noch einen Schritt weiter und stellte neben theoretischem Wissen zur Ideologie und Geschichte der KPCh auch die Ideologie des Staatspräsidenten in den Vordergrund. Während der Show waren die Kandidaten zum Beispiel dazu angehalten, korrekte Zitate Xis zu benennen bzw. zu erraten. ${ }^{358}$ Diese Fernsehsendung spiegelt den neuen Populismus Xi'scher Prägung somit in besonderer Weise wider.

Als offizielles Startsignal für die Intensivierung der ideologischen Bildung von Parteikadern und Studierenden an Hochschulen kann man Xi Jinpings Rede anlässlich der Konferenz über Öffentlichkeits- und ideologische Arbeit am 19. August 2013 interpretieren, in der er die Wichtigkeit der Lehre der korrekten Ideen und Ideologien betonte:

Führende Funktionäre, insbesondere ranghohe, sollten die grundlegenden marxistischen Theorien zur Ausbildung ihrer besonderen Fähigkeiten beherrschen und den MarxismusLeninismus, die Mao-Zedong-Ideen und insbesondere die Deng-Xiaoping-Theorie, die wichtigen Ideen der Drei Vertretungen sowie das wissenschaftliche Entwicklungskonzept gründlich und gewissenhaft studieren. Für die Parteischulen, Schulen für Funktionäre, Akademien für Sozialwissenschaften, Hochschulen und Universitäten sowie zentrale Gruppen für theoretische Studien gilt es, den Marxismus als obligatorisches Lehrfach zu unterrichten. Damit sollen sie eine Hochburg beim Lernen, Erforschen und Verbreiten des Marxismus werden. ${ }^{359}$

Dadurch sollte in den Geisteswissenschaften nun wieder verstärkt die Förderung des offiziellen Kanons im Fokus stehen. Hierfür würden an die Stelle westlicher Lehrmaterialien vermehrt von der Partei herausgegebene bzw. geförderte oder in Auftrag gegebene Lehrmaterialien treten. Diese Entwicklungen seit 2013 ließen neben der Förderung der ideologischen Ausbildung durch Hochschullehrer auch die konservativen Parteihistoriker noch stärker als zuvor auf den Plan treten. Sie entwerfen an die politischen Bedürfnisse Chinas unter Xi angepasste, aber nicht

357 ,节目有理论深度、有实践温度, 浸润着理想情怀, 洋溢出青春气息.“ CCTV 2018, http:// news.cctv.com/special/Marx/.

358 Wan 2018, http://sc.people.com.cn/n2/2018/0930/c345460 - 32118903.html.

359 Xi 2014, S. 188. 
von dem Rahmen, den die Resolution von 1981 vorgibt, abweichende Narrative. Insbesondere Geschichtsbücher nehmen dabei einen wichtigen Stellenwert im Kampf um das kollektive Gedächtnis ein, da sie als Lehrmittel an Universitäten, vorwiegend in den Geschichtswissenschaften, eingesetzt werden, was diesen Narrativen eine enorme Reichweite verschafft.

Doch wie stellt sich der Umgang mit dem „historischen Fehler“ der Kampagne gegen Rechtsabweichler in diesen Werken dar? Besonders interessant ist im Zuge dessen das im Dezember 2013 von den Parteihistorikern Luo Pinghan 罗本汉, Professor der Zentralen Parteihochschule, Lu Yi 卢毅, ebenfalls Professor der Zentralen Parteihochschule, und Zhao Peng 赵鹏 360 im Volksverlag (renmin chubanshe人民出版社) herausgegebene Lehrbuch Studien zu den wichtigsten Kontroversen in der Geschichte der Kommunistischen Partei Chinas (Zhonggong dangshi: zhongda zhengyi wenti yanjiu 中共党史: 重大争议问题研究). Es wird als Standardlehrwerk an chinesischen Universitäten eingesetzt. ${ }^{361}$ In diesem werden laut Vorwort die unterschiedlichen Forschungsstände und Kontroversen zur Geschichte der KPCh seit ihrer Gründung im Jahre 1921 bis zum Ende der Kulturrevolution behandelt. Der Umgang mit „historischen Fehlern“ nimmt in diesem Buch einen zentralen Stellenwert ein. Die Kampagne gegen Rechtsabweichler wird in einem eigenen Kapitel auf 55 Seiten behandelt.

Die Autoren suggerieren, dass sie in ihrem Buch eine große Bandbreite an Narrativen und historischen Meinungen abbilden. Tatsächlich wird dies zum Beispiel anhand der Frage, ob die Hundert-Blumen-Bewegung eine Falle gewesen ist oder nicht, erörtert. Dabei legen die Autoren in zusammenfassender Art und Weise den Kern beider Theorien dar. In diesem Zusammenhang weisen sie auch darauf hin, dass es in der Forschung Stimmen gibt, die die Auffassung vertreten, dass die Hundert-Blumen-Bewegung bereits vor Mitte Mai 1957, also bevor die Partei attackiert worden ist, eine gezielte Falle gewesen sein soll. Bemerkenswert ist, dass die Autoren das Zustandekommen dieser Theorie nüchtern abwägen:

Ob es nun darum geht „die Schlange aus ihren Löchern zu holen“ oder „Fische zu fangen“, die Situation in jenem Jahr stellte sich folgendermaßen dar: Die Demokraten wurden mobilisiert, die Intellektuellen gaben ihre Meinung zuerst ab und wurden danach kritisiert. Man kann also leicht davon ausgehen, dass die Bewegung gegen die Rechten eine zuvor gesetzte

360 Gegenwärtige Tätigkeit unbekannt.

361 Im März 2019 befanden sich insgesamt fünf Exemplare des Buches im Bestand der Bibliothek der Peking-Universität. In einem Gespräch mit Studierenden der Geschichtswissenschaften der Peking-Universität gaben diese an, dass es auch in einem ihrer Seminare zur modernen chinesischen Geschichte eingesetzt werden würde. 
Falle gewesen ist, in die die später als Rechtsabweichler Verurteilen hineingetreten sind. Das ist die sogenannte „Verschwörungstheorie“. ${ }^{362}$

Auch wenn die Autoren darlegen, dass es durchaus abweichende Meinungen zu den Auslösern der Kampagne gegen Rechtsabweichler gibt, stützen sie dennoch eindeutig das offizielle Narrativ, dass es zwar durchaus eine durch die Partei gestellte Falle gegeben habe, diese jedoch erst nach den Attacken durch die Rechten gelegt worden und demnach richtig und notwendig gewesen sei. Sie betonen auch, dass die ursprüngliche Idee der Berichtigungsbewegung der Partei zur Bekämpfung der drei Übel Bürokratismus (guanliao zhuyi 官僚主义), Sektierertum (zongpai zhuyi 宗派主义) und Subjektivismus (zhuguan zhuyi 主观主 义) korrekt gewesen sei, da sich in China bereits zwischen Mitte des Jahres 1956 und zu Beginn des Jahres 1957 Studenten- und Arbeiterstreiks ereignet hatten, deren Ursachen die Autoren eben jenen drei Übeln zuschreiben. ${ }^{363}$ Die Autoren legen in ihren Analysen insbesondere einen starken Fokus auf die Ereignisse der Aufstände in Polen und Ungarn im Herbst 1956 als Auslöser für die politischen Entscheidungen der Parteispitze um Mao Zedong. Hier verweisen die Autoren auf die Studien des bekannten und über Chinas Grenzen hinweg anerkannten Geschichtsprofessors der East China Normal University in Shanghai Shen Zhihua 沈 志华. Daran schließt eine eigene Einordnung der Darstellungen Shens durch die Autoren an, welche wiederum den offiziellen Kanon stützt:

Der Grund, warum der Autor [Anm.: Shen Zhihua] so ausführlich über die Vorfälle in Polen und Ungarn schreibt, ist der, dass diese innerhalb des Zentralkomitees, besonders bei Mao Zedong, einen so großen Schock ausgelöst haben, dass sie eine der Hauptgründe für die Durchführung der Berichtigungsbewegung gewesen sind. Außerdem lassen sich die Spuren der Kampagne gegen Rechtsabweichler auf die unterschiedlichen Bewertungen der Vorfälle in Polen und Ungarn durch Mao und die daraufhin vorgeschlagenen Strategien zurückführen. ${ }^{364}$

Die Darstellungen der Einflüsse der Aufstände in Polen und Ungarn bzw. die Art und Weise der Darstellung der unterschiedlichen Forschungsstände bezüglich dieser durch die Autoren nehmen dabei eindeutig eine erklärende und relativierende Funktion der daraufhin erfolgten „historischen Fehler“ der Jahre 1957 und 1958 ein.

362 Eigene Übersetzung. Original siehe Luo et al. 2013, S. 247.

363 Ebd., S. 249.

364 Eigene Übersetzung. Original siehe ebd., S. 254. 
Insgesamt suggerieren die Autoren, dass sie einen umfassenden Überblick über den Forschungsstand zu den „historischen Fehlern“ der Partei aufzeigen, tatsächlich stützen sie mit ihren Darstellungen und Analysen jedoch das offizielle Narrativ um die Kampagne. Dabei stellen sie die von den offiziellen Narrativen abweichenden Forschungsstände nur so dar, dass sie ihre eigenen Thesen nicht angreifen bzw. sich innerhalb thematischer Grenzen, die nicht in Konkurrenz zur offiziellen Geschichtsschreibung stehen, bewegen. Beispielsweise skizzieren die Autoren, dass nach Meinung einiger Wissenschaftler nicht nur Intellektuelle von der Kampagne betroffen gewesen sind, sondern auch andere Teile der Bevölkerung, wie Arbeiter oder Bauern, was in bisherigen Forschungen nur wenig Berücksichtigung gefunden habe. Dabei legen sie jedoch auch dar, dass die Gründe für ihre Verurteilung wissenschaftlich nur schwer nachvollziehbar seien. ${ }^{365}$

Letztlich weichen die Autoren in ihrer Einschätzung der Kampagne gegen Rechtsabweichler insgesamt auch hier nicht von den in der Resolution von 1981 gesteckten Grenzen ab und relativieren die Gründe für die Übertreibungen der Kampagne immer wieder, indem sie zum Beispiel darlegen, dass Mao selbst versucht habe, diese Übertreibungen einzudämmen:

Das Zentralkomitee der Kommunistischen Partei und Mao Zedong haben versucht, die Bewegung gegen die Rechten auf die extremen Rechtsabweichler zu beschränken, und haben hart daran gearbeitet, die Mehrheit der Bevölkerung für sich zu gewinnen. Dennoch wurde die Situation des Klassenkampfes überschätzt. Als die Massenkampagne erst einmal gestartet war, war es schwer, die Kontrolle zu behalten, und letztlich eskalierte die Kampagne. ${ }^{366}$

Insgesamt stützen die Autoren das Narrativ, dass die Kampagne zwar übertrieben wurde, sie aber dennoch notwendig war, und so wird sie auch hier erneut nicht als „historischer Fehler“ eingeordnet. Ebenso wenig wird die zentrale Rolle Deng Xiaopings für die Durchführung der Kampagne gegen Rechtsabweichler erwähnt.

\section{Deng Xiaoping und Xi Jinping}

Eine der wichtigsten Veröffentlichungen der offiziellen Parteigeschichtsschreibung jener Jahre stellt die Deng-Xiaoping-Biografie (Deng Xiaoping zhuan 邓小本 传) dar, welche im Jahr 2014 anlässlich des 110. Jahrestags der Geburt Dengs von den Parteihistorikern Yang Shengqun 杨胜群 und Liu Jintian 刘金田 sowie der Zentralen Forschungsstelle für Parteigeschichte der KPCh herausgegeben wurde.

365 Ebd., S. 291.

366 Eigene Übersetzung. Original siehe ebd., S. $281 \mathrm{f}$. 
Die Biografie umfasst die ersten 70 Jahre des Lebens und Wirkens des Vaters der chinesischen Wirtschaftsreformen (1904-1974).

Auch wenn in dieser Veröffentlichung ebenso wenig von dem vorgegebenen Rahmen der Resolution von 1981 abgewichen wird, wie bereits in der offiziellen Mao-Biografie oder der Geschichte der Kommunistischen Partei, lässt sich auch hier durchaus eine Adaption in der historischen Bewertung und Einordnung der Ereignisse der Jahre 1956 bis 1958 an die Bedürfnisse der Gegenwart feststellen. Die Themen Berichtigungsbewegung und Kampagne gegen Rechtsabweichler nehmen in dem Buch ein gesamtes Kapitel ein und erstrecken sich über 45 Seiten. ${ }^{367}$

Der größte Teil des Kapitels nimmt dabei die Deskription und Analyse der Berichtigungsbewegung ein. Es beginnt sogleich mit der Beschreibung der Erfolge, die in den Jahren 1953-56 mit der Entwicklung der Arbeit der Partei und des sozialistischen Aufbaus erzielt wurden und die sich viel schneller eingestellt hätten als erwartet. Es scheint, als wollten die Autoren diese Erfolge damit schon früh als relativierende Faktoren für die Fehler der beiden kommenden Jahre nutzen:

In den Jahren 1953 bis 1956 ging die Entwicklung der Arbeit der Partei und des Staates in allen Bereichen viel schneller als ursprünglich geplant voran. Bis zum Ende des Jahres 1956 war die für fünf Jahre geplante sozialistische Transformation der Landwirtschaft, des Handwerks sowie der kapitalistischen Industrie und des Handels innerhalb von drei Jahren weitgehend abgeschlossen. Die im ersten Fünfjahresplan des Jahres 1953 festgelegten Aufgaben wurden ebenfalls ein Jahr früher umgesetzt als geplant. ${ }^{368}$

Es wird also deutlich betont, dass die Partei in den ersten Jahren nach der Machtübernahme deutlich über dem Soll gelegen und hart für das Wohl des Volkes gearbeitet habe. Einen besonderen Stellenwert nimmt in diesem Kapitel auch die Beschreibung des so wichtigen ersten Teils des VIII. Parteitags der KPCh ein, der im Zeitraum 15. - 27. September 1956 in Peking ausgetragen worden ist. ${ }^{369}$ Dieser hatte nicht nur die Zielsetzung ausgegeben, die sozialistische Revolution $\mathrm{zu}$ vollenden und China zu einer sozialistischen Industriemacht $\mathrm{zu}$ machen, ferner wurde die Debatte um eine Zunahme der drei Übel angestoßen. Diese sorgten nach Ansicht der damaligen Führungsspitze der Partei dafür, dass sich Partei und

367 Kapitel 29 „Die Berichtigungsbewegung und die Kampagne gegen Rechtsabweichler des Jahres 1957“ (一九五七年的整风反右). Yang und Liu 2014.

368 Eigene Übersetzung. Original siehe ebd., S. 1010.

369 Der VIII. Parteitag erstreckte sich über zwei mehrtägige Sitzungen. Die erste wurde im September 1956 und die zweite im Zeitraum 05.-23. Mai 1958 abgehalten. Die Ausführungen in diesem Kapitel des Buches beziehen sich weitgehend auf die erste Sitzung. 
Volk voneinander zu entfernen drohten. Um dieser Entwicklung entgegenzuwirken, habe Mao Zedong schließlich die Berichtigungsbewegung eingeleitet, die die Parteikader im richtigen Umgang mit dem Volk schulen, sie ideologisch erziehen und ihnen ihre neue Selbstgefälligkeit durch Kritik und Selbstkritik sowie durch die Umsetzung der Massenlinie wieder austreiben sollte. Die Autoren legen dar, dass Deng Xiaoping von Beginn an entscheidend an der Berichtigungsbewegung beteiligt gewesen sei. Betont wird hier deutlich, dass Deng und Mao in dieser Phase stets Hand in Hand zusammengearbeitet hätten und sich in allen wesentlichen Punkten einig gewesen seien:

Während der Vorbereitungen des VIII. Parteitags schlug Mao Zedong eindeutig vor, den schlechten Stil der Partei zu überwinden. Deng Xiaoping, der von Anfang bis Ende an der Vorbereitung und Organisation des Parteitags der KPCh beteiligt gewesen ist, verstand die ideologischen Absichten Mao Zedongs und versuchte sie direkt während der Vorbereitungssitzungen und Gruppenarbeiten umzusetzen. ${ }^{370}$

Die Einigkeit in dieser, aber auch in anderen politischen Fragen der Jahre 1956 bis 1958 innerhalb des Führungszirkels der KPCh wird auffällig häufig betont. Ein besonderer Fokus wird dabei auf die Zusammenarbeit Deng Xiaopings, Mao Zedongs und Liu Shaoqis gelegt, welche, nach der Darstellung der Autoren, in dieser Phase in jeglicher Hinsicht stets reibungslos und ohne jeglichen Dissens abgelaufen sein soll.

Diese Konstruktion der Einigkeit der Parteispitze setzt sich auch in den Darstellungen der innerparteilichen Diskussionen fort, die nach den Volksaufständen in Polen und Ungarn im Herbst 1956 über die daraus nötigen Konsequenzen geführt worden seien. Einig sei sich die Parteiführung um Mao Zedong und Liu Shaoqi demnach auch schnell in der Analyse der Gründe der Ereignisse in Polen und Ungarn gewesen, welche sie vor allem einer mangelnden ideologischen Bildung zugeschrieben hätten. Gleichzeitig liefern die Autoren bereits an dieser Stelle eine Erklärung für die politischen Verfehlungen der KPCh, aber auch für das zum Teil fehlerhafte Verhalten des Volkes in den kommenden Jahren, welche sie vor allem der noch nicht abgeschlossenen sozialistischen Transformation zuschreiben:

Vor und während der 2. Plenarsitzung hat das Zentralkomitee der KPCh wiederholt Sitzungen des erweiterten Politbüros durchgeführt, um die Vorfälle in Polen und Ungarn zu diskutieren. Mao Zedong, Liu Shaoqi und andere zentrale Führer empfahlen, diese Vorfälle als Warnung zu verstehen, um die Gefahr einer zu starken Spezialisierung der Kader und ein Auseinanderdriften von Volk und Partei abzuwenden. Von einem innenpolitischen Stand-

370 Eigene Übersetzung. Original siehe ebd., S. $1011 \mathrm{f}$. 
punkt aus gesehen, war das neue sozialistische System nach dem raschen Abschluss der sozialistischen Transformation immer noch nicht perfekt. Einige Menschen hatten sich noch nicht an das neue System angepasst, außerdem hat der wirtschaftliche Aufbau noch nicht komplett die Tendenz der Ungeduld aufgegeben, was zu gewissen Spannungen im sozioökonomischen und politischen Leben führte. An einigen Orten gab es Unruhestiftungen wie Arbeiter- und Studentenstreiks und den Rückzug von Landwirten. Viele Parteimitglieder waren darauf nicht vorbereitet und nutzten im Umgang mit den Massen noch immer die Methoden der Vergangenheit zum Umgang mit dem Feind und stifteten dadurch Unruhen, was Widersprüche im Volk zum Vorschein treten ließ..$^{371}$

Die Autoren wiederholen sich in diesem Punkt innerhalb dieses Kapitels mehrfach und fassen es immer wieder zusammen, indem sie verdeutlichen, dass der Aufbau des Sozialismus noch schwieriger als die Revolution gewesen sei. ${ }^{372}$

Neben dem Erklärungsansatz um die politischen Schwierigkeiten jener Jahre, schaffen die Autoren in der Biografie somit auch ein relativierendes Moment für die Fehler der Partei. Wiederholt betonen sie, dass seitens der Partei ein dringender Handlungsbedarf bestanden habe, weswegen die Maßnahmen zur Kritik und Selbstkritik der Partei(-kader) schließlich unter Zuhilfenahme des Volkes ausgeweitet wurden und dessen Übertreibungen letztlich zum Gegenschlag in Form der Kampagne gegen Rechtsabweichler führen mussten. In diesem Punkt ähnelt sich das Erklärungsmodell mit dem der Mao-Biografie von Jin Chongji und Pang Xianzhi.

Betont wird in diesem Zusammenhang zudem, dass Deng Xiaoping sich intensiv mit den Fragen der ideologischen Bildung auseinandergesetzt und dabei vor allem Chinas Jugend im Blick gehabt habe. Diese sollte im Geist des Kommunismus erzogen werden, sodass sie zukünftig noch besser in den Aufbau des Sozialismus miteingebunden werden könnte. „Mao Zedong schätzte Deng Xiaopings Arbeit hinsichtlich der ideologischen und politischen Bildung sehr“" ${ }^{373}$ kommentieren die Autoren und verweisen damit erneut auf das Prinzip der kollektiven Entscheidungsfindung der Parteispitze in jenen Jahren. Dementsprechend soll Mao während einer mehrtägigen Sitzung der Parteikomitees der Provinzen, Gemeinden und autonomen Regionen im Januar 1957 um breite Unterstützung für die praktische Umsetzung der Ideen und Analysen Dengs für die Verbesserung des Systems geworben haben:

Nach der Ansicht Deng Xiaopings müssen wir zur Lösung der Widersprüche im Volk, die vermehrt aufgetreten sind, neben guter Arbeit im Bereich der politischen und ideologischen

371 Eigene Übersetzung. Original siehe ebd., S. 1014.

372 Ebd., S. 1027.

373 Eigene Übersetzung. Original siehe ebd., S. 1020. 
Bildung, uns auch darauf konzentrieren, uns mit Fragen der Demokratieförderung zu beschäftigen. Er glaubt, dass eine der wichtigen Lehren im Umgang mit den Widersprüchen in der Bevölkerung der Sowjetunion und osteuropäischer Länder darin besteht, dass es nicht ausreichend ist, die Demokratie voranzubringen. Deswegen sieht er, während er sich auf die Arbeit der ideologischen und politischen Bildung konzentriert, auch den Ausbau und die Verbesserung des demokratischen Systems als eine wichtige Aufgabe an. ${ }^{374}$

Neben seinem Engagement für die politische und ideologische Bildung der chinesischen Jugend wird auch Deng Xiaopings Einsatz für die Rechte der Arbeiter in den Jahren 1957 und 1958 kanonisiert. Demnach sollten die Massen die Unternehmen fortan stärker kontrollieren und Deng Xiaoping habe zur Demokratisierung der Unternehmen Arbeitervertretungen einrichten lassen. In diesem $\mathrm{Zu}$ sammenhang wird auch deutlich, inwiefern die Autoren die Darstellung des maoistischen Chinas in Einklang mit den politischen Bedürfnissen des postmaoistischen Chinas bringen. So erläutern sie zum Beispiel die grundlegenden und universell anwendbaren Ansichten Deng Xiaopings zur Frage des sozialistischen Aufbaus, die auch unter Xi Jinping immer wieder genutzt werden, wie nachfolgend ausgeführt:

„Solange es für die Entwicklung der Produktion förderlich ist, ist es angebracht, der Begeisterung und der Kreativität der Arbeiterklasse Spielraum zu geben und den Bürokratismus der Führung zu überwachen und zu verhindern; dies zeigt auf, welches System angebracht ist und angenommen wird.“ Das sind die grundlegenden Ansichten Deng Xiaopings zur Beteiligung am sozialistischen Aufbau, als er gerade damit begonnen hatte und seine Auffassungen zu einem grundlegenden Konzept geworden waren. Es zeigte sich, dass er bis zur Reform- und Öffnungspolitik stets an dieser Idee festhielt. „Das Richtige muss bestehen bleiben, das Falsche muss korrigiert werden und das Unvollkommene muss sich einholen“ ist zu einem berühmten Sprichwort geworden, das seine Idee und Methode widerspiegelt, die Wahrheit in den Tatsachen zu suchen. ${ }^{375}$

Der in dieser Biografie auffällige Kanon innerhalb der Darstellungen der Kampagne gegen Rechtsabweichler weist auch weitere Parallelen zu dem politischen Kurs Xi Jinpings auf. Dazu gehören neben der Betonung der Bedeutung der Stärkung der ideologischen Bildung auch der deutliche Verweis auf die Umsetzung der Massenlinie, ebenso wie die Betonung der Bedeutung der Kritik und Selbstkritik der Kader respektive der wichtigsten Führungsfiguren der Partei wie eben Deng Xiaoping. Hier zeigt sich noch einmal deutlich, wie sehr die Parteigeschichte, innerhalb des Rahmens der Resolution von 1981, immer wieder an die aktuellen politischen Bedürfnisse angepasst wird. Dies wird insbesondere durch

374 Eigene Übersetzung. Original siehe ebd., S. 1020.

375 Eigene Übersetzung. Original siehe ebd., S. 1018. 
die hier gewählte Kanonisierung der kollektiven Entscheidungsfindung innerhalb der KPCh in den Jahren 1956 bis 1958 deutlich. Das bereits durch Deng Xiaoping nach 1976 stets betonte leninistische Ideal der kollektiven Führung, wird auch seit der Amtsübernahme Xi Jinpings immer wieder hochgehalten, wie der Politikwissenschaftler Steve Tsang in seinen Studien ausführt. ${ }^{376}$

Zensiert wird in der Deng Xiaoping-Biografie hingegen alles, was auch in der Mao-Biografie schon zensiert worden ist, dazu gehören der Verlauf der Kampagne an sich, das Schicksal des Individuums im Laogai-System oder die Todesstrafen, von denen auch Unschuldige betroffen gewesen sind. Darüber hinaus werden die Debatten um die Hundert-Blumen-Bewegung und der darin deutlich aufkeimende innerparteiliche Dissens ausgespart. Dadurch, dass die Darstellungen zur Umsetzung der Hundert-Blumen-Bewegung, soweit es gerade noch möglich ist, von den Autoren umschifft werden, gibt es, im Gegensatz zur Mao-Biografie, auch keine Einschätzung darüber, ob sie in der Phase ab Mitte Mai 1957 eine Falle gewesen ist oder nicht. Hierzu gibt es nur eine kurze Andeutung, in der die Autoren darlegen, dass der Gegenschlag gegen die Rechtsabweichler bereits am 20. Mai vorbereitet worden sei, also bereits knapp drei Wochen vor dem eigentlichen Beginn der Kampagne am 08. Juni 1957 und damit zu einem Zeitpunkt, zu dem die Partei die Bevölkerung verstärkt zur öffentlichen Kritik ihrer Arbeitsweise aufrief. ${ }^{377}$

Doch wie stellt sich die Bewertung der Kampagne gegen Rechtsabweichler und die Einschätzung zur Verantwortlichkeit der Hauptakteure des Gegenschlags gegen die Rechten, Mao Zedong und Deng Xiaoping, nun dar? Zunächst holen die Autoren noch einmal zu einem längeren Erklärungsansatz aus, warum dieser Gegenschlag notwendig geworden sei, in dem sie deutlich machen, dass es tatsächlich ernsthafte Angriffe auf die Partei gegeben habe, wie zum Beispiel im Frühling 1957 durch konterrevolutionäre Forderungen an der Peking-Universität und der Renmin-Universität, bei der die Kritiker den Führungsanspruch der KPCh in Frage gestellt haben sollen:

Bei den verschiedenen oben genannten Anlässen nutzten nur wenige Menschen die Gelegenheit, der Kommunistischen Partei zu helfen und den Wind zu korrigieren, sie starteten einen heftigen Angriff auf die Partei und auf den Sozialismus. Sie schlugen die Einrichtung eines sogenannten „Instituts zur politischen Gestaltung“ vor. Gegen die Führung der Kommunistischen Partei schlugen sie die Einrichtung eines sogenannten Versöhnungsausschusses vor, der die bisherigen politischen Bewegungen und konterrevolutionären Kämpfe

376 Tsang 2016, S. 36. In der praktischen Umsetzung seines politischen Kurses sieht ein großer Teil der WissenschaftlerInnen eher eine deutliche Abkehr von dem Ideal der „kollektiven Führung“. Siehe zum Beispiel Li 2016, S. 7 ff.

377 Yang und Liu 2014, S. 1032. 
der Partei umfassend negieren sollte und forderten sogar eine „Rehabilitierung“ der Konterrevolutionäre. Sie griffen auch die Führungsposition der Kommunistischen Partei in der Verfassung und im gesellschaftlichen Leben als „Parteienimperium“ an; im Wesentlichen ging es ihnen darum, die Führungsposition der Kommunistischen Partei zu verändern. ${ }^{378}$

Auch hier wird wieder das Kollektiv betont, indem die Autoren darlegen, dass sich die gesamte Führungsspitze zu dem Zeitpunkt einig gewesen sein soll, dass die Kritik an der Partei grundsätzlich gut und notwendig für die Verbesserung ihrer Arbeitsweise gewesen sei. In der Vorbereitung und Durchführung des Angriffs gegen die Rechtsabweichler wird Deng Xiaoping einerseits als Generalsekretär eine wichtige Rolle zugesprochen - so wird beispielsweise dargelegt, dass die Sitzung des Zentralkomitees zur Vorbereitung des Kampfes gegen die Rechten im Zeitraum 21.-25. Mai 1957 unter seiner Leitung stattgefunden habe -, andererseits relativieren sie seine Verantwortung für die Übertreibungen des grundsätzlich notwendigen Kampfes, die mit den zahlreichen Verurteilungen der Rechtsabweichler einhergegangen seien: „Deng Xiaoping, der wie Mao Zedong an vorderster Front für die Leitung der Berichtigungsbewegung verantwortlich ist, hatte keinen Anteil an der ideologischen Vorbereitung des Angriffs gegen die Rechten; man kann sagen, dass dies eine voreilige Schlussfolgerung darstellt.“379

Auch wenn die Autoren einräumen, dass er die Entscheidungen des Führungszirkels, dem er als Generalsekretär ohnehin angehörte, stets mitgetragen habe, sprechen sie ihn von den Verantwortlichkeiten für die Übertreibungen und Fehlurteile weitgehend frei. Wiederholt betonen sie, dass er immer wieder vor Übertreibungen gewarnt habe und eigentlich einen sanfteren Pfad im Kampf gegen die falschen Ideen der Rechtsabweichler einschlagen wollte: „Es ist zweifelsohne richtig, dass Deng Xiaoping dies für den aufkommenden Kampf gegen die Rechten für notwendig gehalten hat. Dennoch waren seine Ideen $\mathrm{zu}$ den Methoden und Schritten zur Bekämpfung der Rechten einfacher und sanfter und er ahnte nicht, was später passieren würde.““380

Gemäß den Ausführungen der Autoren habe Deng Xiaoping im Laufe der Kampagne nicht nur wiederholt vor Übertreibungen gewarnt, sondern er soll sich auch dafür stark gemacht haben, dass den Rechtsabweichlern die Tür für eine Rückkehr in die Gesellschaft stets offenbleiben müsse, wenn sie sich des sozialistischen Ideals entsprechend verändert hätten. Außerdem hätte er sich auch immer wieder schützend vor einige Gruppen von Intellektuellen gestellt, die in besonderem Maße zur Zielscheibe der Kampagne geworden seien. Besorgt soll er

378 Eigene Übersetzung. Original siehe ebd., S. 1032.

379 Eigene Übersetzung. Original siehe ebd., S. 1033.

380 Eigene Übersetzung. Original siehe ebd., S. 1034. 
sich insbesondere in Bezug auf die Tatsache gezeigt haben, dass sehr viele herausragende Naturwissenschaftler, und somit für den sozialistischen Aufbau des Landes wichtige Intellektuelle, als Rechtsabweichler verurteilt wurden, weswegen er im September 1957 die Direktive des Zentralkomitees der Kommunistischen Partei Chinas zum Kampf gegen die Rechten (Zhongguo zhongyang guanyu ziren kexuw fangmian fan youpai douzheng de zhishi 中共中央矢于自然科学方面反右 派斗争的指示) habe ausarbeiten lassen, welche eine besondere Behandlung von Naturwissenschaftlern vorgesehen haben soll. Unterstützung habe er in diesen Belangen vor allem von Zhou Enlai erhalten. Außerdem betonen die Autoren, dass er sich sogar dafür eingesetzt habe, dass ausgesprochene Todesurteile gegen Wissenschaftler ausgesetzt wurden. ${ }^{381}$

In der abschließenden Gesamtbewertung der Kampagne gegen Rechtsabweichler greifen die Autoren weitgehend auf die Formel der Resolution von 1981 zurück und betonen dabei zugleich, dass die Ergebnisse der Fehler, die im Zuge der Kampagne gemacht worden sind, schmerzvoll für das Land gewesen seien:

Zur Zeit der 3. Plenartagung des 8 . Zentralkomitees gab es bereits rund 62.000 Rechtsab-
weichler, und es wurde geschätzt, dass es im gesamten Land insgesamt etwa 150.000
Rechtsabweichler geben würde. Zum Ende der Kampagne waren es insgesamt 550.000
Rechtsabweichler, also 400.000 mehr als bei der 3. Plenartagung des 8. Zentralkomitees
erwartet worden waren. Unter ihnen waren auch viele ehrliche und talentierte Intellektuelle,
ausgezeichnete Parteimitglieder und Kader, die es gewagt hatten, die Wahrheit zu sagen, und
Patrioten, die bereits lange Zeit mit der Kommunistischen Partei zusammengearbeitet hat-
ten. Sie mussten für eine lange Zeit Missstände, Repressionen und Unglück erleiden und
konnten keine angemessene Rolle im sozialistischen Aufbau spielen. Das war eine sehr
schmerzvolle Lektion! ! $^{382}$

Was die Frage der Verantwortlichkeit Deng Xiaopings betrifft, so wird er insgesamt zwar als Teil des Kollektivs, gleichzeitig aber auch als gemäßigter Entscheidungsträger beschrieben, dessen Handlungen während der Kampagne gegen Rechtsabweichler durch die Darstellung der Autoren abgemildert werden, da er sich demnach in den Jahren 1956 bis 1958 vor allem auf die Aspekte der ideologischen und politischen Bildung konzentriert haben soll. Angesichts der Tatsache, dass er zwischen 1956 und 1966 das Amt des Generalsekretärs der KPCh bekleidete, konnten die Autoren es jedoch nicht dabei belassen, ihn als unwissend und naiv zu beschreiben, es reichte auch nicht, den Fokus in den Analysen der Handlungen Deng Xiaopings während der Kampagne gegen Rechtsabweichler auf die ideologische Bildung zu beschränken. Ein Einräumen von politischen

381 Ebd., S. 1040.

382 Eigene Übersetzung. Original siehe ebd., S. 1045 f. 
Fehlern wird durch eine Analyse der Autoren selbst zwar vermieden, jedoch lassen sie ihn mit einem direkten Zitat zu seinen Fehlern „selbst“ zu Wort kommen. So soll er bereits im Oktober 1958 eingeräumt haben:

Deng Xiaoping hat sich nie seiner Verantwortung in der Ausweitung des Kampfes gegen die Rechten entzogen. Er sagte: „Man sollte nicht den Eindruck vermitteln, dass alle korrekt handeln und eine einzige Person nicht korrekt handelt. Ich bin befugt, dies zu sagen, denn ich habe Fehler gemacht. Im Kampf gegen die Rechten im Jahr 1957 sind wir die Aktivisten, ich habe die Verantwortung für die Ausdehnung des Kampfes gegen die Rechten, ich bin der Generalsekretär.“"383

Diese Aussage steht nicht nur ganz im Sinne des Prinzips der Kritik und der Selbstkritik, die Autoren verknüpfen dieses Einräumen von Fehlern Deng Xiaopings sogleich mit einer Korrektur dieser Fehler. Sie legen dar, dass er dem Zentralkomitee bereits am 09. Oktober 1958 vorgeschlagen habe, dem Großteil der Rechtsabweichler die „Hüte zu entfernen“, und entsprechend sei im Zeitraum von 1959 bis 1964 die Mehrheit der Rechtsabweichler rehabilitiert worden. Die Rehabilitierungswelle sei dann nur aufgrund des „zehnjährigen Chaos“ der Kulturrevolution unterbrochen worden, dem Deng Xiaoping zwischenzeitlich auch selbst zum Opfer gefallen ist. Sein Verantwortungsbewusstsein für die Rechtsabweichler habe sich, so beschreiben es die Autoren, nach der Kulturrevolution fortgesetzt und so seien die restlichen Rehabilitierungen von Deng Xiaoping höchstpersönlich befürwortet und angeordnet worden: „Der Fehler der Übertreibung des Kampfes gegen die Rechten wurde vollständig korrigiert.“384

Unterstrichen wird diese starke Kanonisierung des Verantwortungsbewusstseins auch noch durch eine Aussage Deng Xiaopings, die seine Fürsorge für die zu Unrecht Verurteilten hervorhebt. So soll er gegenüber den Mitgliedern des Führungszirkels der KPCh bereits im Jahr 1958 geäußert haben:

$\mathrm{Zu}$ den berühmten Leuten der ursprünglichen demokratischen Parteien, die keine Fehler gemacht haben, müssen in der Schlussfolgerung auch ein paar Worte gesagt werden: Vor dem Kampf gegen die Rechten, vor allem während der Revolution, haben sie Gutes getan. Ihre Familienmitglieder sollten fair behandelt und im Leben, der Arbeit und der Politik angemessen umsorgt werden. ${ }^{385}$

Diese Darstellungen zum Thema Rehabilitierungen stehen im Gegensatz zum Stand der westlichen Forschung, wonach nicht nur der größte Teil der Rechts-

383 Eigene Übersetzung. Original siehe ebd., S. 1046.

384 Eigene Übersetzung. Original siehe ebd., S. 1048.

385 Eigene Übersetzung. Original siehe ebd., S. 1048. 
abweichler erst nach 1976 rehabilitiert worden ist, sondern wonach Deng Xiaoping sich bei den Rehabilitierungen dieser zunächst auch zögerlich zeigte, möglicherweise getrieben von der Sorge, dass er als Hauptverantwortlicher dieses politischen Fehlers die Folgen, die sich aus den möglichen Aussagen der Rehabilitierten für seine politische Zukunft ergeben könnten, nicht absehen können würde (siehe Kapitel 3).

Insgesamt weicht die Bewertung der Kampagne gegen Rechtsabweichler auch hier nicht von der Einschätzung der Resolution von 1981 ab, jedoch lässt sich eine gewisse Anpassung des Narrativs an die Bedürfnisse Chinas unter Xi Jinping durchaus erkennen. Keinem der zentralen politischen Akteure wird in dieser Biografie im Zusammenhang mit der Kampagne gegen Rechtsabweichler ein besonderes Maß an Schuld zugesprochen - das Kollektiv steht im Mittelpunkt.

Im Gegensatz zur Mao-Biografie ist der Shu er bu lun-Ansatz in dieser Biografie kaum noch bzw. deutlich weniger sichtbar. Die analytischen Passagen kommen hier in deutlich stärkerem Maße vor. Obwohl es sich bei dem Buch um eine offizielle Darstellung der Geschichte handelt und gewisse Aspekte der Vergangenheit verändert dargestellt werden, heißt das, ebenso wie bei der MaoBiografie, nicht, dass es sich dabei nur um schlichte Propaganda der KPCh handelt. Auch dieses Buch wird durchaus von einer Reihe von anerkannten Wissenschaftlern in ihren Werken zur Geschichte Chinas zitiert. ${ }^{386}$ Im Zuge der Veröffentlichung betonte der Herausgeber des Buches, dass die (neuen) Erkenntnisse, die im Buch sichtbar werden, zu einem großen Teil auf nicht zugänglichen, internen Regierungsdokumenten beruhen. Er äußerte sich in diesem Zusammenhang auch zu den zahlreichen Veröffentlichungen von Geschichtsbüchern zur Geschichte der KPCh bzw. zu den Biografien ihrer zentralen Akteure durch westliche Wissenschaftler und wies darauf hin, dass diese nur ein sehr unvollständiges Bild abliefern würden, da ihren Autoren der Zugang zu bestimmten historischen Details und Dokumenten gefehlt habe. ${ }^{387}$

Die Bedeutung Deng Xiaopings für das China unter Xi Jinping wird durch dieses Werk der offiziellen Geschichtsschreibung deutlich erkennbar. Dennoch sollte sich auch hier herausstellen, dass der Nutzen von Teilen des historischen Erbes Dengs für die Stärkung der Legitimität des Machtgefüges Xi Jinpings auch ein zweischneidiges Schwert sein kann und das nicht nur aufgrund der durch ihn begangenen „historischen Fehler“ wie der Kampagne gegen Rechtsabweichler. Im September 2018 hielt Deng Xiaopings Sohn Deng Pufang 邓朴方, zwischen 2008 und 2013 stellvertretender Vorsitzender der Politischen Konsultativkonferenz des

386 Siehe zum Beispiel Pantsov und Levine 2013.

387 Lu 2014, http://www.globaltimes.cn/content/878019.shtml. 
chinesischen Volkes (Zhongguo renmin zhengzhi xieshang huiyi 中国人民政治协 商会议), eine bemerkenswerte Rede. In dieser richtete er warnende Töne an die chinesische Regierung, indem er kritisch darauf hinwies, dass China im Sinne der von seinem Vater angestoßenen Reform- und Öffnungspolitik handeln und sich dabei zwar nicht unterschätzen, jedoch in der internationalen Politik auch nicht zu übermütig und expansionistisch auftreten sollte. Dies kann durchaus als Kritik an Chinas Bestrebungen, zur globalen Supermacht aufzusteigen, gesehen werden. Christopher Johnson, Chinaexperte am Washingtoner Centre for Strategic and International Studies, sieht dies als Versuch Dengs, das historische Erbe seines Vaters vor einer Neudeutung durch die chinesischen Machthaber zu schützen. ${ }^{388}$

Öffentliche Wortmeldungen wie diese zeigen erneut, wie wichtig es für Xi Jinping ist, auf dem nun eingeschlagenen Pfad zu bleiben. Denn inzwischen dürfte er zu weit gegangen sein, um in seiner Geschichtspolitik noch umkehren zu können. Und so muss sich der seit 2013 forcierte Kanon der offiziellen chinesischen Geschichte nun auch nachhaltig gesellschaftlich festigen, ebenso wie die ideologische Bildung der Jugend weiter vorangetrieben werden muss, um die Herrschaftslegitimation der KPCh auch zukünftig sicherzustellen. Dies wurde rund um den XIX. Parteitag unter anderem durch die Gründung des Instituts für die Erforschung der Xi-Jinping-Ideen (Xi Jinping xin shidai Zhongguo tese shehuizhuyi sixiang yanjiuyuan 习近本新时代中国特色社会主义思想研究院), welches fortan an die wichtigsten Universitäten Chinas angegliedert sein würde, auch institutionell noch weiter gefestigt.

All dies macht eine Lockerung der Geschichtspolitik in den nächsten Jahren äußerst unwahrscheinlich, insbesondere da Xi Jinping zu Beginn des Jahres 2018 auch noch die Amtszeitenbeschränkung abschaffen ließ. Umso unwahrscheinlicher wird damit auch ein Aufkeimen eines öffentlichen Diskurses um die Neudeutung der chinesischen Geschichte, in der die „historischen Fehler“ der mächtigsten politischen Führer, auf die er sein Ideologiegebäude stützt, aufgerollt würden. Das Narrativ, dass der Aufstieg des Landes untrennbar mit dem Aufstieg der Partei und auch mit ihm selbst verbunden sei, steht daher während der Präsidentschaft Xis unter einem besonderen Schutz. ${ }^{389} \mathrm{Zu}$ Gute kommen ihm dabei die Möglichkeiten, die ihm die technischen Entwicklungen der fortschreitenden Digitalisierung bieten. Dennoch bleibt ungewiss, ob er die Herrschaftslegitimation durch den von ihm eingeschlagenen autoritären Kurs tatsächlich

388 Jun 2018, https://www.scmp.com/news/china/politics/article/2170762/deng-xiaopings-sonuses-unpublicised-speech-urge-china-know-its.

389 Siehe Zhongguo Gongchandang zhibu gongzuo tiaoli (shixing) 中国共产党支部工作条例 (试行) (Vorschriften zur Arbeit der Kommunistischen Partei Chinas [Prozess]) 2018, http://pa per.people.com.cn/rmrb/html/2018-11/26/nw.D110000renmrb_20181126_1-04.htm. 
nachhaltig festigen können wird, da nicht absehbar ist, ob er und seine Anhänger den Kampf um das kollektive Gedächtnis auch wirklich gewinnen können, wie die nachfolgenden Kapitel zeigen werden. Eine Reihe von (digitalisierten) alternativen Narrativen ist bereits seit vielen Jahren im Umlauf, auch Schwarzmärkte lassen sich nicht komplett kontrollieren. Wenn möglicherweise unvorhersehbare (politische) Entwicklungen eintreten, wie zum Beispiel eine globale Wirtschaftskrise oder aber eine Naturkatastrophe, können die Karten ohnehin neu gemischt werden, auch wenn die Intellektuellen für einen politischen Umsturz gegenwärtig zu passiv erscheinen. 